Fand. Wrought Jewelry

Ní

7304

$57 \%$

1916

CHM

$$
\text { Sorensen - Vaughn }
$$






\title{
Hand-Wrought Jewelry
}

\author{
H. R. SORENSEN, \\ Proprietor of The Orno Shop, \\ DeKalb, Ill., \\ and \\ S. J. VAUGHN, \\ Head of the Manual Arts Department, \\ Northern Illinois State \\ Normal School.
}

SMITHSONIAN

FEB 051988

LURARIES

Milwaukee, Wis.

The Bruce Publishing Co. 
Copyright, 1916

The Bruce Publishing Co. 


\section{INTRODUCTORY}

W thing handmade, no matter how crude, has been tempered with better judgment, there still remains a strong, rapidly increasing and discriminating demand for well-designed, well-made, tasteful hand-wrought jewelry.

People are now going to makers of jewelry in very much the same way as they go to their tailors - to have something distinctive made to meet certain specific conditions of purpose, fitness, and personal taste. Very much the largest part of such work is done to order, after the craftsman has submitted original designs. Consequently, the maker of jewelry seldomly, if ever, repeats designs, and hence his every product is unique.

Wherever such work has been carried out properly in the schools, it has had a marked influence upon the tastes of the students with respect to design and beauty of decorative articles. It has accomplished something in doing away with ugly, ornate jewelry with its imitation stones and fantastic patterns.

The authors have purposely omitted discussions of the history and development of jewelry, historic design, the composition and preparation of metals, and similar topics. Full and reliable information along these lines may be found in numerous works already on the market.

It is the purpose of this book to describe in detail, the actual making of jewelry from the very 
simplest work, to the most difficult processes of working complicated patterns and mounting precious stones in gold. In doing this, the same methods of work will be described as are used in the best commercial shops in this country. 


\section{TABLE OF CONTENTS}

\section{Chapter $I$.}

Fundamental Operations-Jewelers' Tools-Oxidizing Page

Silver-The Making of a Fob.

Chapter II.

The Making of a Bar Pin - Cleaning and Finishing Operations

Chapter III

Stone Setting - Making a Scarf Pin - The Bezel -

Making and Setting the Pin

Chapter IV.

A Lady's Coat Chain - Making the Chain Links -

Lapel Chains.

Chapter $V$.

Rings - Shaping the Ring Blank-Making the BezelThe Cutouts 36

Chapter VI.

The Making of a Pendant-Flowers and LeavesMetal Polishing-Electro-Plating

Chapter VII.

The Setting of Odd Shaped Stones-The Abalone Blister

- The Baroque Pearl - Setting a Square Faceted

Stone-Setting a Lentil Shaped Stone

Chapter VIII.

Monograms - Carving and Chasing - Designs for

Carved Pieces

Chapter IX.

The Making of Two Rings .

Chapter X.

Miscellaneous Pieces

Chapter XI.

Mounting Baroque Pearls - Making a Pin - Making a

Pendant

Chapter XII.

Precious Stones-Significance of Gems-Typical Stone Cuttings-Imitations and Reconstructed Gems. 


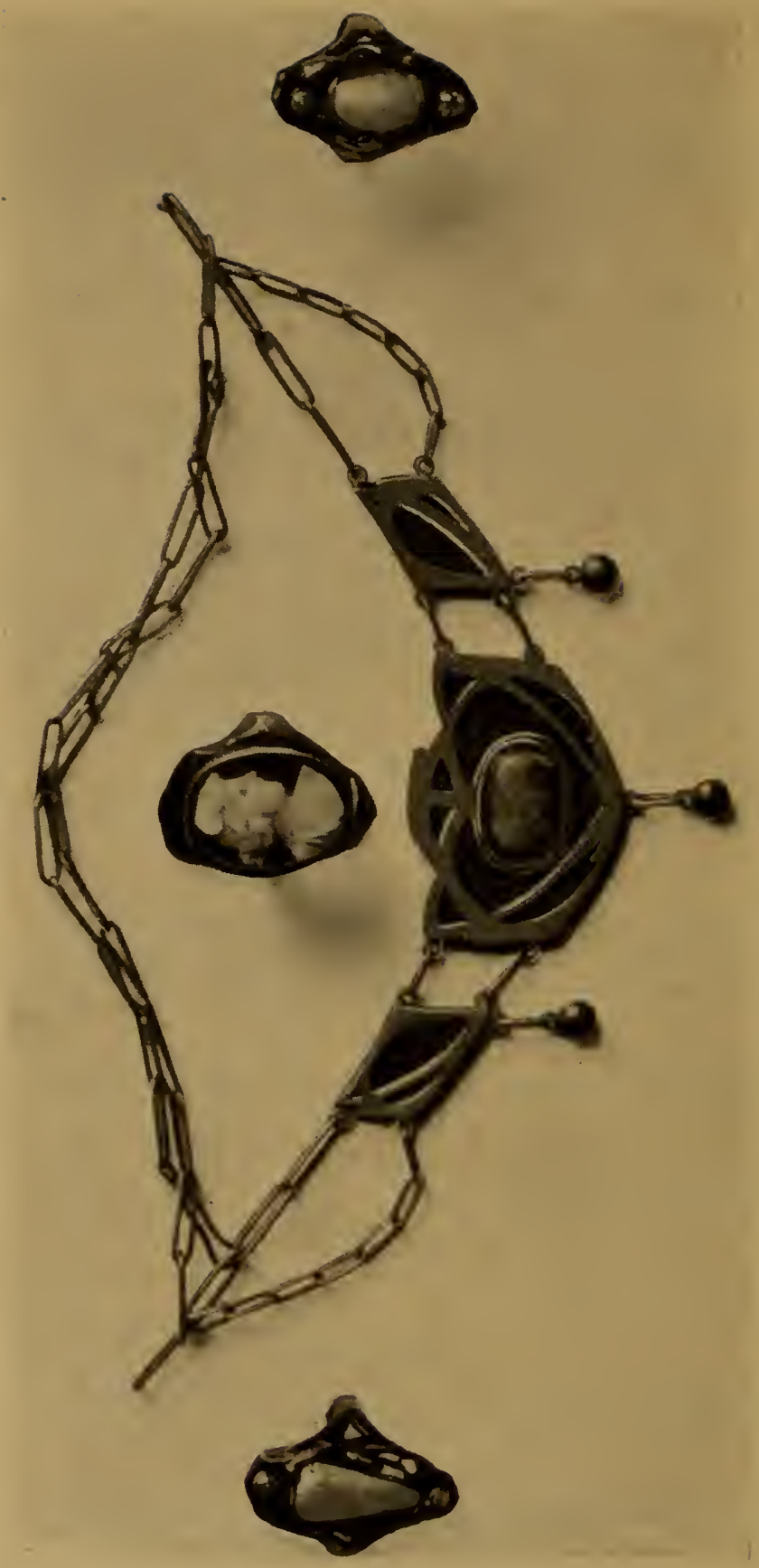




\section{HAND-WROUGHT JEWELRY}

\section{CHAPTER I.}

Practically all the fundamental operations - of jewelry making may be done with a comparatively small list of tools. Some of the tools are easily made. For the most part, the work covered by this book can be made with the following tools:

Sawframe and Blades

Saws

Shears

Pliers with Parallel Jaws

Pliers with Half-round Nose Side Cutting Pliers

Tweezer's

Riveting Hammer

Small Ball Pein Hammer

Ring Mandril
Half-round File No. 0

Bi-convex Needle File

Barret Needle File

Center Punch

Scraper

Soldering Gas Burner and Blowpipe Borax Slate

Burnisher

Rawhide Mallet

The entire list may be bought for $\$ 7.00$. For school work a number of students can work with one set, altho it is not so desirable.

In the more elaborate and complicated problems of advanced jewelry, a few other tools such as gravers, chasing tools, etc., will be mentioned as needed.

The designs for beginning work should be very simple, as illustrated in Fig. 1. In making the design, a center line is drawn first, and one-half of the design is drawn on one side of this line. A piece of thin tracing paper is folded and creased. Then it is unfolded and laid on the design with the crease exactly on the center line. With a sharp pencil, the design is then traced upon the thin paper. The tracing paper is again folded in the same place, and by pressing the two sides together, the pencil marks of the design are transferred on the other side of the crease. 
A piece of gauge eighteen sterling silver should be selected as material for a fob similar to that shown in Fig. 1. Sterling silver is a combination of 925 parts of fine silver and 75 parts of copper and costs

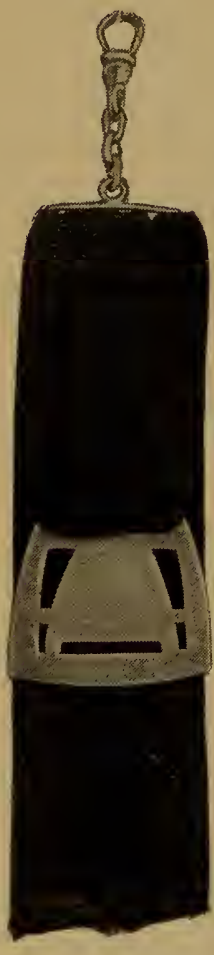
about seventy cents an ounce. Fine silver alone is too soft for practical use.

The gauge of metal is the measurement of its thickness. The

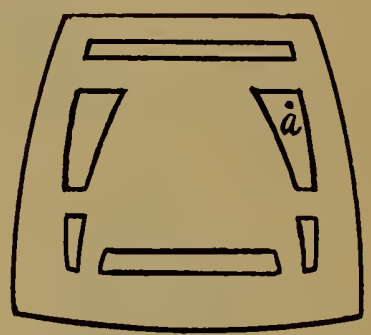

Fig. 1.

Brown \& Sharpe gauge is used by dealers and workers in precious metals. It is numbered from $4-0$ to 40 , the larger number indicating the thinner metal.

A center line is made on the silver and the crease of the tracing paper is placed exactly on this line. The purpose of this line is to serve as a guide in case one desires to correct the design, using dividers. The design is then transferred to the silver by the use of carbon paper. This is done by slipping the carbon paper under the tracing paper, with the carbon side towards the silver. All lines of the design are traced with a sharp pencil or a pointed piece of hard wood. After the design has been 
transferred, all the lines on the silver are retraced. with a steel punch, like the one shown in a, Fig. 2 . The carbon impression is easily rubbed off, hence the need of tracing with a steel tool.

With the silver lying on a hardwood block, the punch is then placed at point a, Fig. 1. Tap the punch with a hammer and at the same time, turn it between the fingers. Continue tapping until the

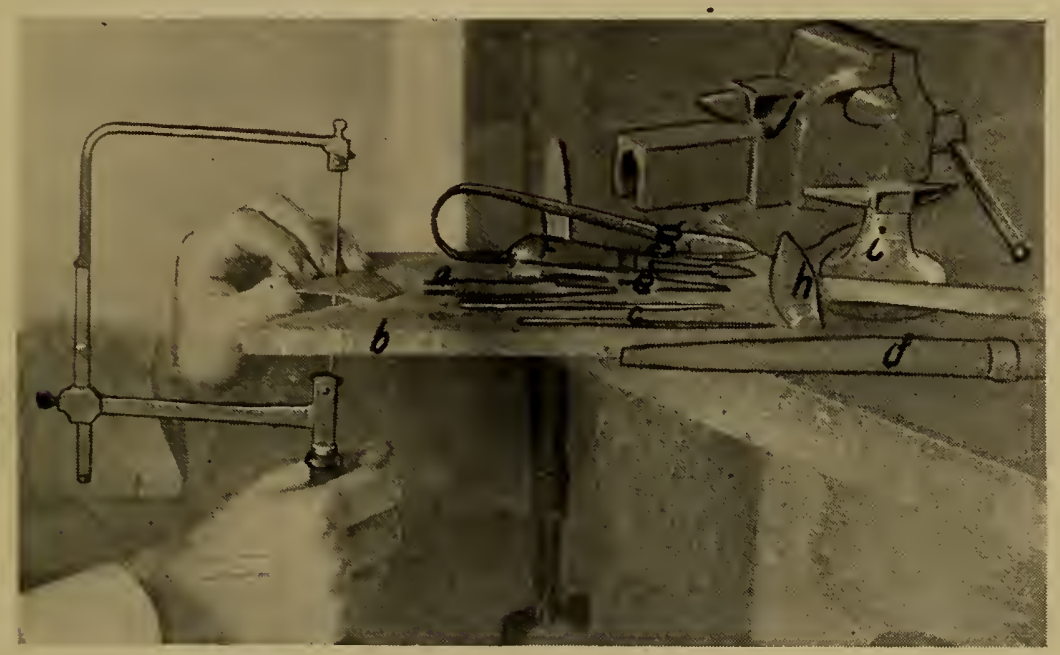

Fig. 2. Using a Jeweler's Saw.

point of the punch is thru the silver. Reverse the silver and proceed as before, until the hole is large enough to admit the saw blade. Do not strike the punch with a hard blow, as that would make the silver bulge out on the opposite side. Often a drill is used instead of the punch for making holes thru the metal.

The sawing is the next step. The jeweler's sawframe shown in Fig. 2, is a good style. The saw blades come in dozen lots and in a variety of sizes. 


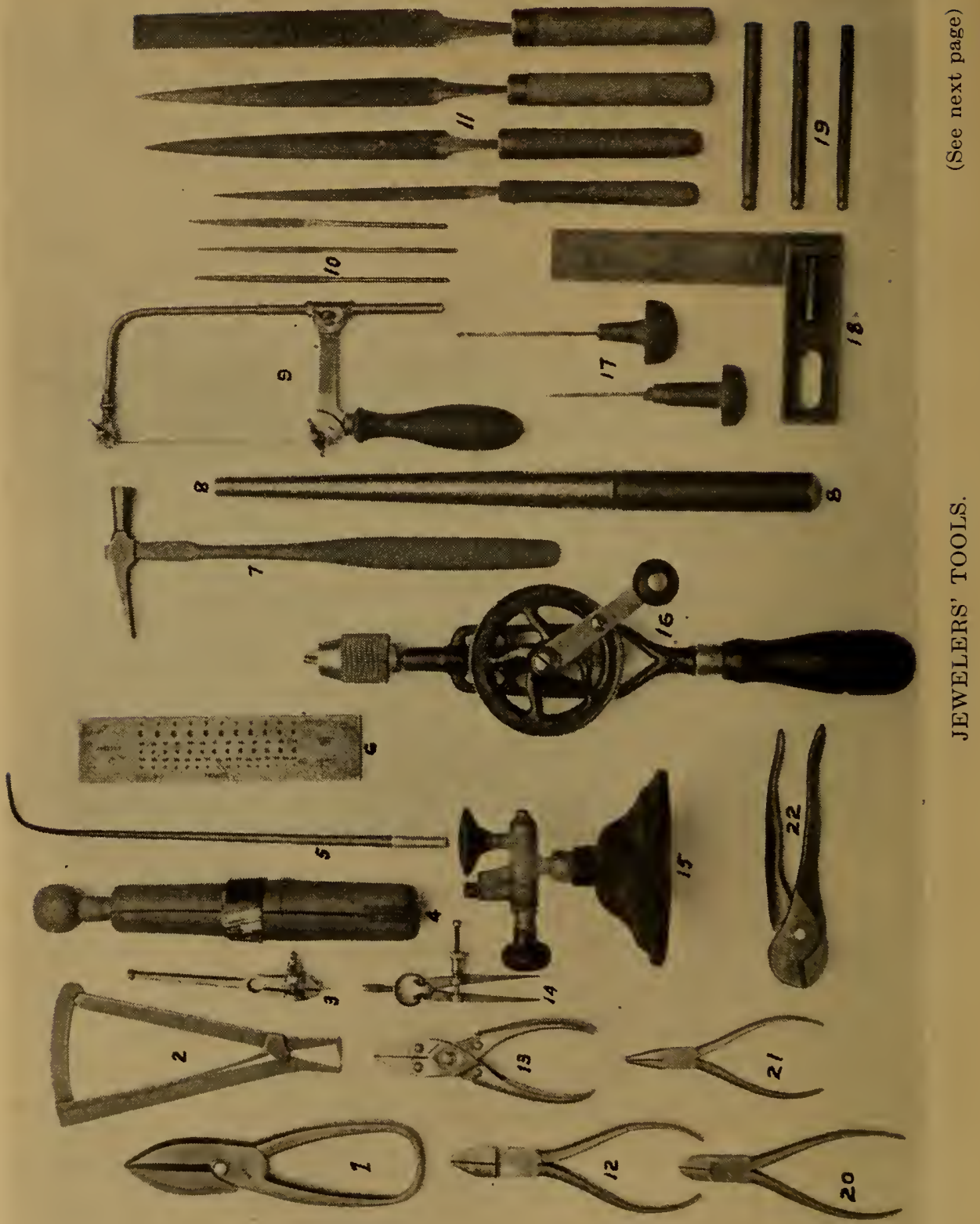




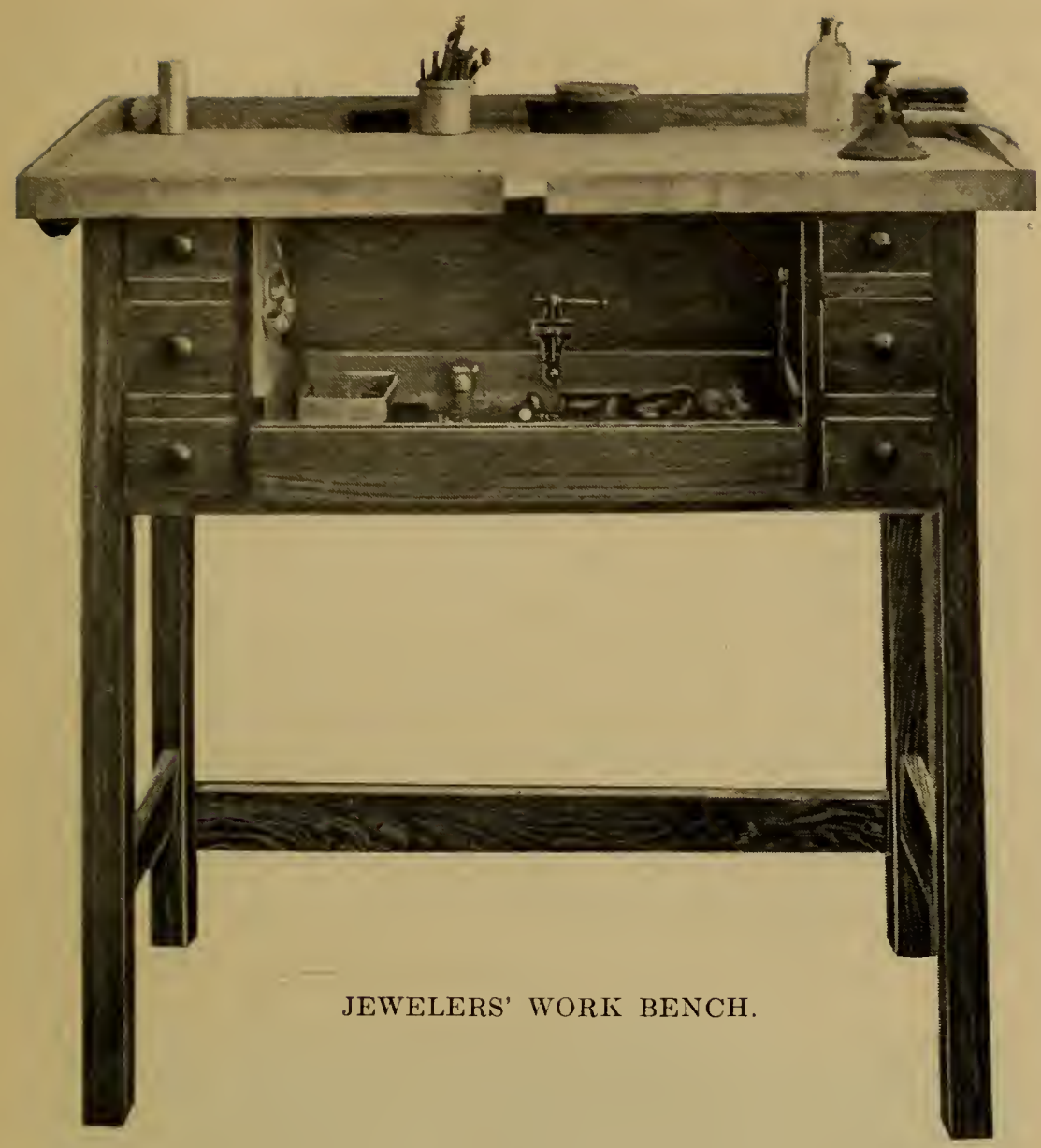

TOOLS FOR WORK BENCH.

(See illustration on page 10)

1. Metal Shears.

2. Spring Gauge.

3. Pin Vise.

4. Ring Clamp.

5. Blow Pipe.

6. Draw Plate.

7. Riveting Hammer.

8. Ring Mandril.

9. Jeweler's Saw.

10. Needle Files.

11. Round, Half-round and Flat Files.
12. Side Cutting Pliers.

13 Pliers with Parallel Jaws.

14. Dividers.

15. Gas Burner.

16. Drill.

17. Engraving Tools.

18. Try Square.

19. Dapping Tools.

20. Side Cutting Pliers.

21. Flat Nose Pliers.

22. Ring Bender, made to order. 
No. 0000 is the finest, and No. 6 the coarsest of the square blades. A beginner should use about a No. 3 blade, as the smaller sizes break easily.

To put the blade into the saw frame and thru the hole in the silver, hold the frame between the body and the bench, as shown in Fig. 3. Fasten one end of the blade into the clamp of the frame nearest the bench. The end of the blade should project into the clamp about one-half inch. The teeth should point toward the handle. Put the blade thru the hole in the silver, the design side away from the handle. Press the body against the frame and fasten the other end of the biade into the other clamp of the frame. The blade should be moderately taut.

Hold the silver and frame as shown in Fig. 2. Begin sawing very slowly with but very little pressure of the blade against the silver. Always keep the blade sawing in waste material, which means that the saw should not come in contact with the line. When a corner is to be turned, keep the saw moving

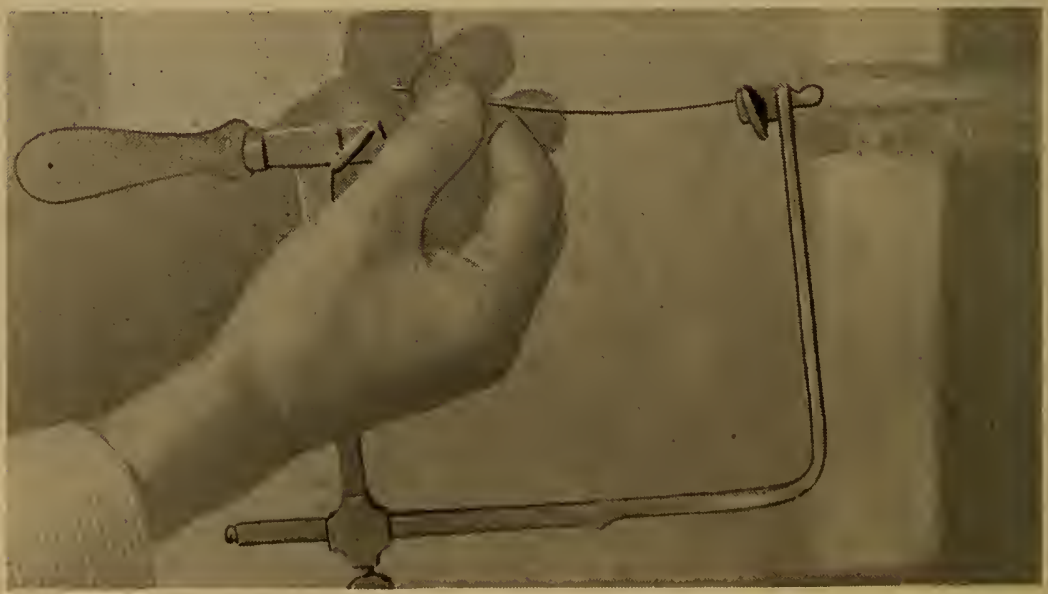

Fig. 3. Putting a Blade into Saw Frame. 
up and down without going forward. Then gradually turn the silver until the desired position has been reached.

The convenience on which the metal rests, as shown at b, Fig. 2, is a small board with a V-shaped cut in the end. This is clamped to a table or bench.

After as much metal as possible has been sawed out without touching the lines, the cut-outs, as the openings are called, should be smoothed with needle files, shown at 10 , page 10 . All the sawing required by the design should be done before the outside edge has been touched. By sawing the inside design first, one has the outer material by which to hold the metal while working on it.

The same care should be used in sawing the outside edge, as that used in sawing the cut-outs. After the sawing, the outside edge is smoothed with the flat side of a half-round file, No. 0, as shown at 11, page 10. Files are made to cut with a forward stroke only. When filing an edge, use an oblique stroke as much as possible.

After the tool work is done, emery cloth or paper is used on the surface of the silver. Emery cloth is numbered from 0000 to 4 . For the present operation, take a piece of No. 0 emery cloth and place it on the bench, emery side up. Then rub the design side of the silver back and forth on the emery cloth, until a perfectly smooth surface has been obtained.

\section{Oxidizing Silver.}

All silver work should be oxidized to give it a pleasing and permanent finish and to prevent its discoloration. A good solution for this purpose is 


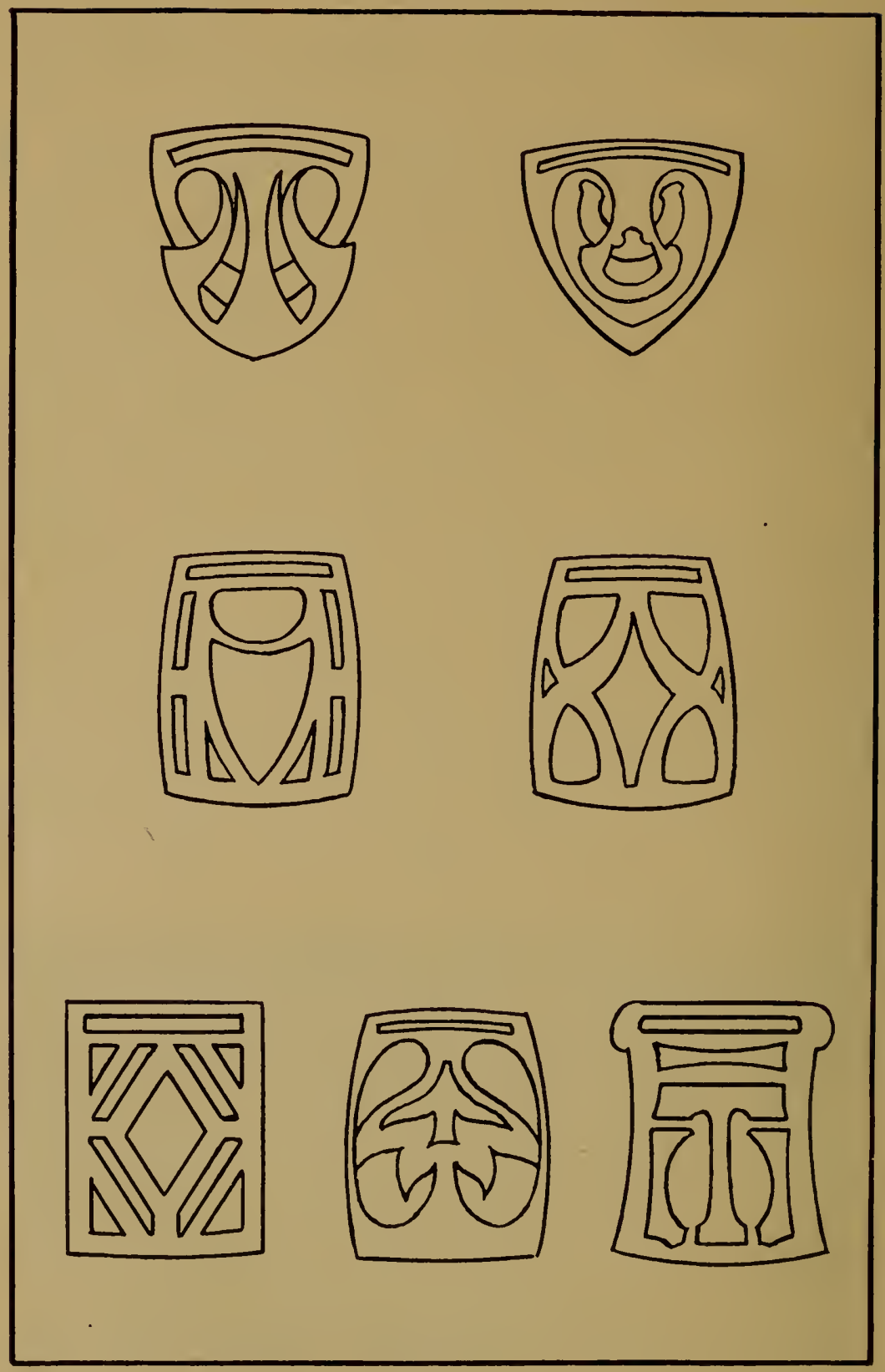

Other Designs for Fobs. 
made of liver of sulphur, or sulphurated potassium. About one cubic inch of this compound is pulverized and mixed with a pint of water. Before the silver is oxidized, it should be cleansed thoroly. This is done by scouring the silver with powdered pumice and an old brush-a tooth brush will do. Rinse the silver thoroly and dip it into the solution. Remove it immediately after it turns black. If it is left too long in the solution, the oxidized surface will come off in scales. When the fob has been removed from the solution, rinse it again, and brush with powdered pumice, until the desired shade of gray is obtained. The process of oxidizing takes much less time when the solution is hot. To dry an article after final rinsing put it into sawdust.

The swivel and bar for the top of the fob ribbon may be bought from any dealer in jewelers' supplies. To make them now, would involve processes which we shall not take up until later. 


\section{CHAPTER II.}

\section{A Bar Pin-Soldering.}

THE making of a simple bar pin, which includes 1 soldering, is the next problem. Fig. 4 shows the design, the fixtures, and the pin tong. Gauge eighteen sterling silver is suitable material for this problem. Transferring the design, sawing, filing, and finishing with emery cloth should be done exactly as described in the preceding chapter in making a fob, before any soldering is attempted.

To get good results when soldering, one must be very careful that all parts to be soldered are perfectly

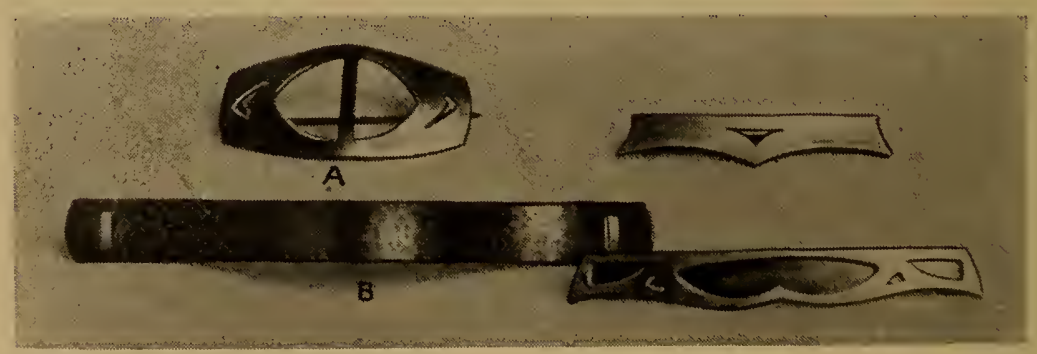

Fig. 4.
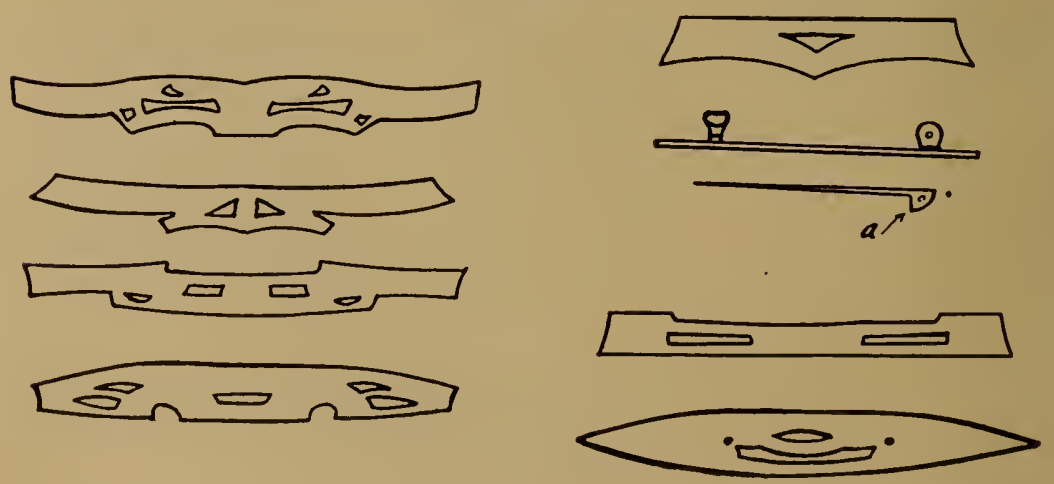
clean. The best way to remove foreign matter from the surface of metal is to scrape it with the tool shown at f, Fig. 2, preceding chapter, or with a knife. To make the solder flow, a mixture of borax and water is applied to the parts to be soldered. This mixture is obtained by putting a few drops of water into the borax slate, a, Fig. 5, and rubbing prepared or lump borax on the slate until the water becomes milky. Heat applied to silver without some such solution, or flux, oxidizes the surface and forms a "fire coat" which prevents solder from flowing.

German silver joints, catches, and pin tongs are quite satisfactory for this piece. After the places on the silver that are to receive the joint and catch have been scraped, the silver is placed on a piece of charcoal or asbestos, so that the top of the bar pin is away from the worker. The joint is placed on the end at the right, and the catch with the opening toward the worker, on the other end of the pin. The bases of the joint and

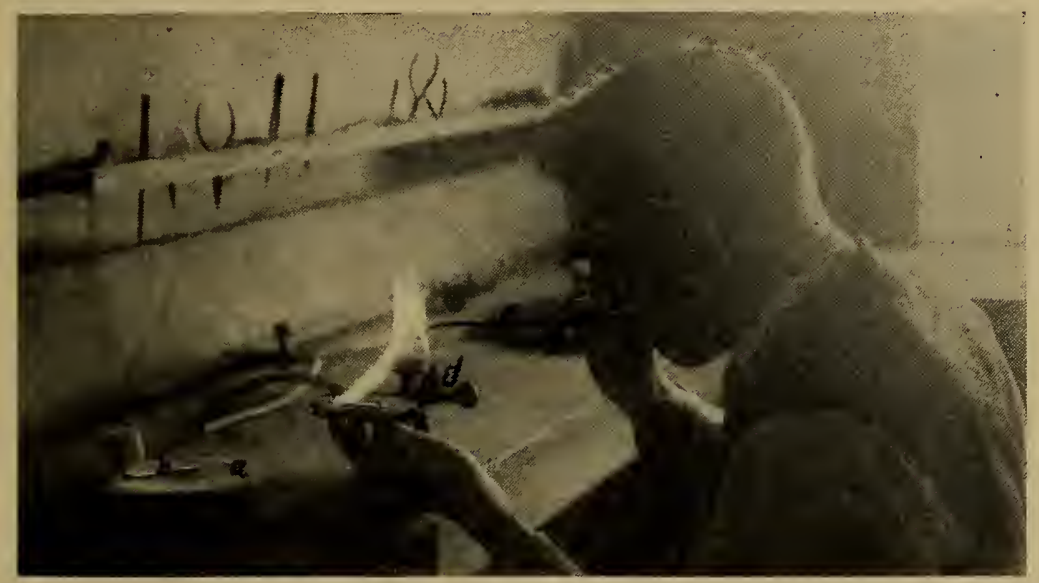

Fig. 5. Soldering with Gas Burner and Blow Pipe. 


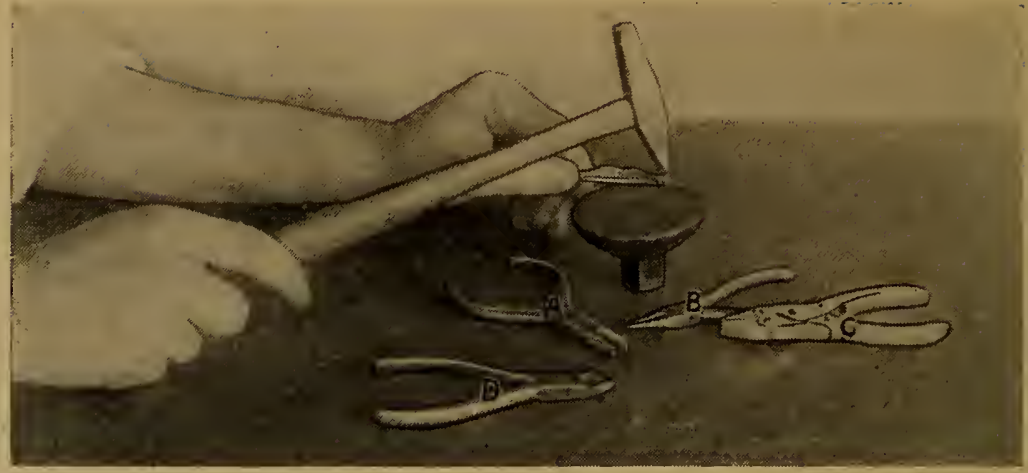

Fig. 6. Riveting the Pin Tong into the Joint.

catch should be filed so that they will sit upright on the silver. The position is shown at Fig. 4.

The borax solution should now be applied by the use of a small brush shown at b, Fig. 5. After the fluid has dried, a piece of silver solder, or hard solder, one-sixteenth of an inch square, is placed on each side of each fixture. Good silver solder is composed of eleven parts of fine silver, six parts of copper and two parts of zinc. This combination has a lower fusing point than sterling silver. Solder may be bought at any jewelry supply house.

By the use of gas soldering burner and blowpipe, (c and d, Fig. 5,) the flame is applied to the silver. The silver is heated gradually by blowing the flame on the central part of the bar pin at first. The flame is not applied directly to the fixture, as this would raise the fixture to the fusing point of the solder before the silver would reach this point, and thus the solder would all flow onto the fixture and none of it adhere to the silver. The solder should receive its heat from the silver. If the flame is applied very suddenly, the borax bubbles and often shifts the fixture to an undesirable position. 


\section{Cleansing Solution.}

To cleanse the piece from the effects of the heat and the oxide formed by the borax, the bar pin should be immersed in a "pickle" of one part Sulphuric Acid and four parts water. The process is greatly hastened by heating the solution. The acid should be kept in a copper, lead, or earthenware vessel. If iron or steel should be present in the acid, it will discolor the silver with a dark deposit which is very difficult to remove.

The fitting of the pin tong into the joint should be done with care. The holes in the pin tong and in the joint should be the same size. If they are not, they may be made so with a reamer or a round needle file. A piece of silver or German silver wire is filed to fit the holes. When the wire has been inserted in the holes, try to fasten the pin tong in the catch. If it does not close easily, remove the pin tong and file off a little at a, Fig. 4. When it fits properly, the ends of the wire projecting on both sides are cut off with cutting pliers, d, Fig. 6 .

The riveting of the wire should be done as indicated in Fig. 6. Place one side of the joint on an iron block and strike the end of the wire on the other side with riveting hammer. When this end is flattened, turn the other side of the joint up and rivet the other end of the wire. If any roughness is left, it may be smoothed with a small file.

Fig. 4 shows a bouquet pin, $b$, and a bow pin, a, which are made exactly by the same method as that just described in making the bar pin. 


\section{CHAPTER III.}

\section{Stone Setting.}

CHE first step in the making of a piece of jewelry 1 in which a stone is to be set is the selection of the stone. For the beginner's work, this includes not only the choice of color, shape, etc., but also the quality of hardness. This usual and desirable quality is not present in all gems. For instance, the Opal, Malachite, Azurite, and Coral are soft stones and are, therefore, not best to begin with. The hardness of stones is graded by an arbitrary scale of from 1 to 10 . Talc is a type of the softest or 1 , and the Diamond is the hardest or 10. See Chapter XII.

The gem used in the scarf-pin described in this chapter is an agate. This stone may be called a fairly hard stone ranking about $6 \frac{1}{2}$ in the scale. One may feel perfectly safe while working with a stone of this or greater hardness, as far as scratching is concerned, pro-

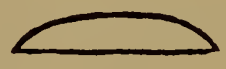

a

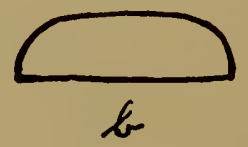

Fig. 7. a-Low Cabochon Cut. b-High Cabochon Cut.

vided it has the cabochon cut. (See Fig. 7.) The Amethyst, Topaz, Sardonyx, Garnet, Jade, and Moonstone are all practical stones for a beginner, as the hardness of each is 6 or above.

After the stone has been selected, a suitable design must be worked out. The design to be used depends 
very largely upon the shape of the stone. The lines of the design should harmonize with the outline of the stone. Therefore, when starting a design, the outline of the stone should be traced upon the paper and a pleasing design created around it. It may be necessary to make several designs before a satisfactory one can be obtained. If the design is to be symmetrical, one-half can be drawn accurately and traced on tracing paper. By folding the tracing paper, the second half may be drawn to correspond to the first, as indicated in a previous chapter.

The number of designs one can make around a single shape is unlimited, as they may be varied and elaborated as shown in the sketches. (See Fig. 8.) This should always be kept in mind, that the stone is the center of interest, and that the design must enrich its beauty, not detract from it or overwhelm it.

After the design has been completed, it is traced upon a piece of gauge 18 sterling silver and retraced with a sharp point. Then the outside edge of the design is sawed out and finished as explained in preceding chapters.

The bezel is an important factor in the setting of a stone. This is a metal band which holds the stone in place, and in this problem, it consists of a strip of silver, gauge 28. This strip is cut by use of shears for this particular stone, about one-eighth of an inch wide and three times the length of the stone. This is a good rule for most shapes. The silver should be annealed before cutting. Annealing is the process of heating and gradually cooling the silver for the purpose of softening it and rendering it less difficult to work. 


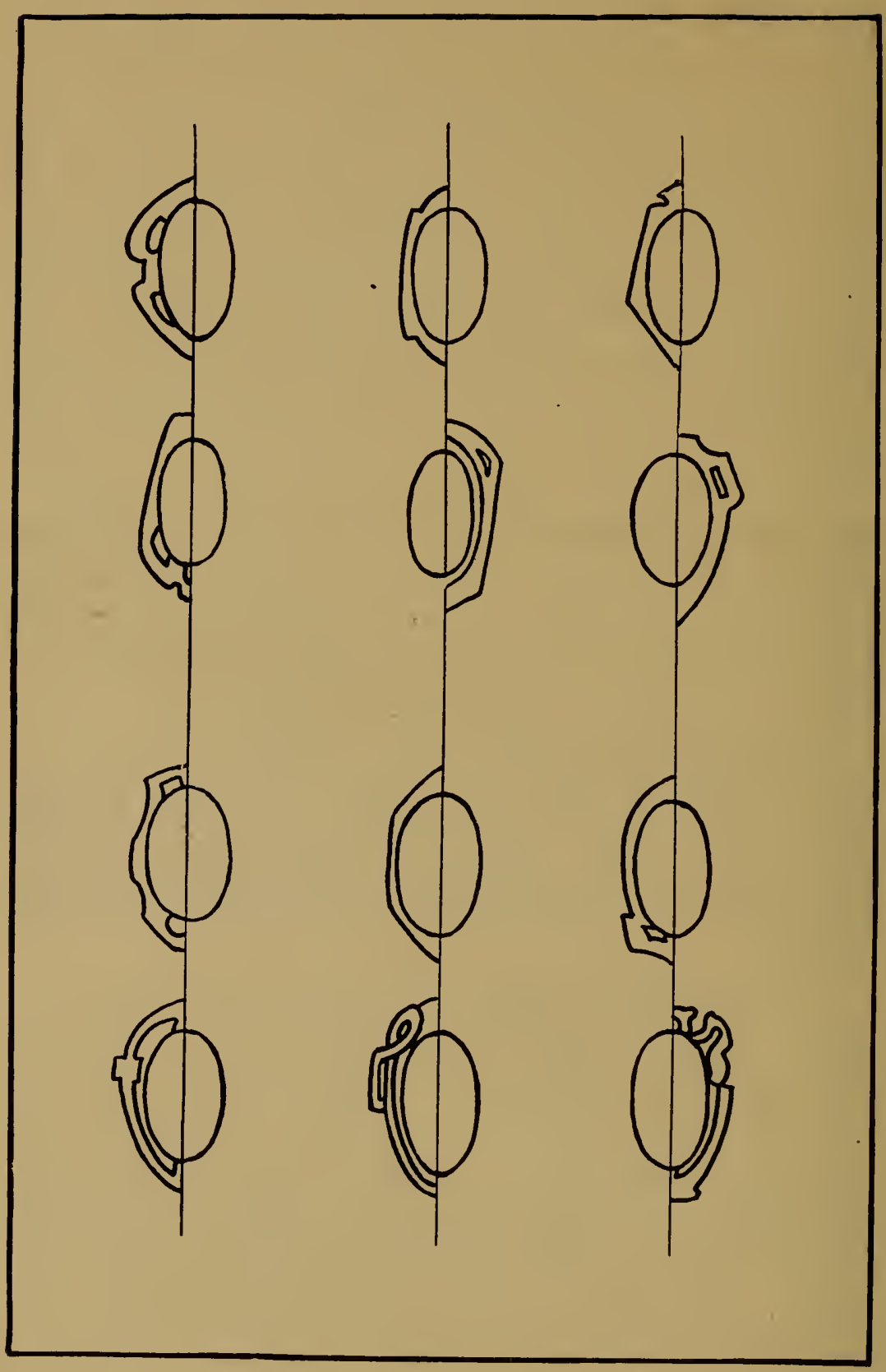

Fig. 8. Designs for Scarf Pins. 
By the use of the half-round pliers, the strip of silver is shaped as nearly like the outline of the stone as possible. The stone is then laid on a flat surface and the bezel placed around it. The silver will be seen to be longer than the distance around the stone, hence it must be cut off. It will be necessary to continue the shaping and fitting of the bezel until it fits snugly about the stone. The ends must be filed until they meet perfectly. The bezel must not be too large. If it should be a little too small, it can be easily stretched after it has been soldered.

By bending the silver back and forth, the ends can be brought together to make a perfect joint. Sometimes a piece of fine iron wire is wrapped around the bezel and twisted at the ends with pliers, to hold the ends of the silver in perfect contact. This method is not advised in this case. The difficulty is that the ends either tend to lap or to stand apart. Unless the ends come in direct contact, the solder will flow on only one end of the silver.

The bezel is placed on the soldering block in the position it will have on the silver of the scarf-pin. Borax solution and a piece of solder are now placed exactly on the joint. The blowpipe is used and the soldering done exactly as described in the preceding chapter. Since the silver is very thin, there is some danger of melting it, so care must be used not to get it too hot.

The soldered bezel should be cleansed with the sulphuric acid solution, and rinsed in water, being sure to remove the iron wire if it has been used. The superfluous solder is filed away, and the bezel tried on the stone. If it is too small, it may be stretched by placing a tool of the proper shape inside of the bezel and tapping 
the outside with a hammer. It is a common practice among jewelers to place the bezel over the handle of a pair of pliers and strike with the hammer. The bezel should be large enough for the stone to be placed into it and removed without difficulty. When it is finished, it should be gotten ready to solder to the silver which forms the base.

That part of the bezel which comes in contact with the base silver must be filed flat with a fine file. The outside of the bezel must be free from marks of file or hammer. The beginner should paint the joint with a mixture of Ochre and water to prevent it from unsoldering when the second soldering takes place.

The bezel is picked up with tweezers and the lower edge dipped into the borax solution and put in position on the silver, which has been previously scraped. After the borax has dried, there is not much danger of the bezel being moved out of place. Four or five small pieces of solder are placed on the inside of the bezel, touching both the bezel and the base silver. The work is then placed on a piece of charcoal or asbestos in such a position as to admit the flame under it. The heat is then applied as before.

The next step is to make and solder on the pin stem. Scarf pin stems can be made or purchased. The making is very simple. A piece of German silver wire gauge 18 and $2_{4}^{3}$ inches long, is filed flat on one end and to a point at the other. A little ring of silver wire is made to fit the pin stem, Fig. 9. It is for the purpose of adding strength to the pin stem at the place of soldering. Altho this is the stronger and better way, and is used by experts, a great many people solder on the pin stem without this reinforcement. 
The pin stem is soldered on the silver in an upright position. The reason is that the heat softens the pin stem which must be hardened after the soldering is completed. In order to solder it in an upright position, a device (See Fig. 9) is made of gauge 20 iron or German silver wire and stuck into the charcoal block. It is a great convenience.

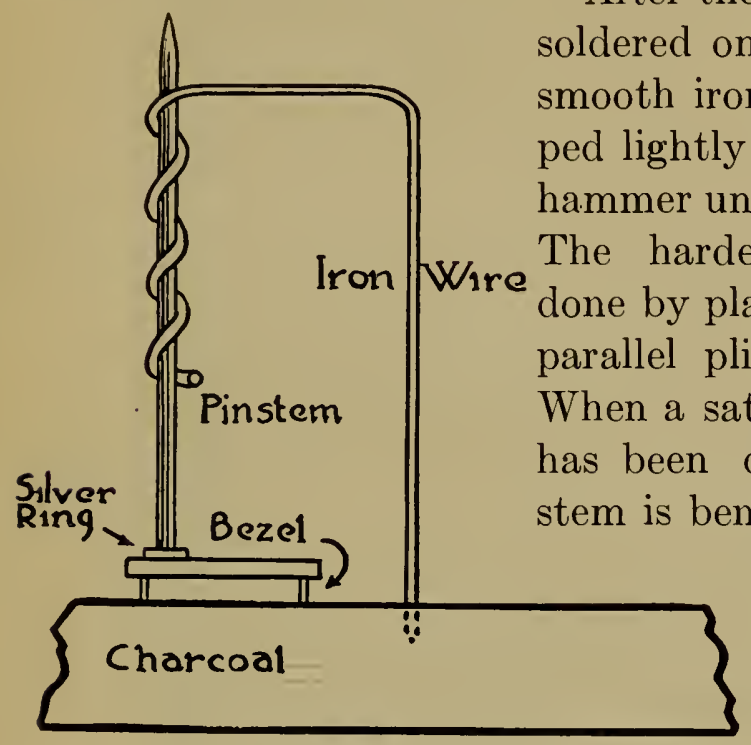

Fig. 9.

After the pin stem has been soldered on, it is placed on a smooth iron surface and tapped lightly a flat faced pecomes hard. Therdening can also be placing the pin in the parallel pliers and twisting. thatisfactory hardness obtained, the pin by holding the pin with pointed nose pliers and bending it into position with the fingers. The scarf pin is then cleansed thoroly with pickle. It will now be necessary to reduce the height of the bezel before setting the stone. It is always advisable to make the bezel quite high to start with, as the surplus can be filed off, but it is impossible to add anything. The height of the bezel is decided by examining the cut of the stone. This stone having a low cabochon cut (See A, Fig. 7), a low bezel may be used, as the curve of the stone forms a small angle with its base. In the high cabochon cut, a higher bezel is required, since 

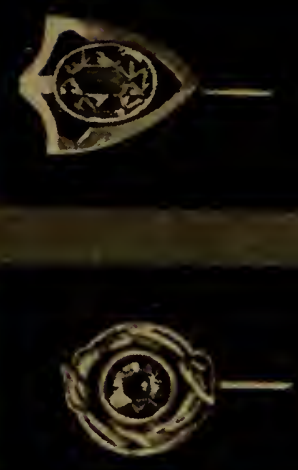

离
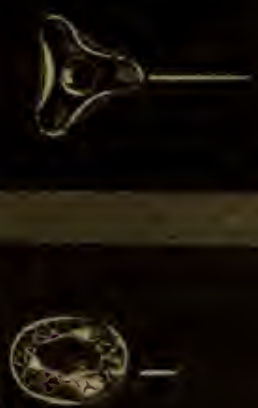

$(-$ 
often the sides of the stone stand almost at right angles to its base.

One-sixteenth of an inch is enough for the bezel in this problem. It is always the aim of the craftsman to have as little of the bezel showing as possible, in order to show as much of the stone as possible and to lend its proper element to the design. Care must be taken, of course, not to get the bezel so low that it will not hold the stone; the constructive necessity always comes first.

When the filing has been finished, there will be a burr on the outside and on the inside of the bezel. The inside burr can be removed by the use of the scraper and the outside one by the use of the file.

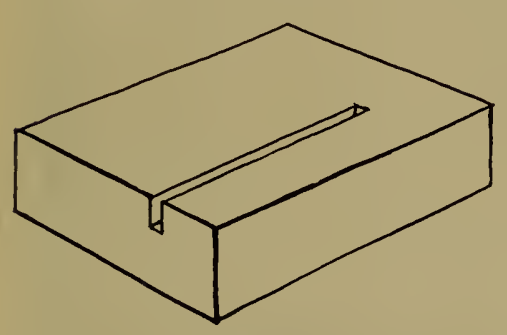

Fig. 10 .

In order to hold the scarfpin firmly while setting the stone, one should have a block of hardwood with a $\frac{1}{4}$-inch deep saw cut in it. (See Fig. 10.) The pin stem fits into the saw cut.

The tools used in setting are very simple and are easily made. One is a pusher and the other is a burnisher. (See Fig. 11.) Place the stone into the bezel and put the pin stem into the saw cut in the wooden block. One hand holds the stone in the bezel while the other hand pushes over the edge of the bezel against the stone with the

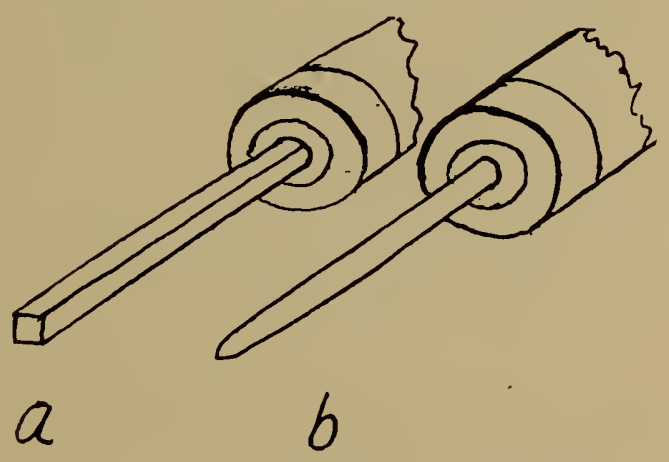

Fig. 11: a-Pushing Tool. b-Burnisher. 
pushing tool. The pushing should be started at a certain point and continued around the stone. This process leaves the edge of the bezel rather rough. This is removed by forcing the burnisher along the side of the bezel. The very edge of the bezel is finished by running the burnisher along the top of the bezel against the stone.

The scarf-pin is now ready for oxidizing as described on page 13.

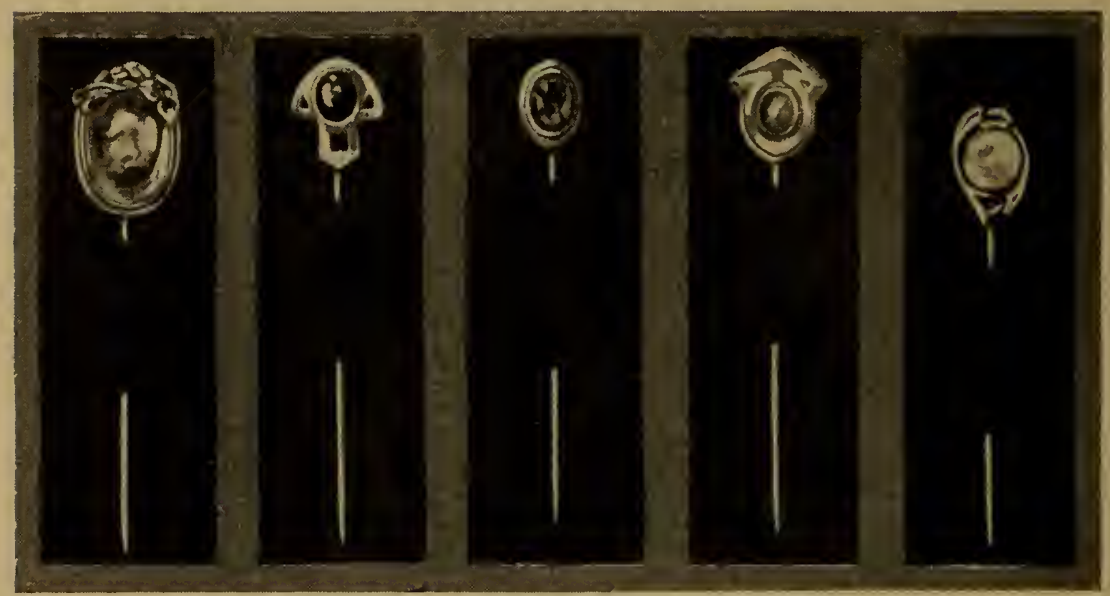

Scarf Pins. 


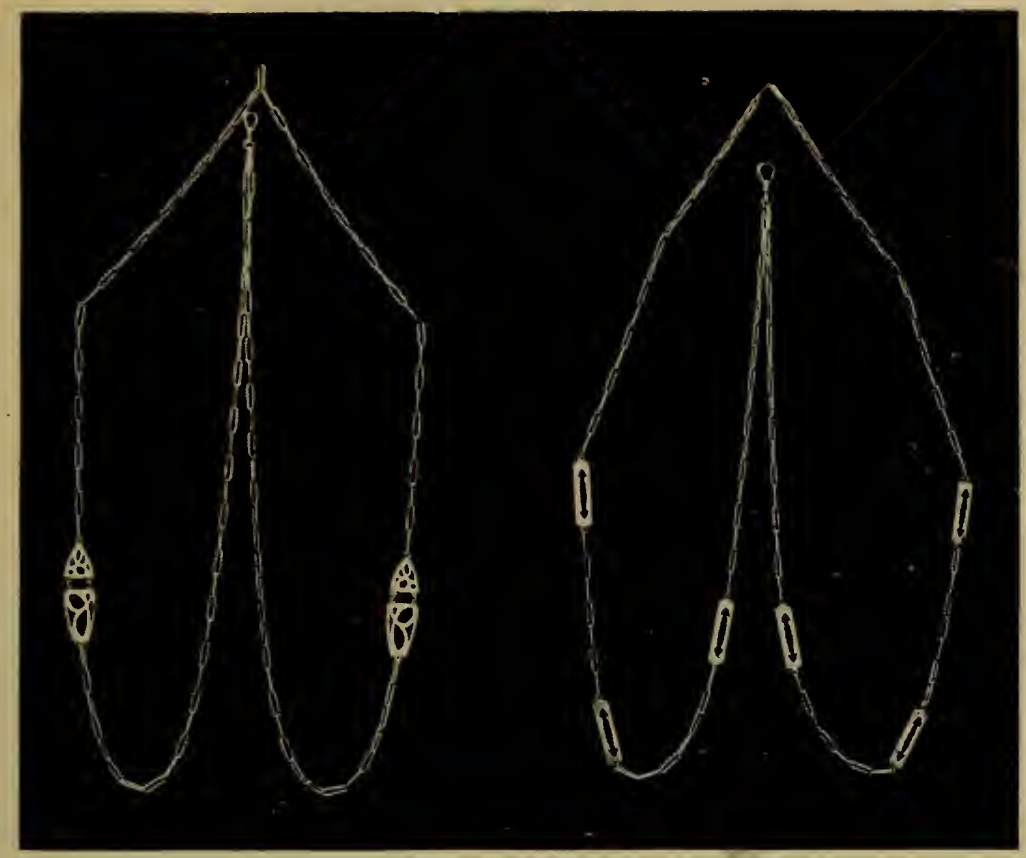

Fig. 12. Ladies' Coat Chains.

\section{CHAPTER IV.}

A Lady's Coat Chain.

THE only new work to be described in this problem $\mathcal{L}$ is the making of the links and the rings which are to be soldered onto the motifs. The process of making the motifs (See Fig. 12), needs no further explanation, since all the work necessary has been described in previous problems.

The motifs can be varied to a great extent both in design and in number. Some coat chains are made with six motifs, some with four, and some with only two. Simple designs are desirable for the first.

The small round rings which are soldered to the motifs are made by winding wire around a mandril. 
This mandril is a round piece of metal, anything one happens to have at hand. It should be the size of the inside of the rings. When enough wire has been wound on the mandril, the spiral of wire should be removed and cut thru the center with a fine saw. A number of small, separate rings will be the result. It is

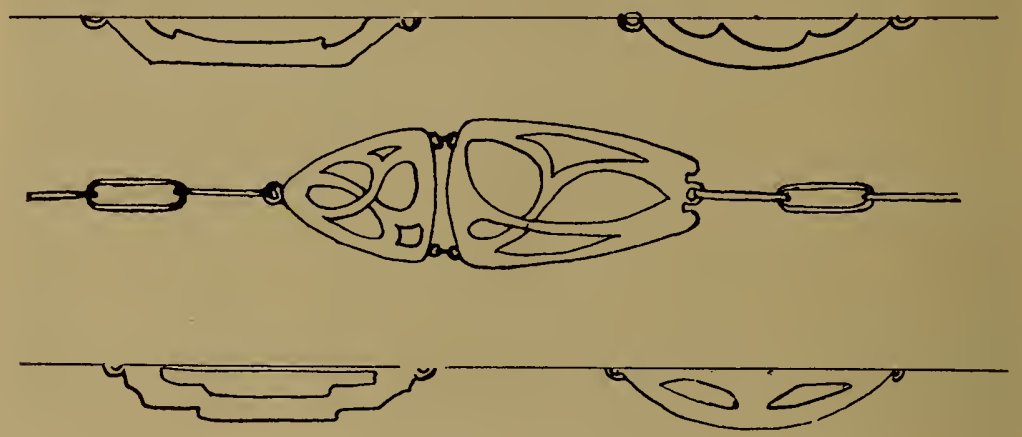

Designs for Motifs.

necessary to make the two ends of the wire of each ring join perfectly. This can be done by bending back and forth with pliers until they meet. Each ring is then filed at the point where the ends join, in order to make it fit the place where it is to be soldered onto the motif.

The making of the long oval links for the chain is a little more complicated. The thickness of the wire from which the chain is to be made, depends upon the size of the link wanted. For the coat chain, gauge 18 or 16 may be used. The mandril used for these links can be made of brass, copper, or iron. The best size for the mandril is about one-sixteenth of an inch thick, sevensixteenths of an inch wide, and four or more inches long. It must be accurate in measurements or there will be difficulty in removing links. 
First of all, two strips of tough paper, $\frac{1}{4}$-inch wide, should be wound onto the mandril as shown (See Fig. 13b). One strip is wound one way with the edges of the paper meeting, and the other strip is wound the other way. A piece of binding wire (iron wire) is wrapped around the end to keep the paper in place.

The silver wire should be annealed before winding it onto the mandril. The wire is then fastened in the

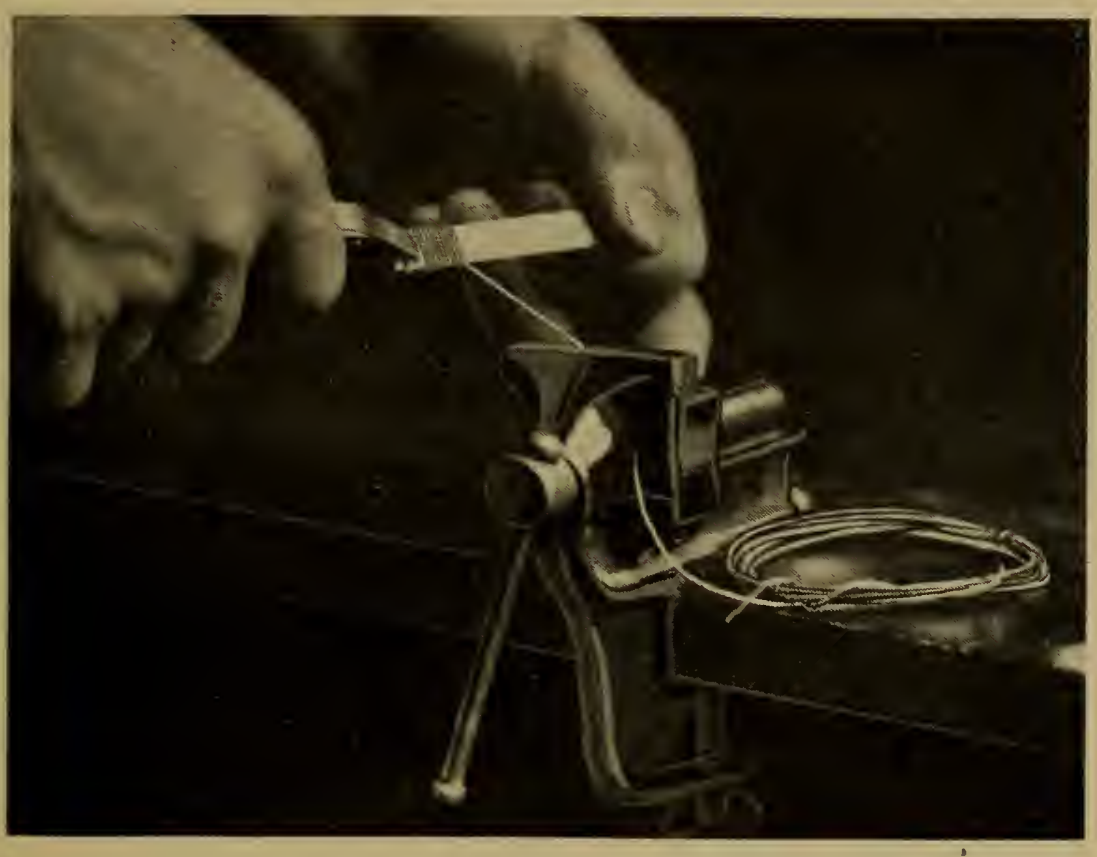

Fig. 13a. Wrapping Wire on the Mandril.

vise (See Fig. 13a). The end of the wire is held with the pliers tightly on one end of the mandril. The

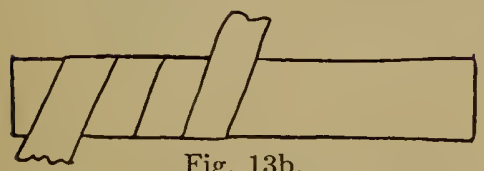

Fig. 13b.

Wrapping Paper around Mandril. mandril is then turned over and over by meansof the pliers, thus wrapping the wire round and round the mandril. The 


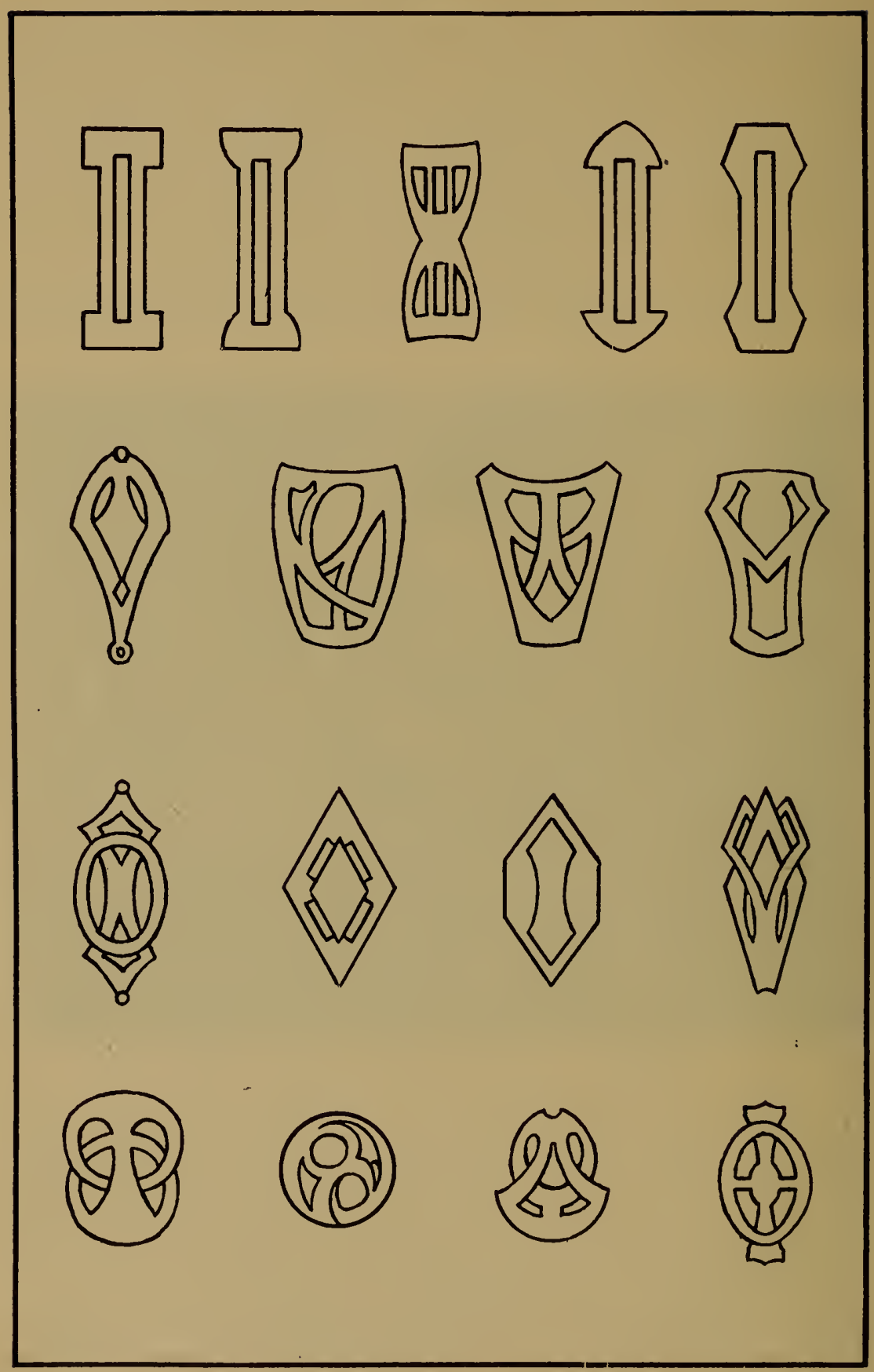

Designs for Ladies' Coat Chain Motifs. 
wire should be kept very tight all the time. The links should be wound as close to each other as possible. After the mandril has been filled with the links, the wire is cut off.

Before trying to remove the coil from the mandril, it is thoroly annealed again. This not only makes the wire soft so that it will keep its proper shape, but it also burns off the paper beneath the wire. This permits the coil to slip off easily.

When the coil has been removed from the mandril, the links must be cut with a fine saw; as were the round ones. Great care must be used to see that the joint comes in the end of each link. It is also necessary to bend the ends with the pliers to make them form a perfect joint. Sometimes the links are cut with shears. Great care must be used to see that the shears have the proper shape of blade, and that the cutting is so done as to leave the ends of the wire in such a condition as not to interfere with the making of a perfect joint.

When the links are ready, several of them are laid on the charcoal block and a drop of borax solution is applied with a small brush to each joint. A small piece of solder is placed on the joint so that it connects the two ends of the wire. By use of the blowpipe, the flame is applied to the end of each link until it is joined. If too large a piece of solder has been used a little lump will be left at the joint. This must be filed off.

After a number of links have been soldered as described, two soldered links are connected with an unsoldered one. Several such groups of three are placed on the block and the unsoldered links soldered as those before. Then two of the three-link groups are connected with an unsoldered link, and so on until the chain has reached the proper length. 

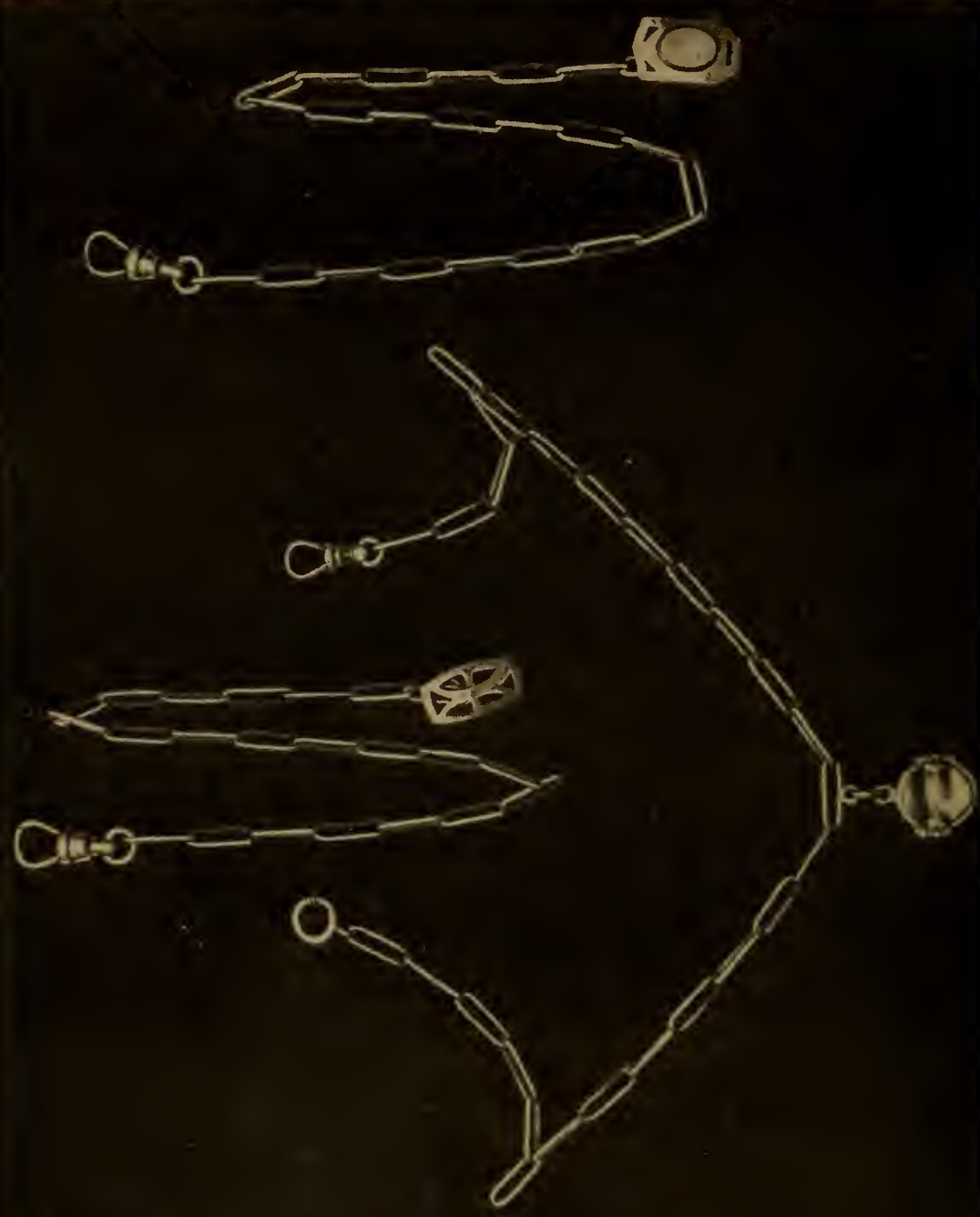

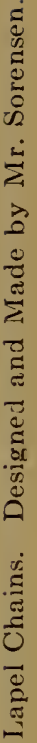

Cresto<smiles>C1=C2C=C1C2</smiles>

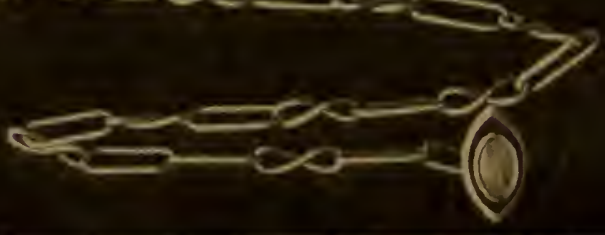


After the chain has been cleansed with the acid solution, it is tested as to strength by pulling with the hands. It is then drawn thru a draw-plate, in order to make the links all the same size. The draw-plate is of hardened steel and has graduated holes in it. As a substitute for the draw-plate, a hole a little smaller than the width of the links may be bored in a piece of hardwood and the chain drawn thru it. See 6 , page 10 .

When the links have been thus straightened, the chain is cut at the places where the motifs are to come. Of course, the motifs may be placed anywhere on the chain, but as a rule, the following measurements are good: First connect two motifs with 16 inches of chain, then put the other motifs about three inches apart, putting the same number on the two sides of the chain. The whole chain, when completed, measures from 50 to 54 inches.

The chain is connected with a swivel for the attachment of a watch, purse, or vanity bag. When it is completed, it is oxidizẻd as previously described.

\section{Lapel Chains.}

The gentlemen's Lapel Chains shown in the picture on page 34, are made in the same manner as the Coat Chain. The links may be made of the same size and the same gauge of wire. When completed, the chain is nine inches long. In order to connect the chain with the lapel button, a small round link is soldered underneath in the center of the button. The Lapel Chains are worn a great deal and make a most acceptable and practical gift. 


\section{CHAPTER V.}

\section{Rings.}

TN planning to set a stone in a piece of jewelry, the 1 proper method is to select the stone first and to make it the center about which to form the design. Any color of a moderately hard stone may be selected, but it is advisable to select one with the cabochon cut. In making the ring described in this article, a green Chalcedony was used.

As can be seen by the accompanying sketches, Fig. 14, a variety of ideas in design may be worked around the outline of the stone. We make it our rule never to

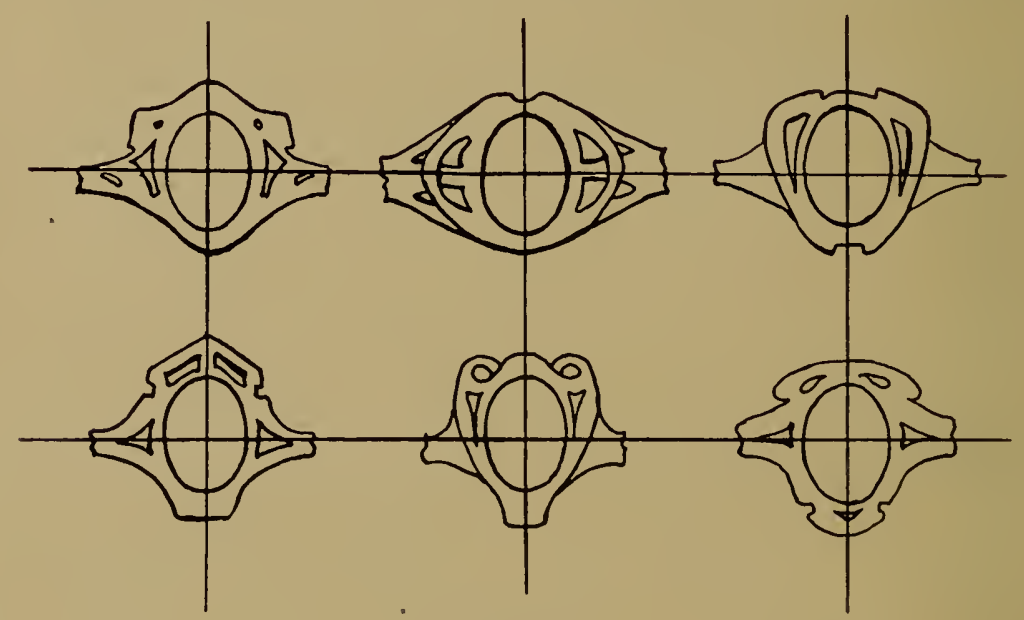

Fig. 14.

decide on any one design, until we have put at least three or four ideas on paper. This is not a waste of time, as it seems to some, for we often choose the second or third idea. It may be simply a modification of the 
first one, but we find something more pleasing in the design, the proportion, the size of the top, or in a line which harmonizes better with the stone.

In this, as in the previous problems, an effort is made to explain and illustrate the fundamental principles and methods of jewelry work by doing simple, tasteful pieces well, and gradually working our way into the difficulties and complications of advanced work. Hence, we are using silver, gauge 18 or 20, and are still working with the sawed out decoration. The sawing of a design in a ring already shaped is quite a different matter from the sawing of a design in a flat piece of silver. Gold work and greater complications are reserved for future articles.

In selecting the stone and planning the design, the size of the finger is an important element. The finger size is usually measured by a card having a series of holes ranging in size from three to twelve, or by a series of rings numbering from one to thirteen. The sizes of ladies' little fingers run from three to five. The diameters of these ring measures from three to five, are as follows: Number three, 9-16 inch; number four, 19-32 inch; number five, 5-8 inch; and number six, 21-32 inch.

In order for one to know how long to make the piece of silver which forms the ring blank, so as to fit a finger of definite size, one may measure off approximately one and thirteen-sixteenth inches, which corresponds to a number three. To get a whole size larger, one should add three-thirty-seconds of an inch to this amount. To get two sizes larger, three-sixteenths of an inch must be added, etc. 
It is understood, of course, that the design has been traced from the original drawing to tracing paper which is to be used thruout the problem. A center line should now be scratched on the silver, as shown at A, Fig. 15, when a symmetrical pattern is used, so that the crease in the tracing paper may be placed on this line.

The pattern shows that the cut-outs at the sides of the ring and nearest the bezel, are about 1-16 inch from the bezel. If the pattern were transferred to the silver and the sawing performed before the ring is shaped, the distance from the cut to the bezel would be
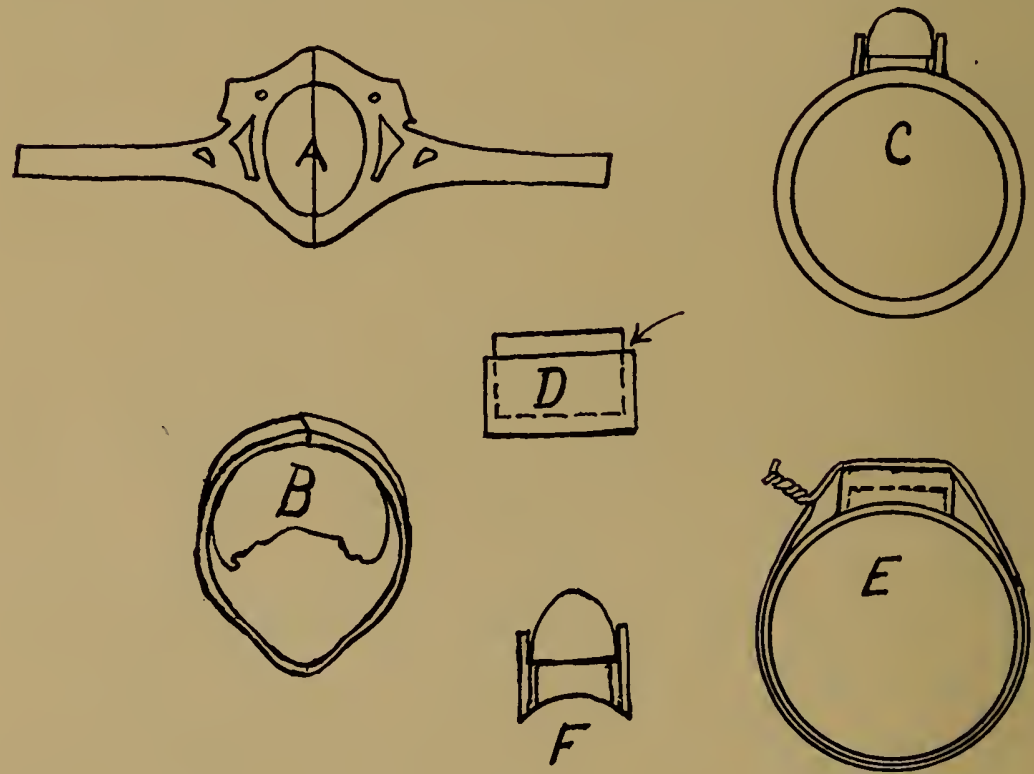

Fig. 15 .

A-Ring Blank. B-Meeting of Ends on Bending. C-Cross Section of Ring, Bezel and Stone. D-Double Bezel in the Making. $\mathrm{E}-$ Binding Wire in Place. $\mathrm{F}$-Curve Filed in Base of Bezel.

found to be different from that shown by the pattern. This must be avoided. Besides, the shaping of a ring after the cut-outs are sawed throws the edges of the openings at such an angle as to make an unpleasant 
appearance. A still further reason for shaping the ring before sawing the design is that it entirely eliminates all danger of breaking any of the parts of the sawed design.

Only the outline of the ring blank is transferred to the silver and sawed as close to the line as possible. The blank is then filed and finished. It is now ready to be shaped. For this process, an addition to our tool supply is almost necessary. This is a cake of lead with a

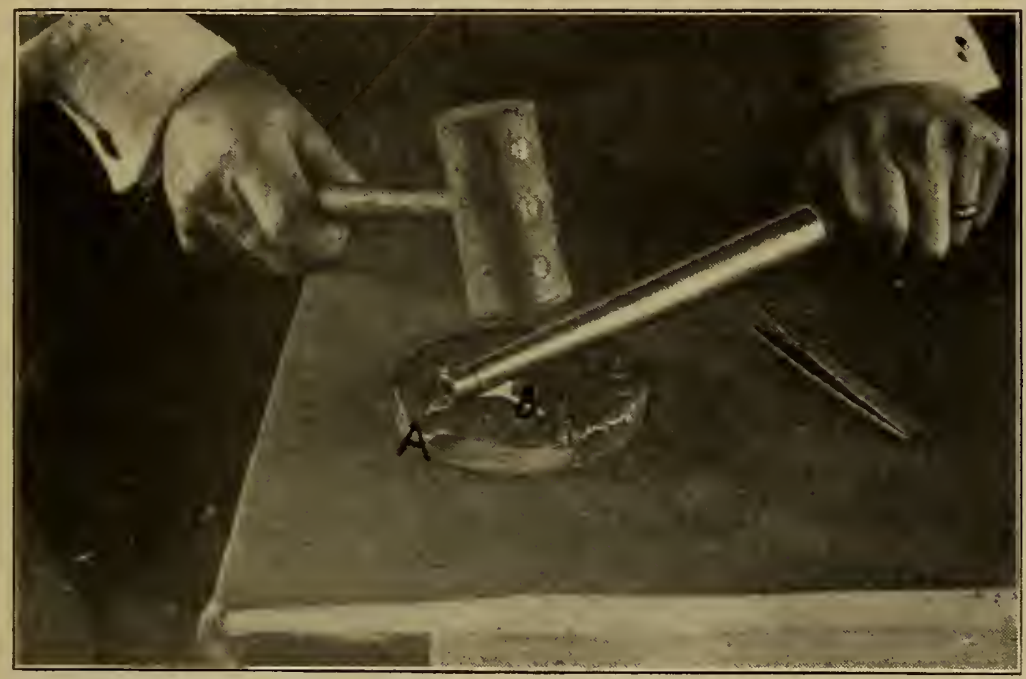

Fig. 16. Shaping the Ring on Lead Cake.

half-round groove across it, ring mandril and a rawhide mallet. (See A, Fig. 16.)

The outline of A, Fig. 15, shows how the ring blank should look before the shaping takes place. The blank is long enough to make a size 4 ring, that is 1 29-32 inches. Place the ring blank across the lead, the center being directly over the groove, as shown at B, Fig. 16 and A, Fig. 16. Hold the ring mandril on top of the blank over the groove and parallel to it. Strike the mandril as shown at B, Fig. 16. The ends are 
filed until they form a perfect joint which is then soldered. It is not necessary to try to make the ring perfectly round before the soldering is done.

The joint is soldered as suggested in other problems, by applying a piece of solder about 1-16 inch $x$ 1-8 inch on the outside of the ring and covering the joint. The ring can be held with tweezers or placed on a charcoal block while the soldering is being done, either method being practical.

A few difficulties will probably arise at this point. The solder may flow on one of the ends only. This is due to the fact that one side of the ring has become hotter than the other. Both sides must be heated evenly. Another difficulty which frequently arises is that the ends spring apart before enough heat has been applied to fuse the solder. In such a case, stop applying the heat, force the ends together until they again meet perfectly, and try again. The possibility of this may be avoided by the use of binding wire, but it is unnecessary. Sometimes the solder will not melt entirely, merely enough to form a round ball at the joint. This means one of two things: It may be due to the fact that the joint was not properly cleaned, but it is probably due to the fact that not enough heat was applied. To overcome this difficulty, place a piece of charcoal close to the ring and on the opposite side from the one on which the flame is applied. This piece of charcoal helps to hold the heat which was otherwise wasted by going past the ring.

The ring is now ready to be cleansed with the sulphuric acid solution commonly called "pickle." It is then placed on the mandril and made round by the hammering of the rawhide mallet. Reverse the ring a time or 
two on the mandril to prevent its becoming cone-shaped.

A ring mandril is a round, tapered piece of steel used to give rings their proper circular shape. See No. 8 on page 10 . It is advisable to buy a good mandril which has standard graduations of sizes.

After the ring is perfectly round, the design for the cut-outs should be transferred to it by placing the tracing paper around the ring so that the crease of the paper is exactly on the center which was scratched on the silver, and scratching the traced lines with a pointed tool.

A new and important part of this problem is the bezel. It was explained in a preceding chapter how to make a simple single bezel and to solder it to a flat piece of silver. But it is quite another matter to make a double bezel and to fit and solder it to a curved surface. The double bezel consists of two bezels, one inside the other. The inside bezel is a little lower than the outside one, thus forming a ledge for the stone to rest upon. If it were not for this ledge foundation, there would be considerable difficulty in setting the stone, as it would not rest evenly on the curved surface of the ring. C, Fig. 15, shows a cross section of the double bezel with the stone in position.

The outside bezel is first made to fit the stone, as explained in Chapter III, using a $\frac{1}{4}$-inch strip of gauge 28 silver. A second bezel is made of the same material small enough to fit tightly inside of the first one. After the bezels have been fitted perfectly, the tops of the two are filed flat and straight, using a flat medium file. The inside of the larger bezel and the outside of the smaller one should be perfectly cleaned to insure successful soldering together. 
When the smaller bezel has been inserted in the larger one, it should project as shown at D. Fig. 15. They are then placed on the soldering block, and the borax solution and eight or nine pieces of solder on the edge indicated by arrow in D, Fig. 15. After the soldering, the bezel is pickled and then it is ready to be shaped to fit the ring. Saw off that portion of the inside bezel which projects. This edge of the bezel must now be filed with the curved side of the half-round medium file. While filing, hold the bezel between the thumb and three fingers of the left hand. File until the curve in the bezel, F, Fig. 15, fits perfectly the curve of the ring, and the bezel sits straight with the center line. When this perfect fit has been obtained, the bezel is soldered to the ring. It is advisable to wrap a fine binding wire around the ring and bezel, in order to hold them in the proper position. See E, Fig. 15.

The borax solution is applied and several pieces of solder are placed on the inside of the bezel, touching the ring. When the bezel is being soldered on, the ring should be held with tweezcrs. The reason is that this process requires considerable hcat, and holding it in this manner, one can direct the flame to better advantage. Regular soldering tweezers are used for this purpose. See Fig. 28, page 73.

When the bezel has been satisfactorily soldered to the ring, the sawing is done. It is necessary to drill a hole where each cut-out is to be. A drill like the one shown in Fig. 17, can be bought for a small sum, and will be most useful in this and other problems to follow.

Before commencing to drill, an impression should be made with the punch to prevent the drill from slipping. The ring may be held by placing it on a round 
piece of wood and holding it in the groove of the lead cake, or by placing it in a ring clamp, as shown at B, Fig. 17.

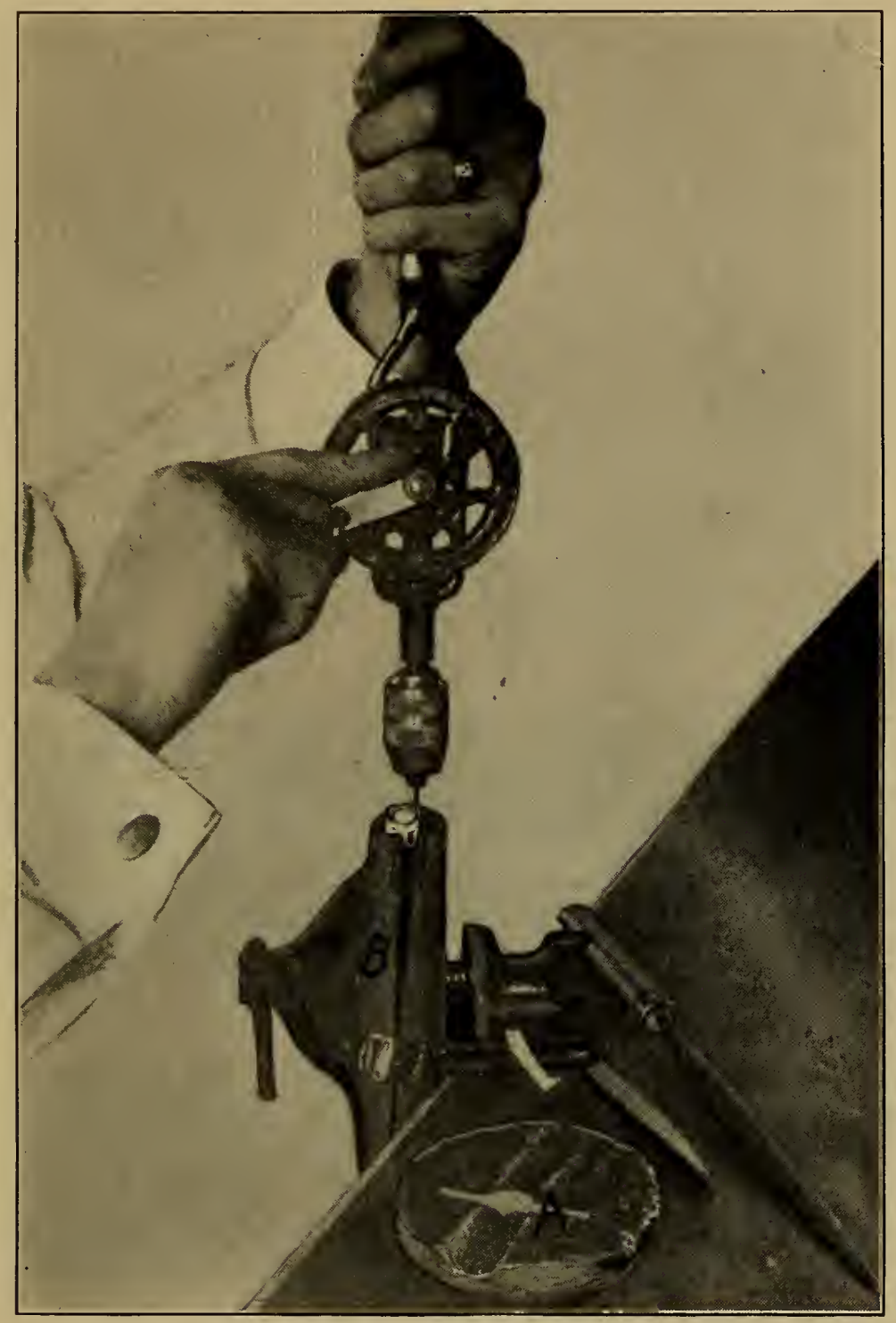

Fig. 17. Drilling Holes for the Cut-Outs. 
Great care must be used in sawing to prevent injuring the shank of the ring and making it necessary to refinish it. The cut-outs should be finished with needle files.

If a transparent stone is to be used, the part of the ring inside the bezel should be sawed out.

After the ring has been finished with' emery cloth, the setting of the stone takes place. In order to hold the ring securely, use a ring clamp. The stone is placed into the bezel which is examined as to the height necessary for the setting of the stone. If the stone has a low cabochon cut, the bezel may be made quite low. If the stone has a high cut, the bezel must be left high above the ledge of the inside bezel.

The actual setting is done by forcing the bezel to the stone, exactly as described in Chapter III.

The final step is the oxidizing, which has'been fully described.
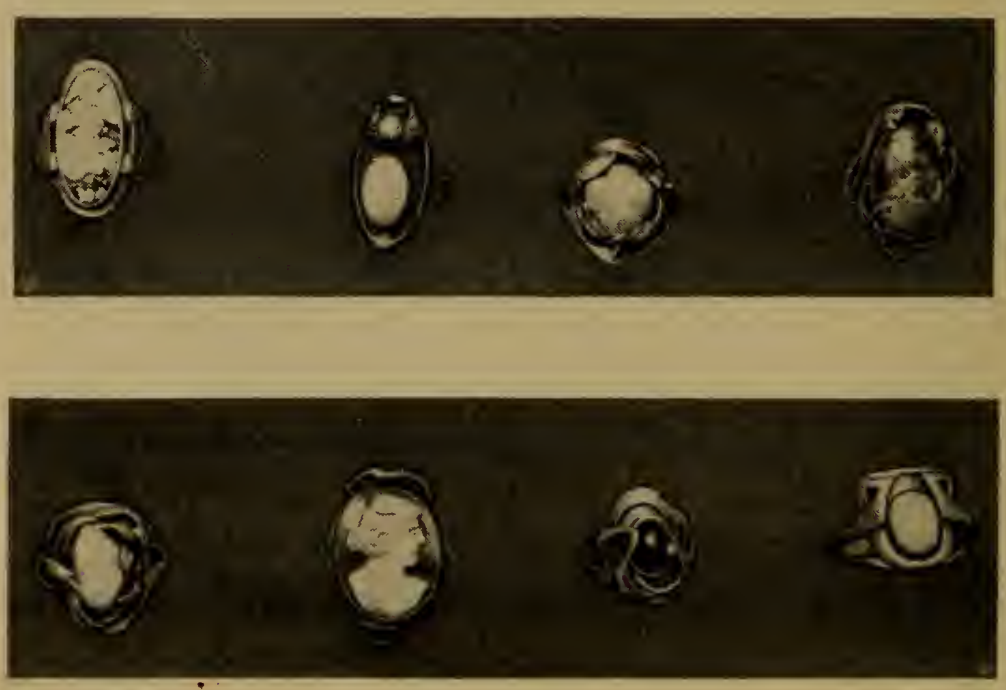

Rings. 


\section{CHAPTER VI.}

THE making of a pendant similar to the one shown $\mathcal{L}$ in the photograph, will be described in connection with a discussion of gold and the difficulties encountered in working with it. This pendant has an applied design and a faceted stone.

Fourteen carat gold is used in making this piece. The largest per cent of good jewelry is made of this grade of gold. Carat, which signifies a twenty-fourth, is a term used to express the proportion of gold in an alloy. The whole mass of metal to be estimated is divided into twenty-four parts. If eighteen of the parts are gold, the metal is said to be eighteen carat, or threefourths pure. In a piece of fourteen carat gold, there are fourteen parts of pure gold and ten parts of alloy. The alloy consists of pure silver and pure copper.

More heat is required to melt fine gold (gold of twenty-four carats) than to melt gold of any other carat. The lower the carat of gold, the lower the fusing point. Twenty-four carat gold melts at 2016 degrees Fahrenheit, fourteen carat at 1991 degrees, and ten carat at 1982 degrees.

We have selected the topaz for the setting in this pendant. This stone has facets, is translucent, and its resting edge is at the middle of its height instead of at the base as in the case of a stone cut cabochon.

The reason for facet cutting of stones is to increase their brilliancy, hence, cutting of this style is done only on transparent or translucent stones. 
HAND-WROUGHT JEWELRY

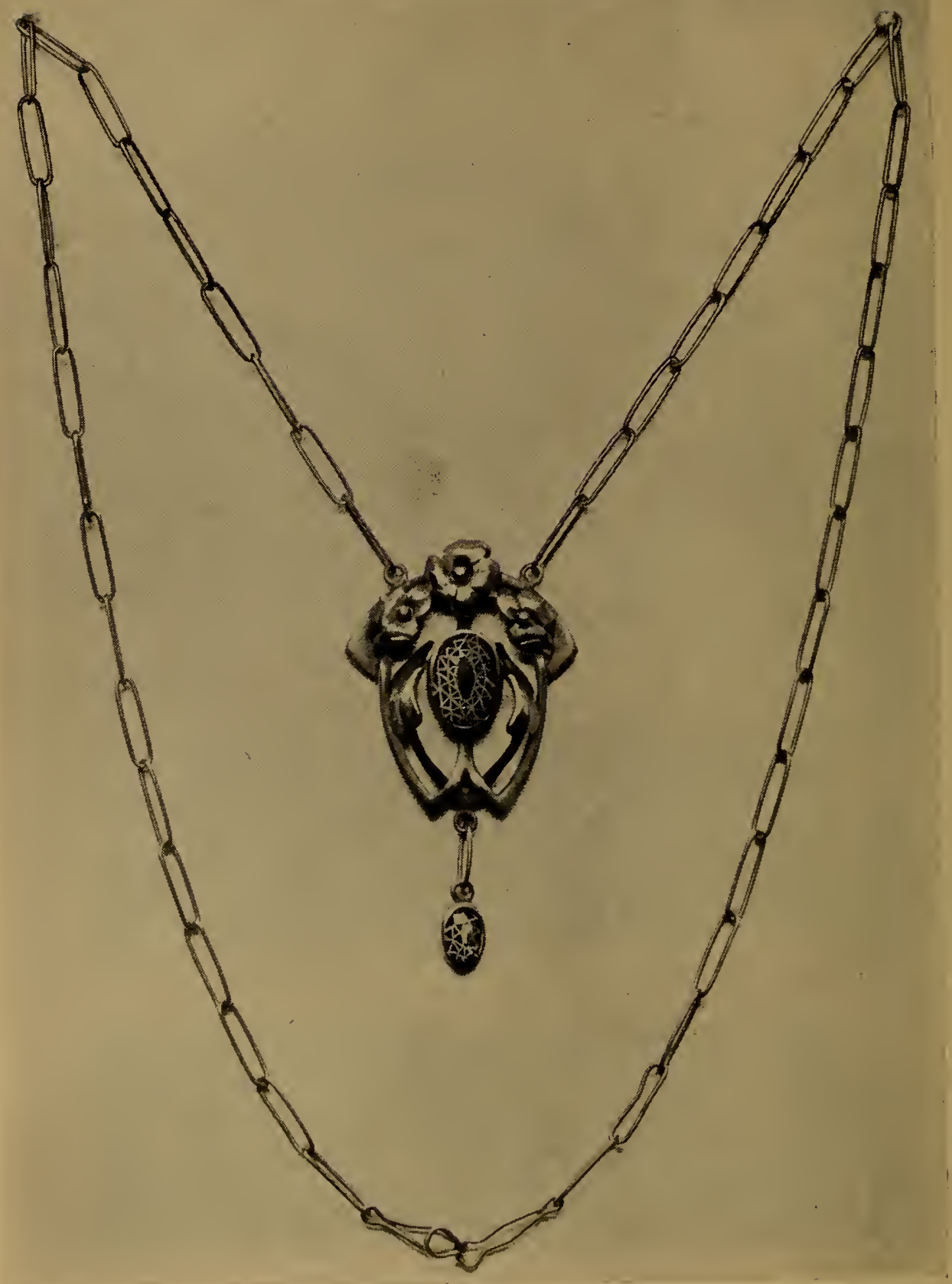


A faceted stone should always be set in a double bezel and have an opening beneath for the passage of light rays. The process of making a double bezel was described in Chapter IV.

A few things should be said about the solder. While making a silver bezel, we used only one kind of solder, whereas we shall use two kinds on the gold. The seams of the two bezels should be soldered with fourteen carat solder. Then after the bezels have been fitted one inside the other, the solder used to join the two together should be ten carat, as it flows under much less heat than the fourteen, hence this precaution practically eliminates the danger of opening the seams. When soldered, the bezel should be cleaned with sulphuric acid.

The faceted stone rests on the bearing made by the inner bezel, as shown at d, Fig. 18. Compare this with the resting of the cabochon stone at e, Fig. 18.

The pendant has three separate parts, Base, a; Bezel, b; Applied Design, $c$. Fig. 18. Now we can take up the work of portion $a$, which is the base or body of the pendant. For this the gold may be thinner than the silver we have been using, since gold is quite a good deal harder than silver. Instead of gauge eighteen, we shall use gauge twenty. Another reason for using a lighter weight, is that gold is much more expensive than silver. Gold costs from 66 cents to 70 cents per pennyweight, which is one-twentieth of an ounce. Silver costs less than 80 cents per ounce.

After selecting our material, the design is transferred to it. Only the portion $a$, (including the dotted lines), Fig. 18, is traced on the metal. When $a$ has 

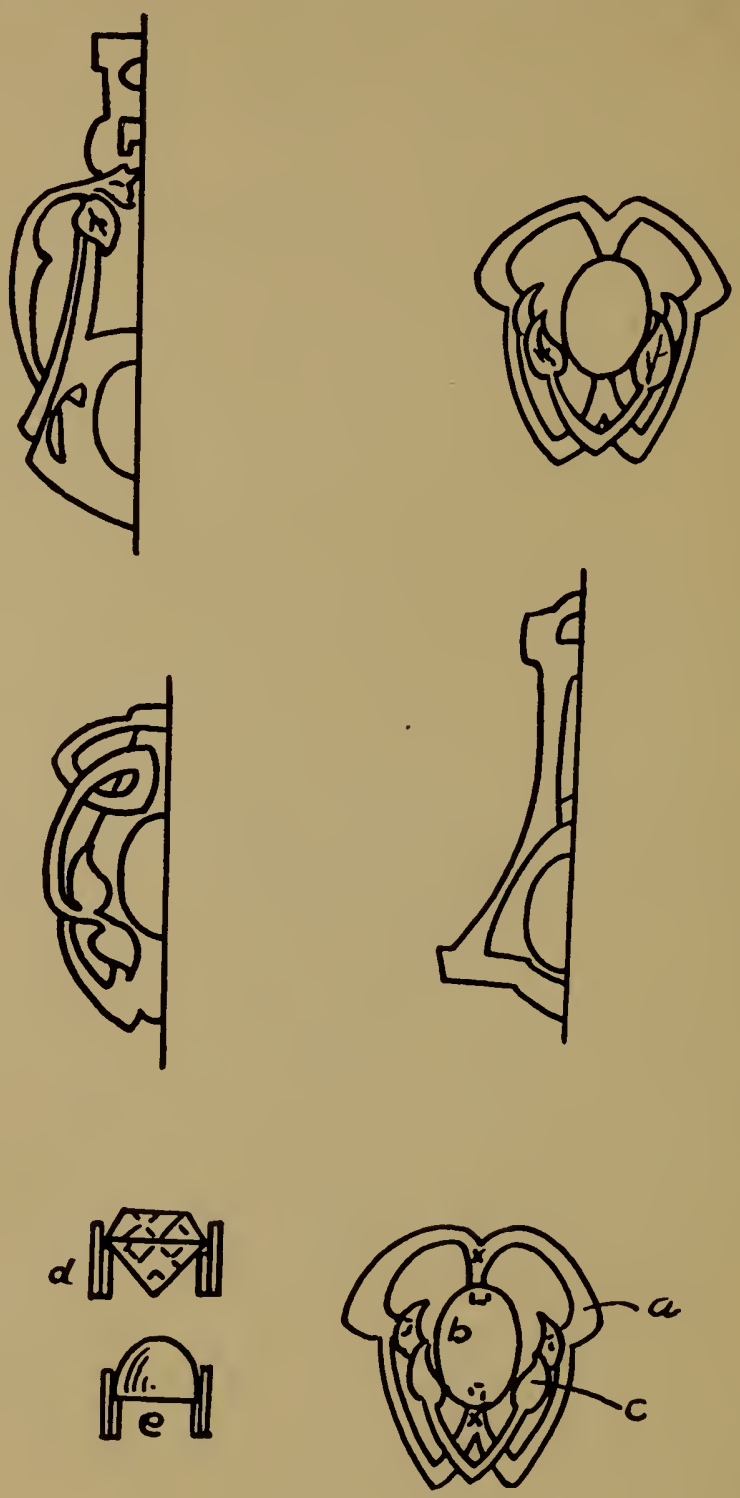

Fig. 18. 
been cut out and finished with emery cloth as in previous problems, the leaf forms, $c$ are made. This part is made of gauge 22 gold. After this part has been sawed out and finished with emery cloth, the leaves are formed a trifle. This is done by placing the leaf forms on the lead cake and dapping the reverse side of the gold with a ball punch, Fig. 19.

To give the effect of one leaf going over another, the edge of the upper leaf can be filed in with a fine

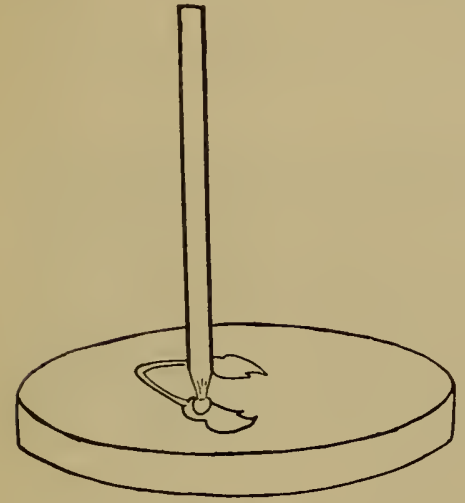

Fig. 19. needle file. This really belongs to the branch of carving which is done with gravers, and will be fully explained in a later chapter.

The flowers on this pendant are easy to make. The outline of the flower is transferred to the metal, then it is sawed out. Now forcing the center of the flower down by placing the ball punch in the center of it and striking it with the hammer a place is made for the little ball which one can observe. The reverse side of the flower petals are also shaped with the hammer.

To make the little balls place a small piece of gold on charcoal and apply borax. Then hẹat it with blowpipe until it melts and runs into a ball.

To solder the ball to the flower, melt a little solder in the center of flower, place the ball in the same spot and solder.

After the pieces $a$ and $c$ have been finished, we are ready to solder the bezel to $a$. Try the stone in the 
bezel to make sure that the bottom of the stone is flush with the bottom of the bezel. Cut away enough of the parts indicated by the crosses, Fig. 18, so that the bezel fits down very snugly between these ends. Now we are ready for soldering, provided that all parts have been thoroly cleaned. One should be even more particular in this respect, working with gold than in working with silver.

A small piece of solder is placed on the reverse side where the bezel makes connections with the base. With the work lying on the charcoal, the soldering is done as in the previous problems.

At this point, there will undoubtedly arise some difficulties. These cannot be overcome by anything except a lot of practice. So, in order that one may become acquainted with the action of gold solder, it might be advisable to experiment with a piece of scrap gold. A point always to be kept in mind is that the parts to be soldered must be heated evenly.

The bezel is now soldered to the base $a$. Following this operation, the leaf portion is applied. There is a possibility that the general shape of the leaves has been altered while forming them with the ball punch. This of course must be remedied by bending and shaping them so that they fit properly around the bezel and to the base or body. After the leaves have been fitted, they should be soldered at the points where the stems cross the base and where the leaves touch it. Very small pieces of ten carat solder should be used.

It is necessary that two small rings be soldered to the pendant for the attachment of the chain. When doing this soldering; it will be necessary to heat the 
entire pendant gradually, so that the rings may not get hot too soon.

A chain of gauge 22 gold wire should be made after the method of making a Coat Chain, explained in the fourth chapter.

The entire pendant should now be pickled and cleaned thoroly. The stone is set in the same manner as described in previous chapters.

\section{Metal Polishing.}

As a rule, jewelry shops are equipped with polishing lathes, and many of them employ men whose only business it is to polish jewelry. This is an important part of the work.

The polishing lathe in its most convenient form is simply a motor with projecting tapered spindles to which are attached the polishing brushes.

Silver jewelry is finished on the lathe in the following manner: After the jeweler has given the article as smooth a surface as possible by the use of fine emery cloth, the polisher takes it and polishes it with a felt buff. These buffs come in various shapes and the worker chooses whatever shape suits his purposes best. Tripoli is applied to the buff. This preparation aids in removing fine scratches.

To reach sunken places in the work a bristle brush is used, applying Tripoli as before.

Great care should be taken while doing this work to kecp the article of jewelry constantly moving from one side to the other. If this precaution is not taken, the buffs and brushes are liable to cut grooves in the article, thereby ruining it. 
When all marks have been removed, the article should be washed in hot water containing a little ammonia and a small piece of laundry soap. A brush should then be used to remove every particle of dirt.

The final polishing is done by using a steel brush. This gives the piece a frosted or satin finish. The satin finish is advised in case a gold article is to receive a Rose or Roman Gold Finish or a silver article is to be oxidized.

Gold is polished in the same manner as silver, except when a bright finish is desired such as is used on wedding rings. Then instead of using a steel brush, a woolen buff is used, applying polish-rouge which gives gold a very bright finish.

The finishing of gold is quite different from the finishing of silver. Gold work is finished by polishing it brightly or by covering it with a deposit of fine gold which is commonly called Roman or Rose finish, and which must be done by a process known as Electro-plating. In order that a good finish may be obtained by electro-plating, it is necessary to polish the work first and satin-finish it. The polishing is done by first using felt buffs and bristle brushes touched occasionally with a bit of tripoli, which is a polishing preparation.

After all scratches have been removed, the work is boiled in water with a little strong ammonia and soap. This mixture with the assistance of a brush, removes all the greasy substance left by the polishing. The satin finish can then be applied by using the steel wire brush. The work should be cleansed again and it is then ready for the plating.

The operation of electro-plating can be performed 


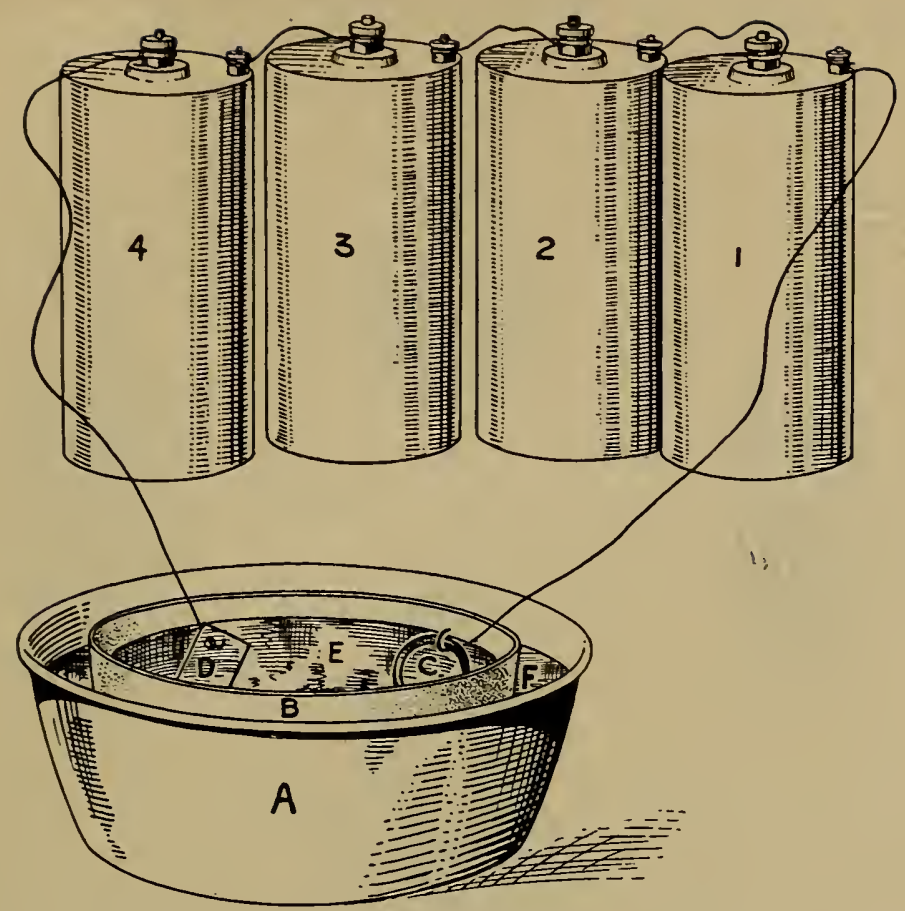

Fig. 20. Simple Apparatus for Gold Plating, 1, 2, 3, 4 Batteries properly connected. A Granite Pan, B Earthenware Vessel, C Piece of Jewelry to be plated (Cathode), D Piece of the fine gold (Anode), E Plating Solution, F Water.

by a beginner without a great deal of expense. A plating outfit can be made with the following material: Four dry batteries.

Six feet of thin copper wire.

Gas plate with single burner for heating solution. Piece of thin fine gold, $\frac{1}{2}$ inch $\times 1$ inch.

One quart of distilled water.

Glazed earthen vessel large enough to contain the quart of water.

Vial of Chloride of Gold (15 gr.).

Granite pan quite a bit larger than earthen vessel with which it is used as a double boiler. 

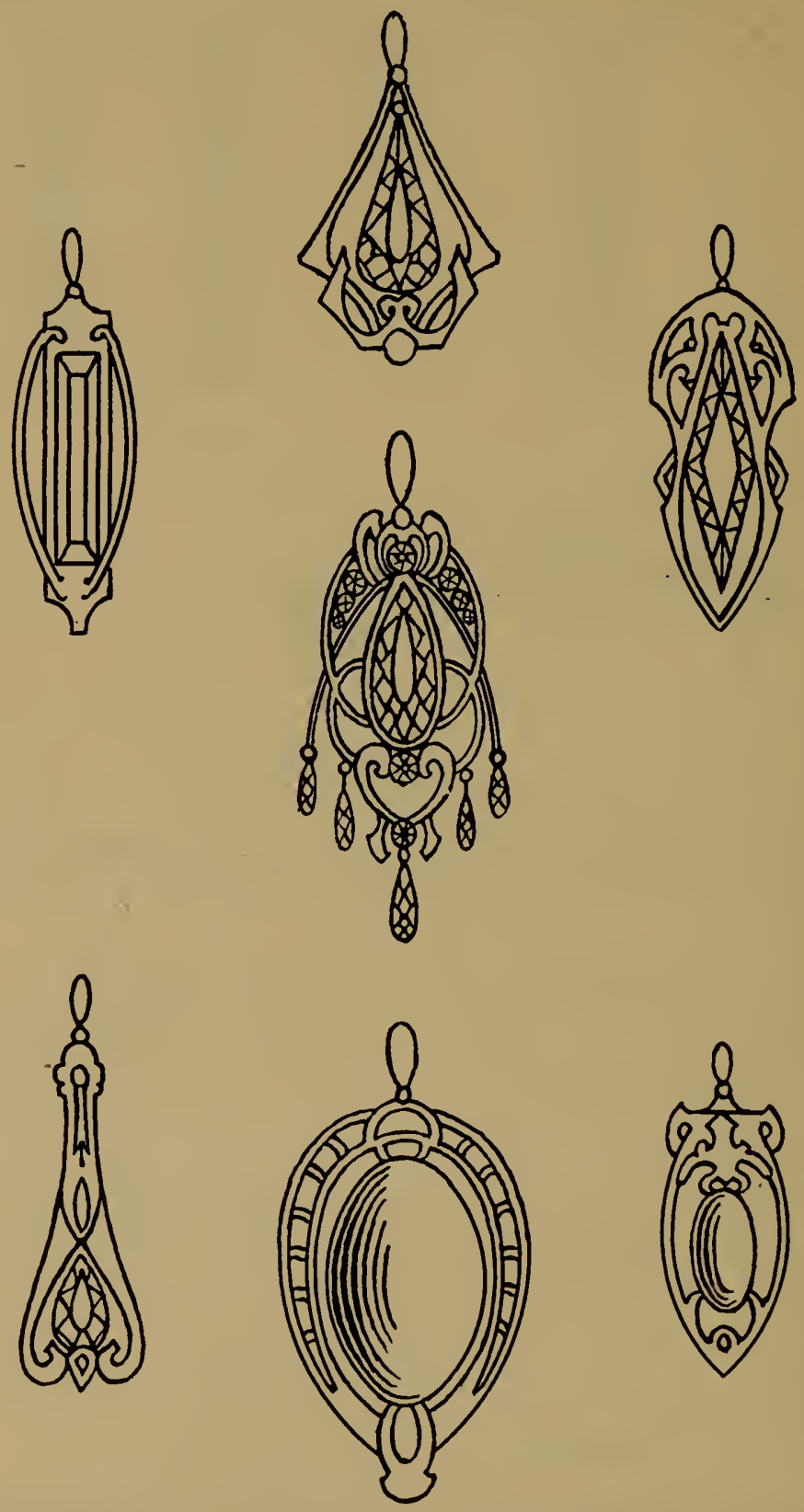

Designs for Pendants. 
Directions for making solution and using batteries:

The distilled water and about one cubic inch of Potassium Cyanide, C. P., (a deadly poison) are put into the earthen vessel. This should stand for 24 hours. Then the $15 \mathrm{gr}$. of Chloride of Gold are put into the solution, which is then ready for use.

The batteries should be connected with short pieces of copper wire, which should be scraped well at the contact points. To connect two batteries, one end of the copper wire is attached to the center clamp of one battery, and the other end of the wire is attached to the outside clamp of the second battery. A third battery is attached to the second in the same manner, as is also a fourth attached to the third.

A wire long enough to reach from the batteries into the solution is attached to the center clamp of the fourth battery, and another piece the same length is attached to the outside clamp of the first battery.

Of course it is understood that the center clamp of a battery is called the positive pole, and the outside clamp is called the negative pole.

The piece of fine gold, called the Anode, is attached to the long wire which is attached to the positive pole. The article to be plated, called the Cathode, is placed on the end of the other long wire. By putting the anode and the cathode into the solution, the circuit is completed and the electro-plating takes place. Care must be used not to bring the anode and the cathode into contact with each other.

When the article to be plated has become a dark brown, it is removed from the solution and rinsed. It is then polished with a little soda until the desired shade and finish are obtained. 


\section{CHAPTER VII.}

The Setting of Odd Shaped Stones.

The Abalone Blister.

$\triangle$ BALONE BLISTERS are cut from the inside of 1 Abalone shells having an iridescent and irregular surface. These shells are found in the waters of the Pacific Ocean on the coast of California.

The blisters when considered good, usually possess beautiful colors. They are, as a rule, very thin at the top and require a filling of plaster of paris or jewelers' cement.

The difficulty experienced in setting these blisters lies in the fact that the edge is very irregular and the bottom is not even. The irregularity of the bottom can almost always be remedied either by filing off as much material as possible without injuring the shell or filling the low places with jewelers' cement, thereby giving it an even surface as shown at A, Fig. 21.

It is very important that the bottom should be flat as it is very difficult to make the setting when it is not so.

The bezel material should be gauge 28 . It should also be eut a little wider than the highest point of the edge of the blister when lying on a flat surface, Fig. 21. The silver can then be fitted to the blister, just as one would fit it to any other stone. After the silver has been fitted, the connection made and soldered and the 
final fitting has taken place, it is ready for soldering to the article for which it is intended.

The article should be cleaned thoroly. The blister is then placed in the bezel and with a pointed tool a line is traced along the top of the shell on the inside of the bezel. The shell is then removed. The bezel should then be filed to within 1-32 of an inch from the traced line. Files of different shapes are necessary when re-
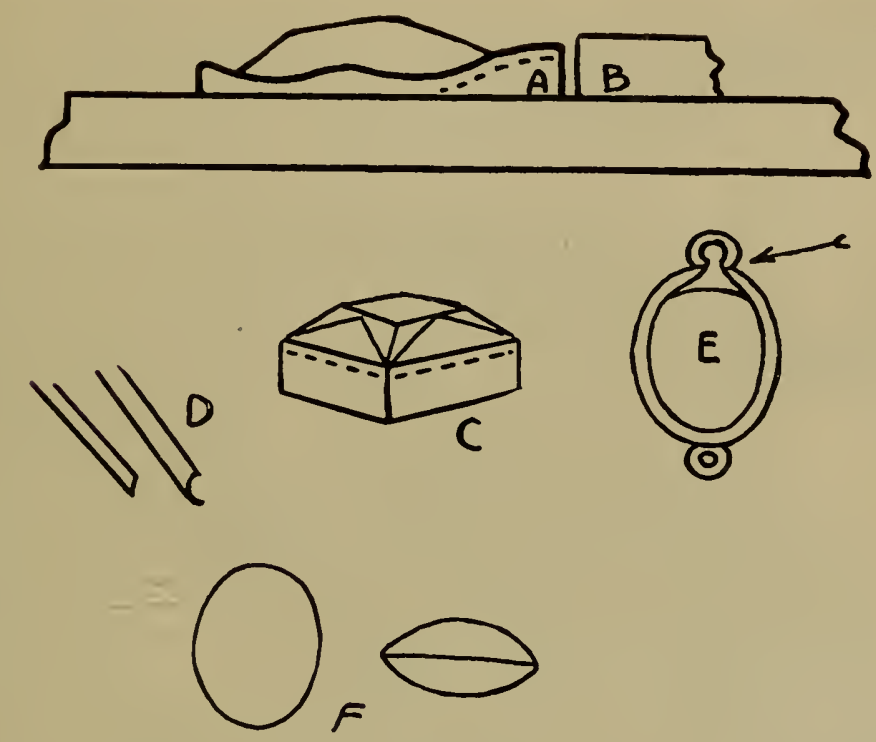

Fig. 21.

moving the surplus bezel material. Engravers' tools are of great assistance also.

When an even edge of silver projects above the edge of the abalone the edge is filed on the outside, near the top, making it thinner and easier to turn over the edge of the shell.:

The burnishing tool described before should be used in turning the bezel over the shell. 


\section{The Baroque Pearl.}

The Baroque Pearl is usually white and is commonly called a slug. It is set in many different ways. One way is on a rivet. This is done by drilling a hole into the pearl and inserting a piece of wire the size of the hole. The wire is first soldered to the article in which the pearl is to be set. The pearl is fastened to the rivet

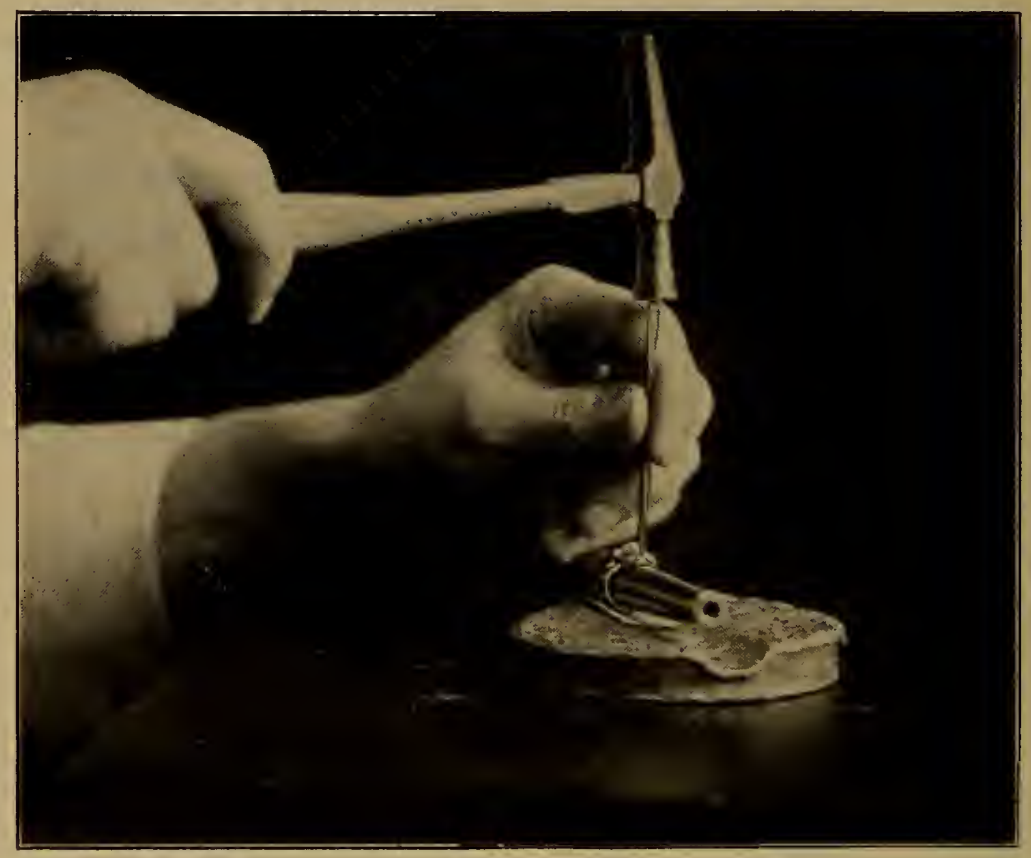

Fig. 22. Setting Baroque Pearl.

with pearl cement. This method is not very secure as something might easily catch under the pearl and release it from its setting.

This method of using the rivet is good when one intends using leaf or flower forms around the pearl. The leaves can be soldered to the article in such a way that 
some portion of the leaves can be forced over the pearl. This setting is very attractive and is used a great deal.

The bezel is often used in setting pearl slugs. When using the bezel, when the pearl is quite high, it should be filed on the under side. If the pearl is to go on a flat surface it should be filed flat; if on a curved surface, it should be filed concave. The filing is also for the purpose of having it rest solidly.

In making a bezel for a pearl it is almost impossible to make it fit the outline of the pearl and really it is not necessary as will be shown when the actual setting takes place.

When the bezel has been completed and the soldering to the article has taken place it is cleaned thoroly. The pearl is then placed in the bezel and an estimate made as to the amount of the bezel to be removed.

Some parts of the bezel will be quite a little lower than other parts. The bezel must be high enough all around the pearl to fit over it and assist in holding it securely.

When setting a pearl, in a ring for instance, the ring is put on the ring mandril, resting on the lead cake and the setting is done by a tool which resembles the pushing tool which is used for other settings.

This tool has no handle and the end is only onethird as large as the end of the pushing tool. It becomes necessary to use a hammer with this tool, Fig. 22. With this tool and hammer we can easily force the metal very close to the pearl. This tool is liable to leave ugly marks if not used carefully. When using it use it in such a way as to give the edge of the bezel a finished appearance. This can be done by tapping the tool lightly. 


\section{Setting a Square Faceted Stone.}

A stone of this kind usually needs a wide bezel as it is almost always very deep. Another thing to keep in mind is that a square stone is seldom very accurate; one side is almost always a little different from the others.

In making the bezel the seam is put on one side, not in a corner, as it is liable to fill up with solder. It is also necessary to make this bezel double as the stone must have a base on which to rest.

One will most likely discover a difficulty in getting the metal close to the stone at the corners, but this can be remedied by filing a V-shaped notch at each corner. Then when the sides are forced over the stone the corners should meet perfectly, C, Fig. 21.

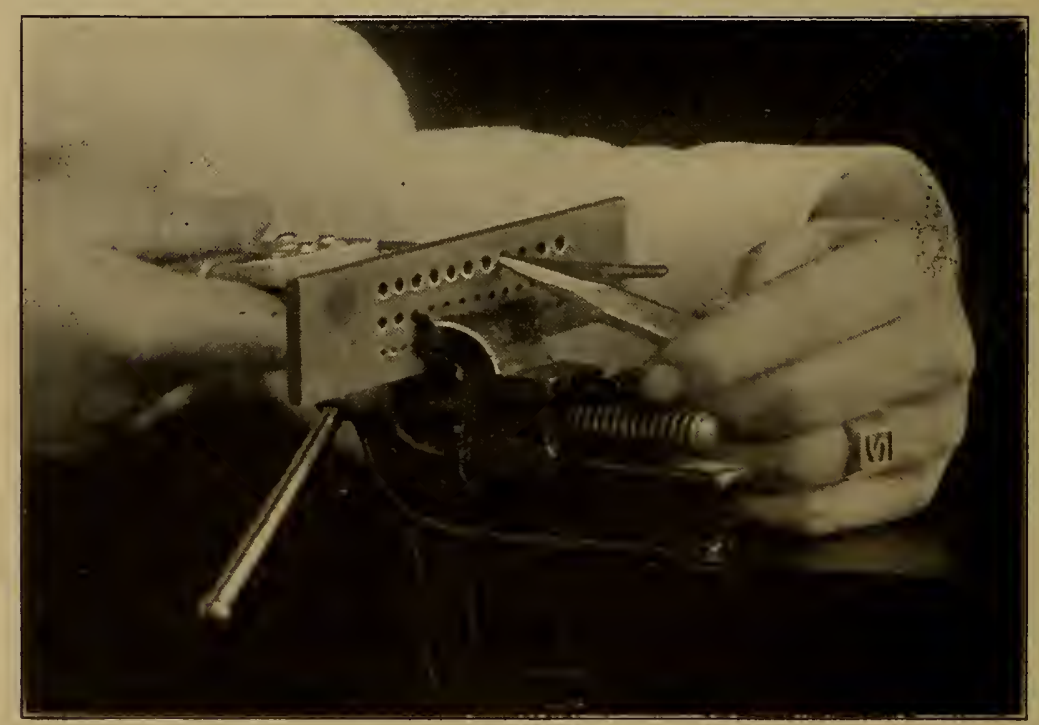

Fig. 23. Using the Draw Plate. 


\section{Setting of a Stone Having the Lentil Shape.}

These stones, F, Fig. 21, are used in chains or other pieces of jewelry where there is a possibility of its turning over and exposing both sides. The band which holds the stone is made of bezel material and is halfround hollow wire.

To make this, one can take a piece of bezel material a little less than $\frac{1}{8}$ inch wide and as long as desired and shape it half round with the riveting end of the hammer, Fig. 24. This should be done on the lead cake. When the material has started to shape half round, it is drawn thru the drawplate until the desired curve has been

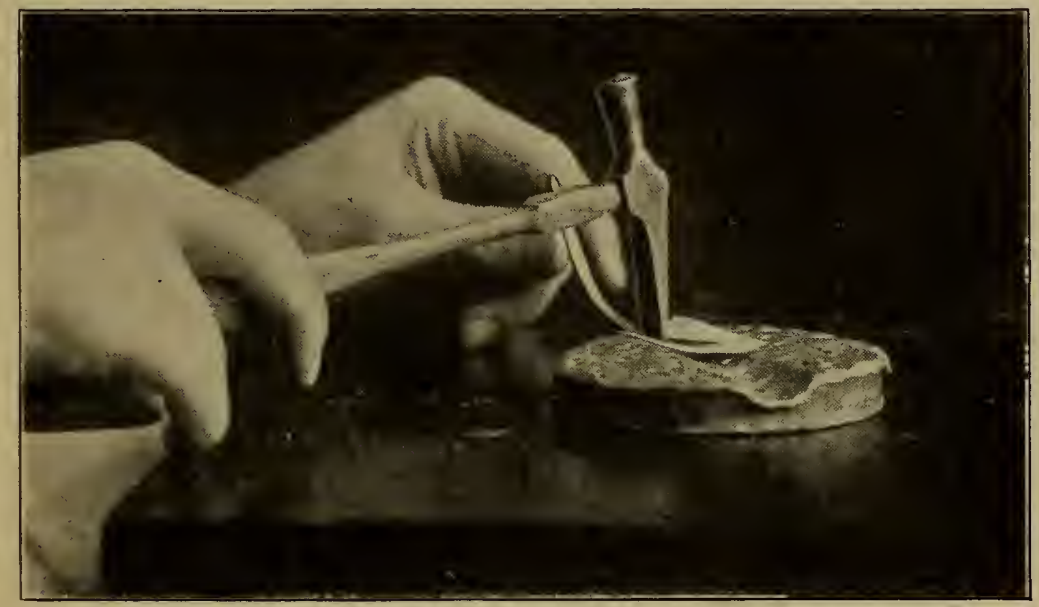

Fig. 24.

obtained, D, Fig. 21. When drawing the material thru the drawplate a piece of pointed hard wood should be held in such a way that it fits between the curve of the drawplate hole and the inside of the bezel material. This piece of wood helps to make the wire smooth. 
The wire should be annealed several times during this operation. See Fig. 23.

It is quite difficult to shape the wire to the stone, so a piece of solid wire is shaped as near like the outside edge of the stone as possible. Then the bezel wire is shaped around the solid wire the seam being at one end if an oval shape is used. The bezel wire should fit around the stone so the ends meet perfectly.

The band of hollow half wire is now ready for the rings on which the chain is connected. The open end of the band should be separated as shown in E, Fig. 21. The little ring should also be separated and soldered to the band at points indicated by the arrow.

Then, when the stone is slipped in the setting the band is forced together using pointed nose pliers and the stone is set.
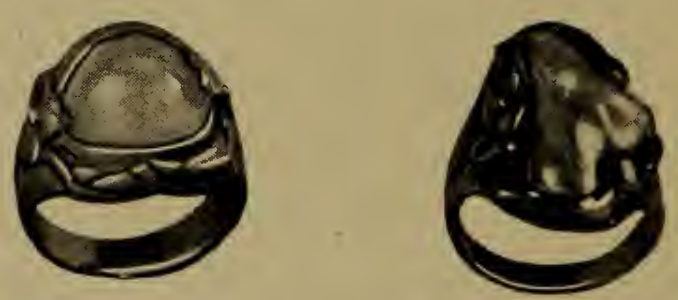

Typical Odd Shaped Stones Set in Rings. 


\section{CHAPTER VIII.}

W $\mathrm{E}$ are going to discuss the carving of monograms and, of course, this explanation applies to any kind of carving, for instance, rings, brooches and interlaced designs of all kinds.

Some very attractive effects can be obtained in the working of wrought jewelry by carving. The work of carving, chasing and engräving is really a separate line of jewelry work, but the beginner can do some very good work by a little practice and patience.

There are many men who specialize in this work and really are classed as artists as it takes good judgment and taste to execute attractive designs. Now, we feel that if a person can manipulate jewelers' tools he undoubtedly can learn to handle engravers' tools.

The first thing to do is to decide on the letters, then sketch a few arrangements of the letters as shown at Fig. 25. The straight line monogram having been selected, the transferring is done in the following man-

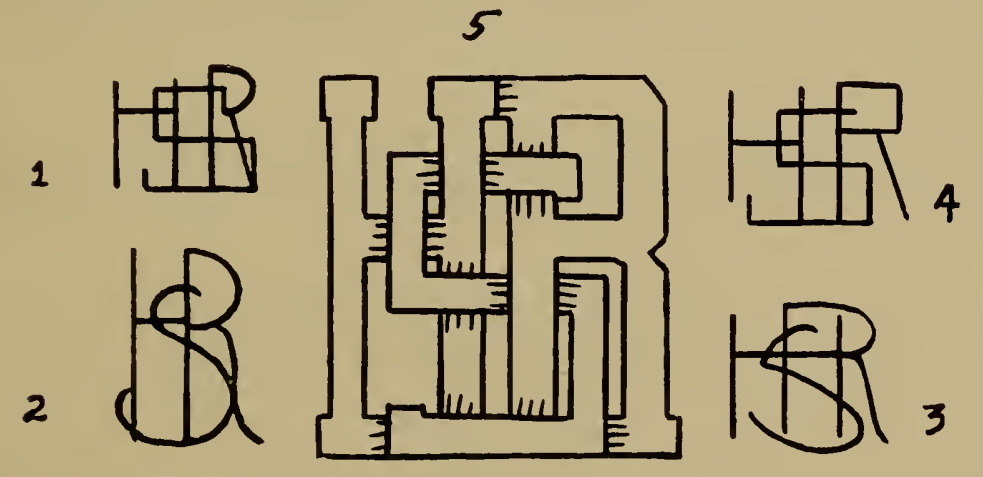

Fig. 25 . 
ner: A piece of metal about gauge 16 is chosen. This piece of metal should be a little larger than the outline of the monogram. One edge of this metal is filed perfectly straight and it will serve as a guide when the steel tracing is performed. At this point we will make use of the dividers and try square, A and B, Fig. 26.

The dividers are set so the points are about 3-16 of an inch apart, then a line is traced on the metal using. the straight edge of the metal as a guide.

The transparent paper which has the design on it should be placed on the metal so that the outside line of

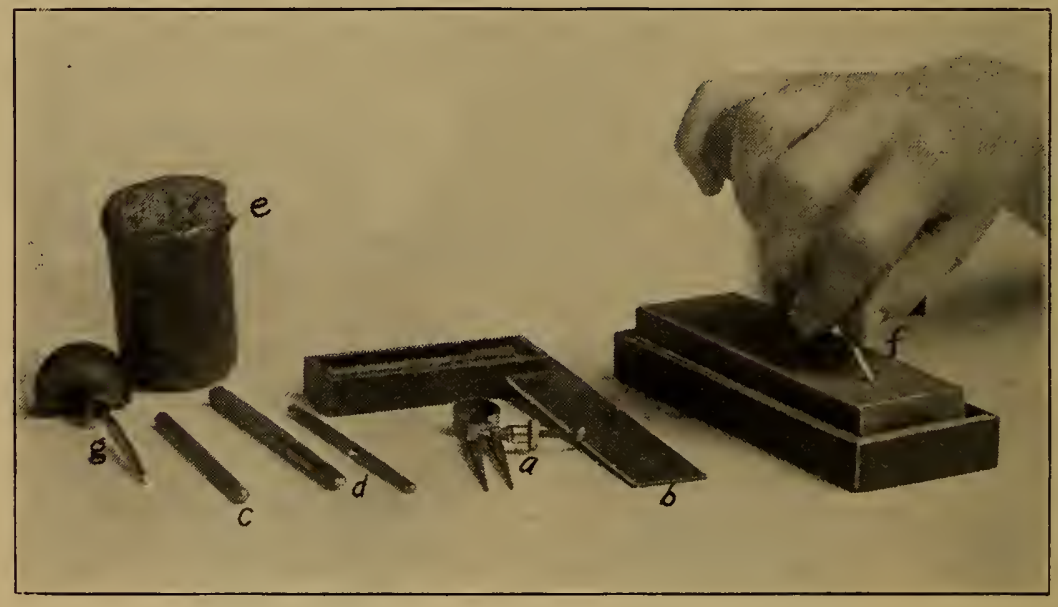

Fig. 26.

the $\mathrm{R}$ meets the line which was scratched with the dividers, then the transferring is done using the carbon paper.

After the transferring has been done all the vertical lines should be traced with the dividers using the straight edge of metal as a guide. The horizontal lines are traced by placing the try square against the straight edge of the metal and using the stcel point as a scratcher. 
If this method is followed carefully, all of the lines will be true.

The drilling of the holes and sawing are the next steps. The sawing should be done very carefully. The lines should not be touched with the saw blade at all. The finishing up to the lines should be done with small files as in previous problems.

Before finishing the filing completely, the monogram should be dapped or bulged on the back at the points where the letters cross each other. This is done on the lead cake by using a small dapping tool C, or repousse tools D, Fig. 26. The interlaced effect will be much better if this is done.

The dapping of the monogram is apt to leave it out of shape, but this can be remedied by annealing the work and placing it on a smooth hard surface, right side up, and tapping it lightly with a hammer. The hammering should be done at the point where the monogram bulges out the most. Now the monogram may be filed true and up to the lines.

At this point the job is ready for carving. In order to hold the work securely it is cemented to a cement stick by slightly heating the monogram and the cement.

Cement sticks can be made very easily. They consist of a round piece of wood about $1 \frac{1}{2}$ inches in diameter and 3 inches long with chasers' cement melted on one. end E, Fig. 26.

There are only two gravers needed for this kind of work, namely, a pointed or lozenge shape and a flat one, $\mathrm{F}$ and G, Fig. 26.

These tools can be purchased, of course, but they come without handles and are not sharpened. They are not difficult to sharpen as it is done on an India oil 

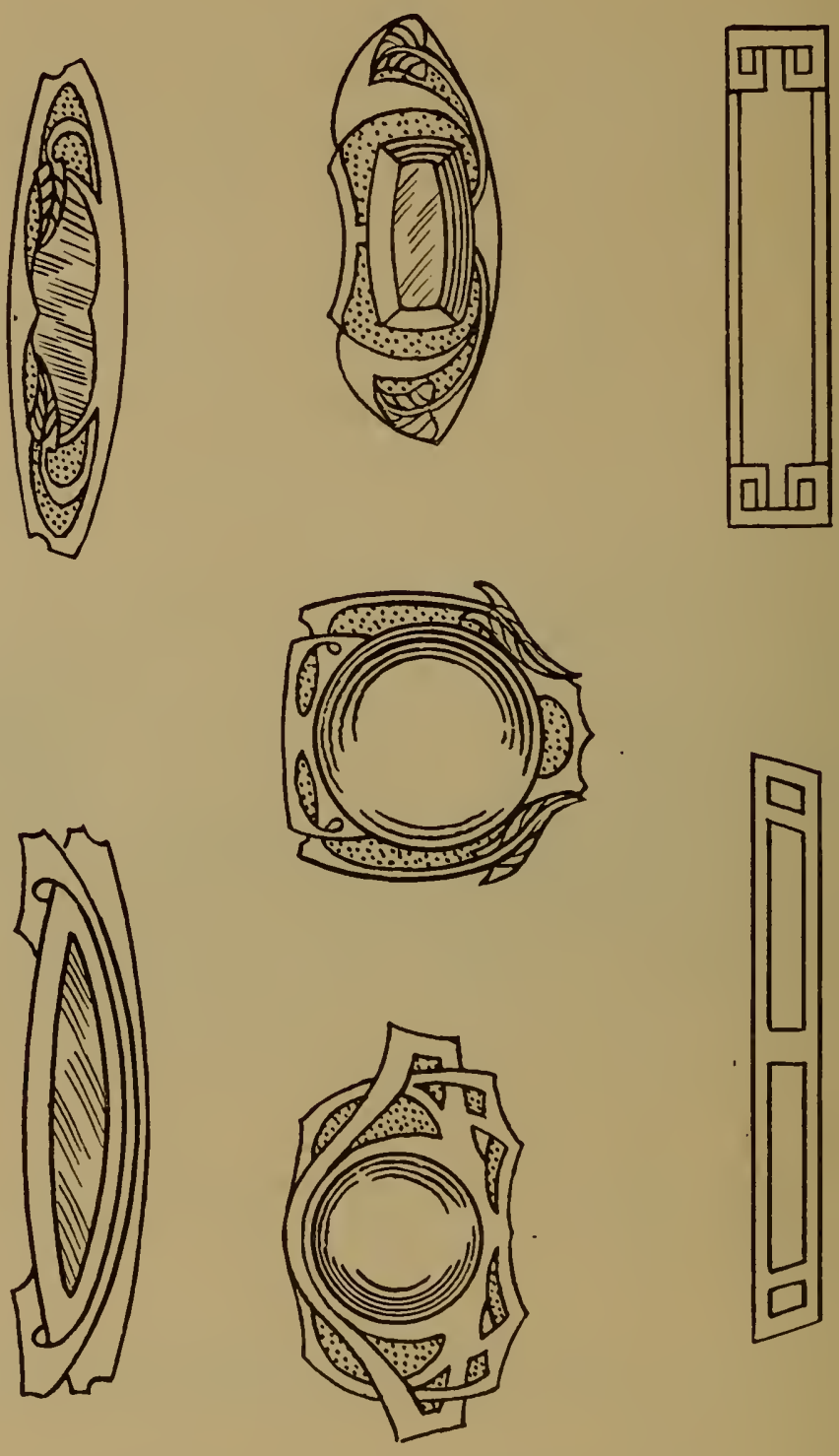

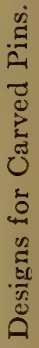



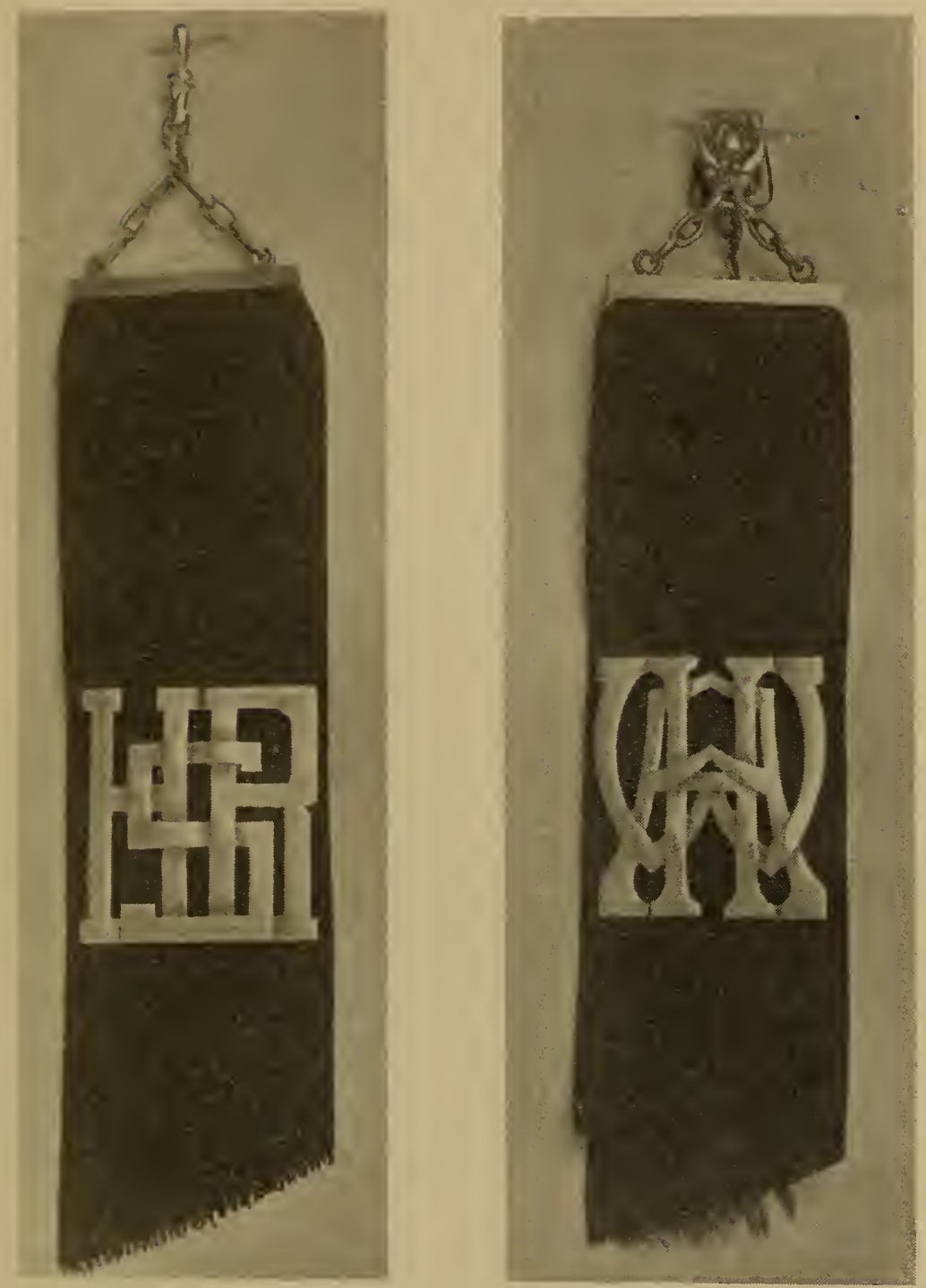

Fobs.

stone by holding the tool at an angle of 45 degrees and using a forward and backward movement, F, Fig. 26.

There are many different opinions among jewelry workers as to the best way to hold the engraver's tool. 
We are quite safe in saying that there are very few workmen who hold their gravers in exactly the same way.

But nevertheless it is a fact that the handle of the gravers should be placed in the palm of the hand near the little finger and the thumb placed on one side of the graver. Now the thumb or the ball of the hand should be resting on the cement stick and the graver given a forward motion without moving the entire hand. No matter how hard one pushes forward there should be such control as to avoid injury to the work in case the tool should slip. Remember that the thumb should always serve as a guide for the tool, and that the graver can be moved forward for cutting without changing the position of the thumb and ball of the hand.

The pointed graver is the one to use first. It is for the purpose of cutting closely to the line of one letter which goes over the other letter. After that line has been cut the rest of the cutting is done with the flat graver. One can carve at least 1-16 inch deep and about $3-16$ inch on the letter which goes underneath, that is 3-16 inch on each side of the top letter.

It is almost impossible to do any carving without leaving traces of the graver. Therefore the marks of the graver are removed either by the use of chasing tools or fine files.

What are chasing tools? They are small tools of steel about the thickness of the handle of a needle file. The ends of these tools are variously shaped as shown in Fig. 27. If the workman comes across a place which has an unusual shape and needs finishing with the chasing tool, he very often makes his own tool.

These tools are, of course, tapped with a hammer. 

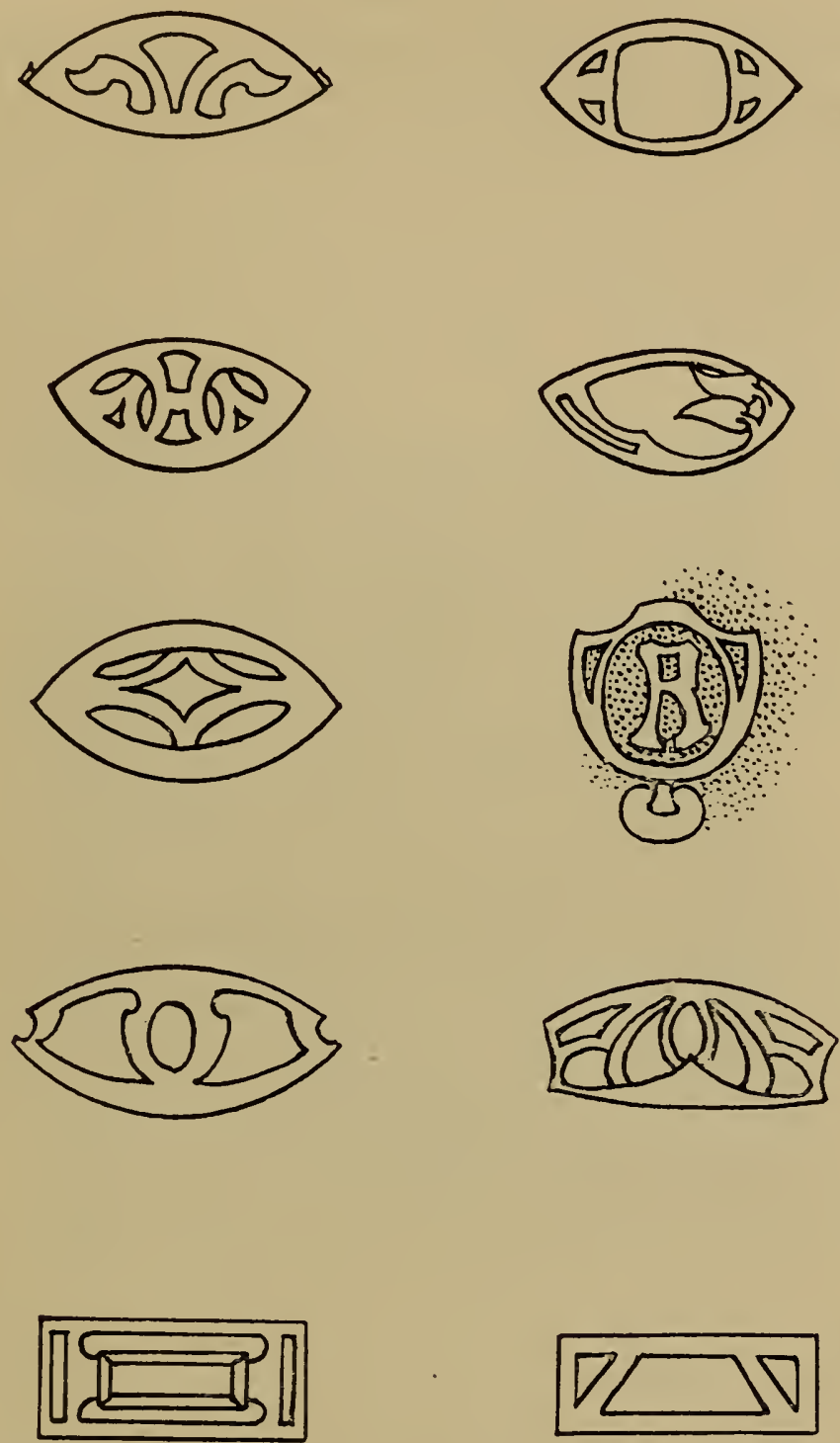

Designs for Carved Cuff Links. 
Great care must be exercised when doing this work or the results might be too rough.

One can buy an assortment of one hundred different tools but this is unnecessary as this kind of work requires only a few shapes, the most useful being shown in Fig. 27.

Another method of removing traces of the carving tool is by using riffle files and needle files especially the barret and flat file. Riffle files are files with the ends

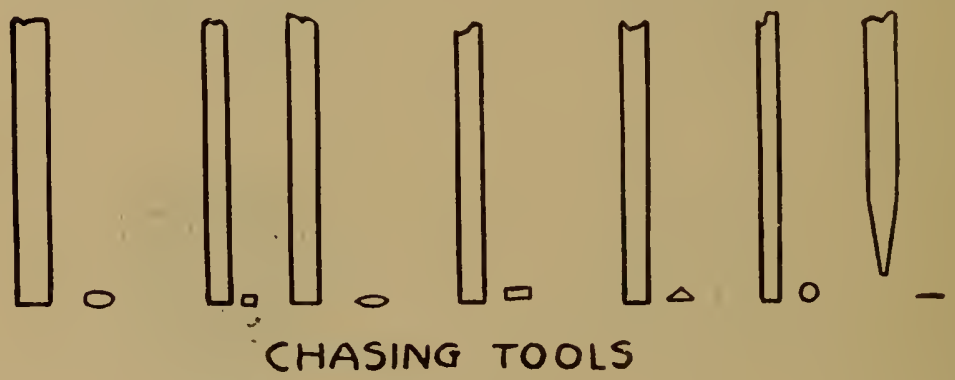

Fig. 27.

variously shaped for special purposes. A barret file is one that has only one cutting side, the other being smooth to prevent injury to the work. The coarse, flat needle file is a good one to use for the roughest places and should be followed by finer files until there are hardly any unsightly marks.

When the interlaced effect has been obtained, the edges of the letters should be rounded a trifle with a fine file. Then coarse emery cloth is used over the whole monogram, following this with a finer piece of emery cloth. To remove the monogram from the cement it is heated slightly. The cement can be removed by placing the whole thing in alcohol for about fifteen minutes. When taken from the alcohol the article should be 
brushed lightly with a brush dipped in alcohol, to remove any cement which may still cling to it.

In order to efface all scratches, a polishing lathe is often used to a great advantage, but a fine emery finish is quite satisfactory. A piece of wire is soldered to the back so as to receive the ribbon.

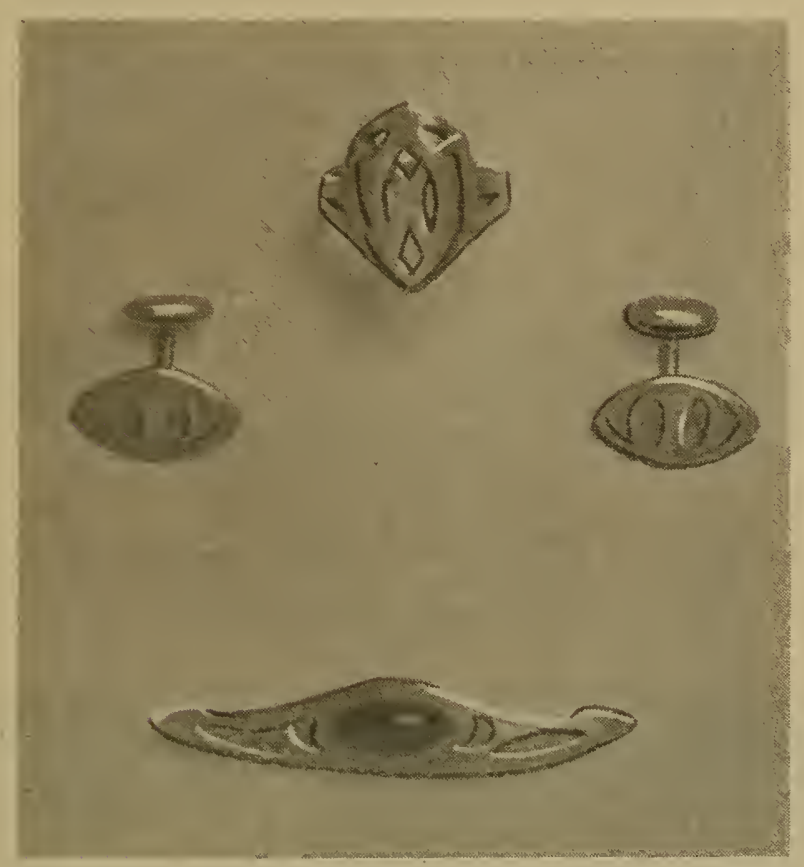

Carved Cuff Links, Ring and Necktie Holder 


\section{CHAPTER IX.}

WHY is it that we use leaves, stems and flowers so much in applied designs? We think, of course, that they are beautiful, but that is not all.

This style of design is very effective when a high bezel is required, and the worker must reduce the high appearance as much as possible. The photograph on page 75 shows this point clearly. The side view shows that the leaves have been so placed as to actually go up on the bezel and this helps to reduce the height of the bezel.

\section{The Longer Ring Described in Detail.}

A tracing of the original drawing should be on hand such as is shown at a, Fig. 28. The outline of this tracing should be transferred to eighteen gauge material. Now this can be sawed out and shaped around the ring mandril to whichever finger size is desired. It is then soldered at the connection of the two ends.

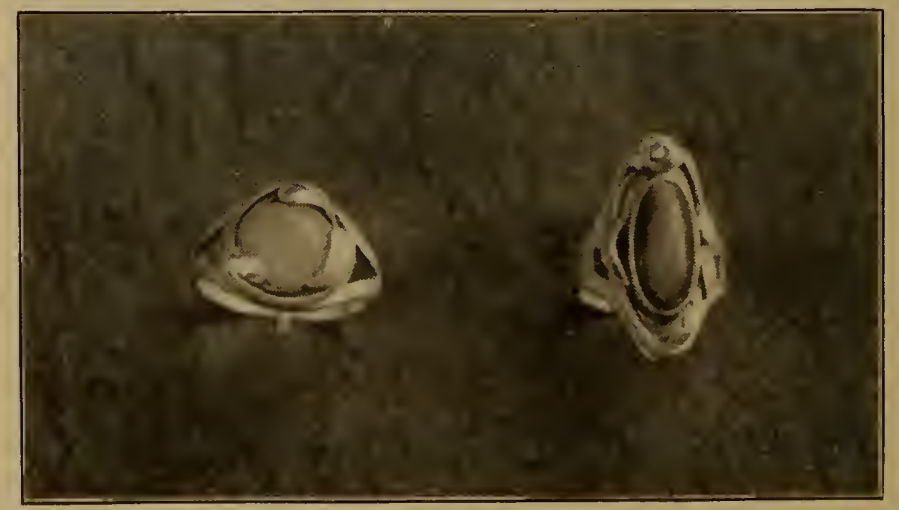

Rings. 
The next thing is to make the bezel; a double one is advised. The making of this has been previously described. The bezel should then be filed to fit the ring and made as low as possible, leaving, however, a complete ledge on which the stone may rest. Sometimes, when filing a bezel to fit a ring we file too much, thereby spoiling the inner bezel. This must be avoided.
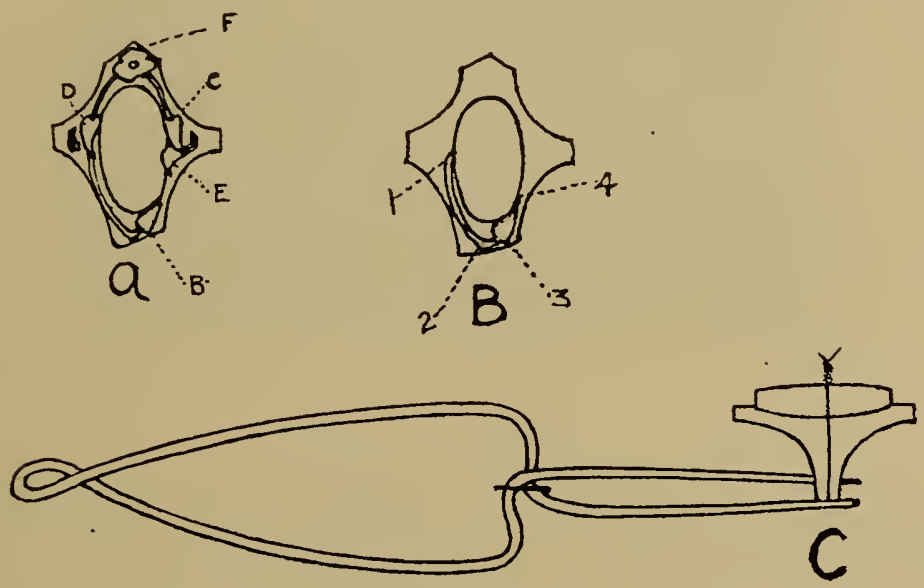

Fig. 28.

When the bezel has been prepared for soldering, and fastened to the ring, with a fine piece of wire going over the bezel and around the ring (Fig. 28 C.), it should be held in soldering tweezers. By holding the ring in these tweezers the flame can be applied to the work at any angle by a slight change of the position of the hand.

The ring should be cleaned well after each soldering. Now the leaf and stem at b, Fig. 28 A., should be cut out and shaped. Gauge 22 metal is used for leaves and flowers. The stem and leaf are of one piece. The stem is made long enough so that it will reach under the other leaf. The leaf form is now dapped, or bulged, on the reverse side until it receives a satisfactory shape. 
That is to say, the leaf may be dapped just a little bit, but then it might look stiff and not graceful. Therefore, shape the leaf until a graceful effect has been obtained. The shaping of leaves and flowers is done according to the taste of the maker. The main object is to get the decoration up on the bezel as much as possible.

It will be noticed that this leaf is soldered half way up the bezel.

After dapping the leaf its original shape has been changed, that is, the leaf will probably have been forced closer to the stem so that it does not fit around the bezel as the design indicates. This can easily be remedied. Simply use pliers and bend the leaf back to its original shape or better yet, bend the leaf and stem so that they will fit around the bezel better than the design shows. This, I find, can very often be done.

When the leaf has been placed on the ring ready for soldering, borax should be applied and the whole heated slightly. This is done for the purpose of drying the borax which then holds the applied piece in position.

Very small pieces of solder are placed at points 1 , $2,3,4$, Fig. 28 B. The ring should be held in the tweezers as shown at Fig. $28 \mathrm{C}$ and soldered.

Remember that the ring part must be just as hot as the leaf. Therefore, do not blow the flame directly on the leaf. Heat the ring gradually and the leaf will get hot enough.

The next leaves, with stems, at C and D, Figure 28, are shaped in the same manner as the preceding leaf. The stems are left long enough so they will go under the flower. Leaf E can be put on next.

Now the flower can be made. The same gauge material is used for the flower. It is traced in the silver 
and cut out but not filed until later. Then with a small ball punch, a depression is made in the center of the flower, for the purpose of receiving a little silver ball.

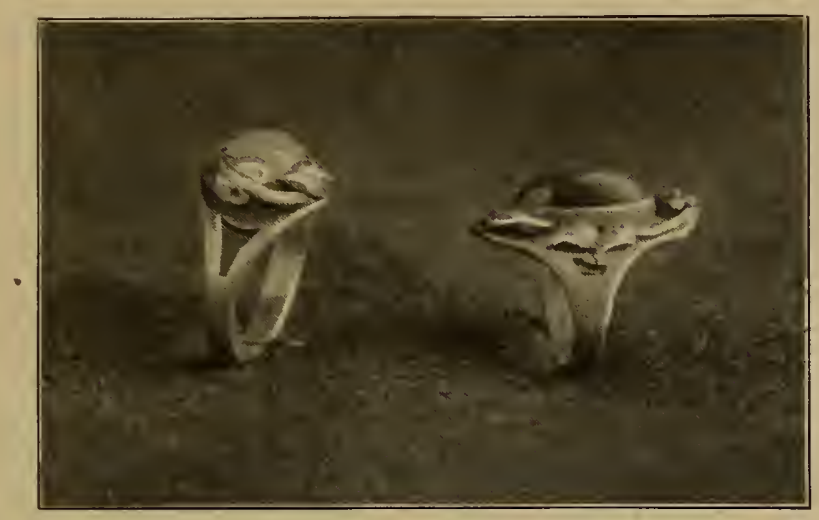

Side View of the Rings.

After the first impression is made the flower is reversed, and a depression is made on the back of each petal. The flower may then be finished, the edges being rounded a trifle with a fine needle file.

The little ball which is in the center of the flower is made as follows: Take a small piece of silver, about the size of the ball desired, and place it on the charcoal. A little borax solution should be applied; then it should be heated until it melts. The result will be a round ball.

To solder the ball in the flower, place a small piece of solder in the depression intended for the ball and melt the solder.

After that the ball may be placed in the depression and the whole flower heated until the solder flows on the ball.

When placing the flower on the ring, one may find 
the stems too high. This can easily be remedied by filing the stem so that the flower rests satisfactorily. Point $\mathrm{F}$ should be soldered to the ring, and the points toward the bezel may be raised. The solder should be placed on point $\mathrm{F}$ and where the flower touches the stems.

When all the soldering has been completed the piercing is performed. Then the outside edge of the ring may be finished with files and emery paper just as one would any other article. 


\section{CHAPTER X.}

TO be a really successful jewelry craftsman, one 1 must not only be able to work in metals, but must also learn to read or interpret designs. From the flat outline on a piece of paper, one must learn to imagine the finished article with its depth, and lights and shades; gained only by the finishing touches which are rarely, if ever, shown in the design.

Each individual will have to work out for himself, these finishing touches, and only a great deal of practice will make this part of the work satisfactory.

One reason amateur work looks so crude is that the beginner cannot at once learn to handle the gravers' tools with which a line might be carved or an edge beveled, thus taking away the flat, dead appearance of the article. It is in these final touches that so much individuality may be shown.

The accompanying designs are very much like those received by the craftsman from the drawing he has worked out for him. If two men were given the same design the possibilities are that the finished articles would differ to a great extent.

Each design requires considerable study before actual work is begun. Experience will teach the artist in metals to make the finished piece of jewelry as different from the rude work of an amateur as the pencil sketch, shaded in all details, is different from the same sketch done in outline only.

The following designs which have been worked out, will now be explained as clearly as possible. 

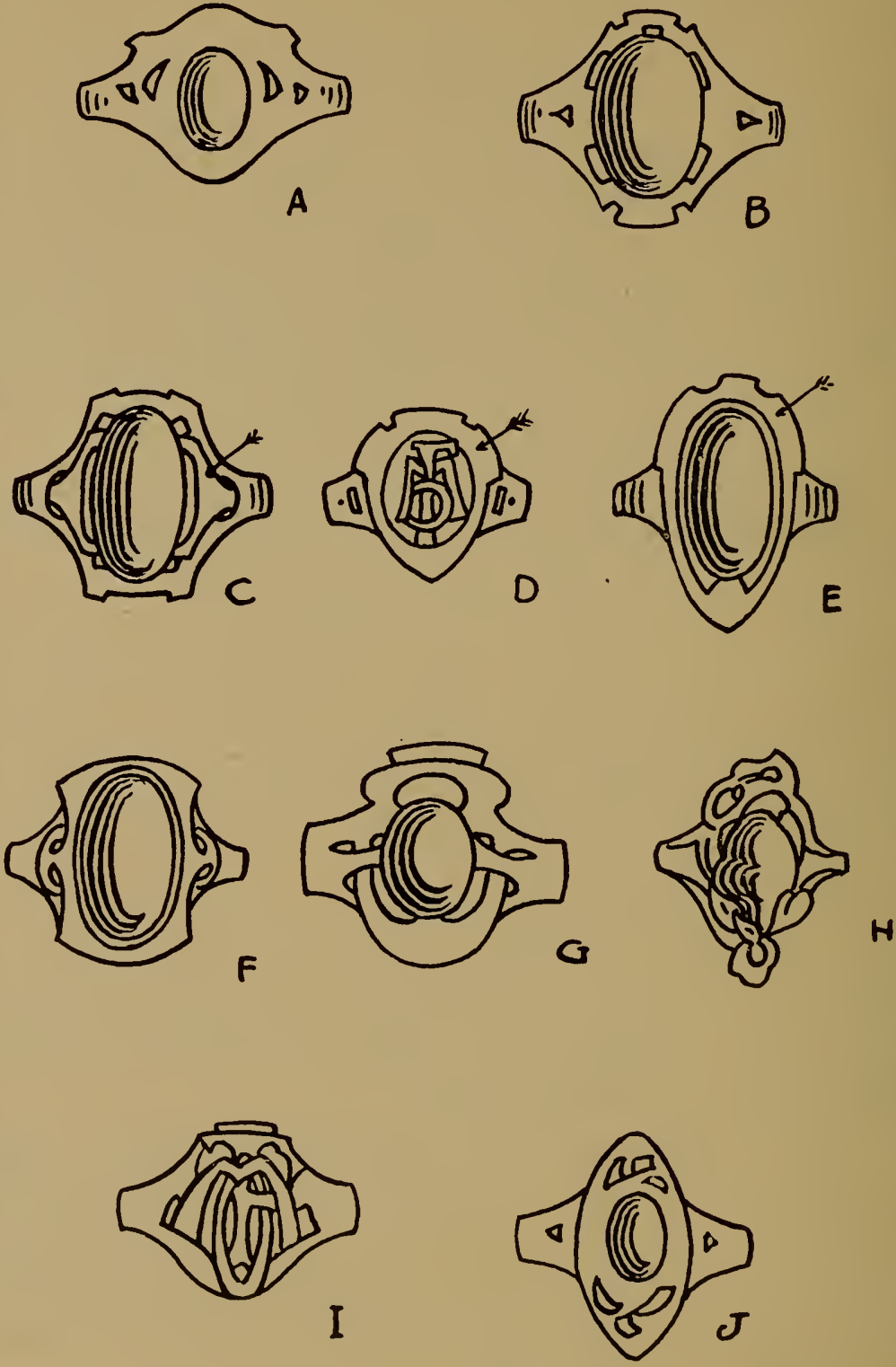

Plate I. Designs for IRings. 
Figures $\mathrm{A}$ and $\mathrm{B}$ are similar in construction, the entire design being cut out with the jeweler's saw. In some cases, designs such as these have been misconstrued, parts which should have been cut out having been made from another piece of material and soldered on the ring. Such an execution of the design would result in an unattractive ring.

Figure $\mathrm{C}$ is made on the order of $\mathrm{A}$ and $\mathrm{B}$, leaving out the side portion indicated by the arrow. This portion is made separately and soldered so as to appear to be coming from under the ring shank on to the side of the bezel. This operation is done after the ring has been shaped and the bezel soldered on. This is the finishing touch that may differ; the portion being soldered higher or lower on the bezel as the individual may think best.

In Fig. D, the portion indicated by the arrow is made from another piece of metal and is soldered to the ring shank. The monogram is made, shaped to fit the top of the ring, and carved so as to appear to be interlaced. Then it is soldered to the ring, a little solder having been previously melted on the back of the monogram.

Figs. E and $\mathrm{F}$ are similarly constructed, portions indicated by the arrows being soldered on the ring. Portions soldered on in this manner serve to break the height of the bezel, so that a deeper stone may be used than would be suitable for Fig. A or B.

In Figure $\mathrm{G}$, the design was traced on a heavy piece of silver, long enough for the entire ring shank, shaped round, cut out and then carved deeply where the interlaced effect is seen. After this a thin piece of silver was fitted on the inside of the ring following the out- 


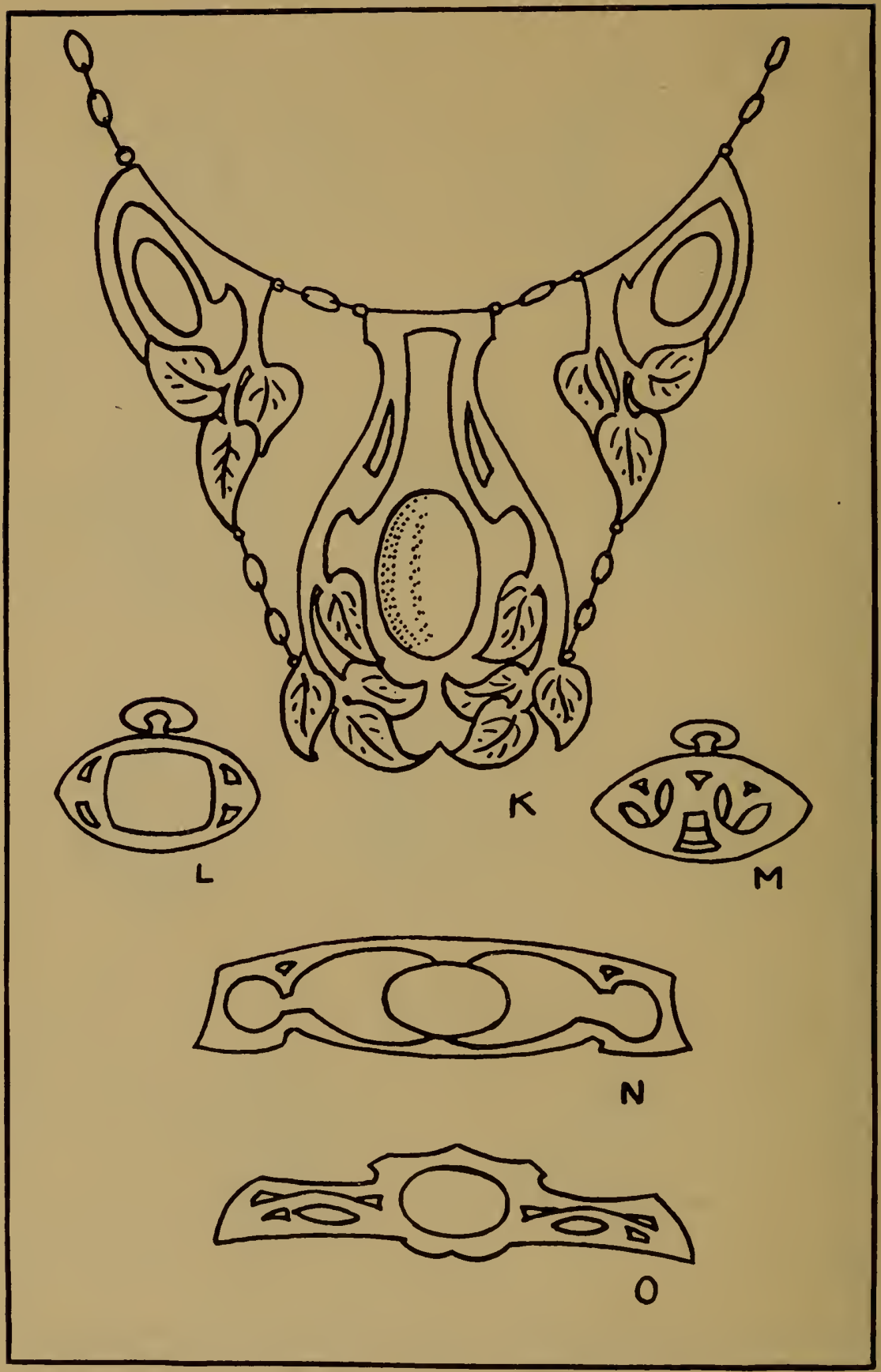

Plate II. Pendant, Cuff Buttons and Brooches. 
line of this first piece, except right at the top where a small portion protrudes.

Such a method of working out this design makes what appears to be an intricate piece of carving and chasing, and makes a ring heavy enough to be a desirable ring for a gentleman.

Fig. $H$ has a baroque pearl as a set, the leaves and stems of the design being very adaptable for this kind of stone. The bezel conforms to the shape of the pearl, and the leaves and stems are shaped around it. They are cut from separate pieces of metal and shaped as desired, then soldered to the ring.

A great deal of individuality is possible in this sort of a design. The leaves may be shaped and carved so as to look very natural, and the stems may be twined about the bezel much as a real vine would twine. A slightly different position of a leaf might change the general appearance immensely. So must the finishing touches be worked out to the best of one's ability.

Fig. I is made of fairly heavy material, dapped up in the middle where the monogram is traced. The portions around the monogram are cut out, after which the lines of the different letters are carved so as to give the interlaced effect. When a part is supposed to look as tho it went under another, the worker should endeavor to carve this under piece so that it slopes gradually down to the line that goes over, that it really appears to go under.

Fig. $J$ is perforated, no extra part being soldered on, as might appear. The lines at the side are filed or carved. 


\section{Plate II.}

Fig. K. In this lavaliere the edge and leaves were made of one piece. After they were cut out and filed, the leaves were dapped on the reverse side so as to render them graceful. The border and leaves were entirely finished as to sawing and filing, and then soldered to the silver plate which acted as a base. The bezel for the stone was, of course, soldered to this base.

Fig. $\mathrm{L}$ is a cuff button, the design cut from a piece of metal and applied to another piece which serves as a back.

Fig. $\mathrm{M}$ is a cuff button made of fairly heavy material dapped up considerably on the back so that the center of the button is quite high. The design is cut out and carved so as to give the effect of interlacing.

Fig. N. This is a design for a bar-pin, the border being cut out separately and applied to a back of silver. The bezel is soldered to the back as in similar articles mentioned.

Fig. $O$ is a bar pin with the design pierced and carved, made from just one piece of silver.

\section{Plate III.}

Four fobs are shown in this plate.

Figs. 1 and 3 are made with the edges raised, that is cut out and applied to a back as was described in Fig. O, Plate II. 


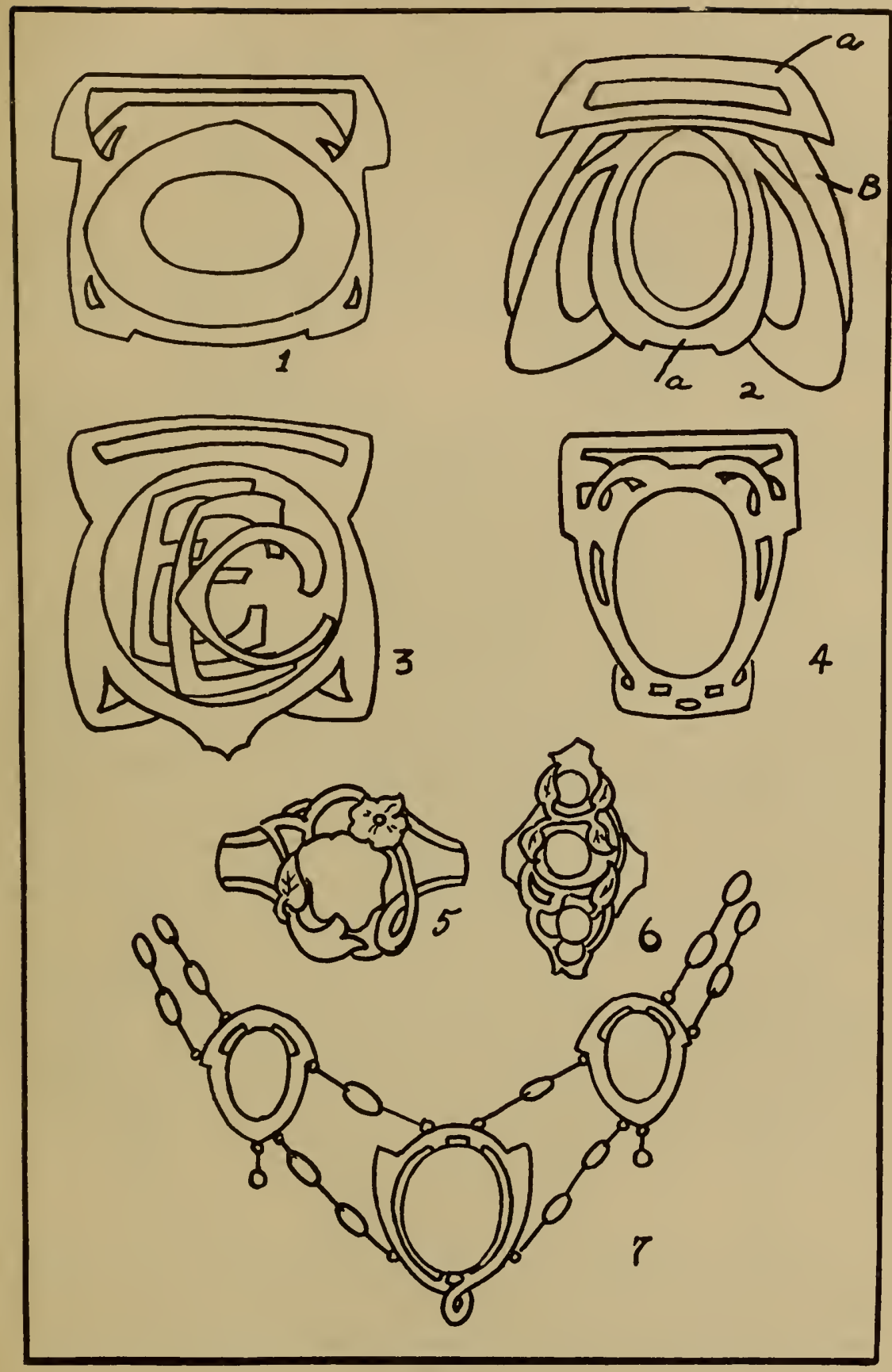

Plate III. 
The bezel in Fig. 1 and the monogram in Fig. 3 are soldered to the back plates after the edge has been applied. The monogram is constructed in the same manner as the one described for Fig. D, Plate I.

Fig. 2 is made of three pieces. Two pieces, $A$ and $B$, are made separately and interlaced. The portion on which the bezel is soldered is made and soldered to the back of portion $A$.

Fig. 4. This pattern worked out into a very attractive, tho simple, silver fob. The design was pierced, that is cut out with the saw, the interlaced effect being obtained by carving.

Fig. 5. This ring contains a pearl slug set in a bezel. The flower, leaves and stems were made of separate pieces and applied piece for piece. Bits of the stems are carried down on to the shank, then filed so as to gradually disappear, giving, when finished, the appearance of being really a part of the shank.

Fig. 6 is a ring made on the order of Fig. 5, the leaves and stems being applied around the bezels.

Fig. 7 is a simple necklace with the design cut thru the metal as was described in Figures A and B, Plate I. The balls used as drops are made of two halves of thin silver dapped up, and soldered together to form a hollow ball.

\section{Plate IV.}

Figures 8 and 9 are pendants made with the border only, the rest being entirely open, with the stone set in a bezel swinging in the center. Flowers and leaves are made in separate pieces and soldered to the rim. 


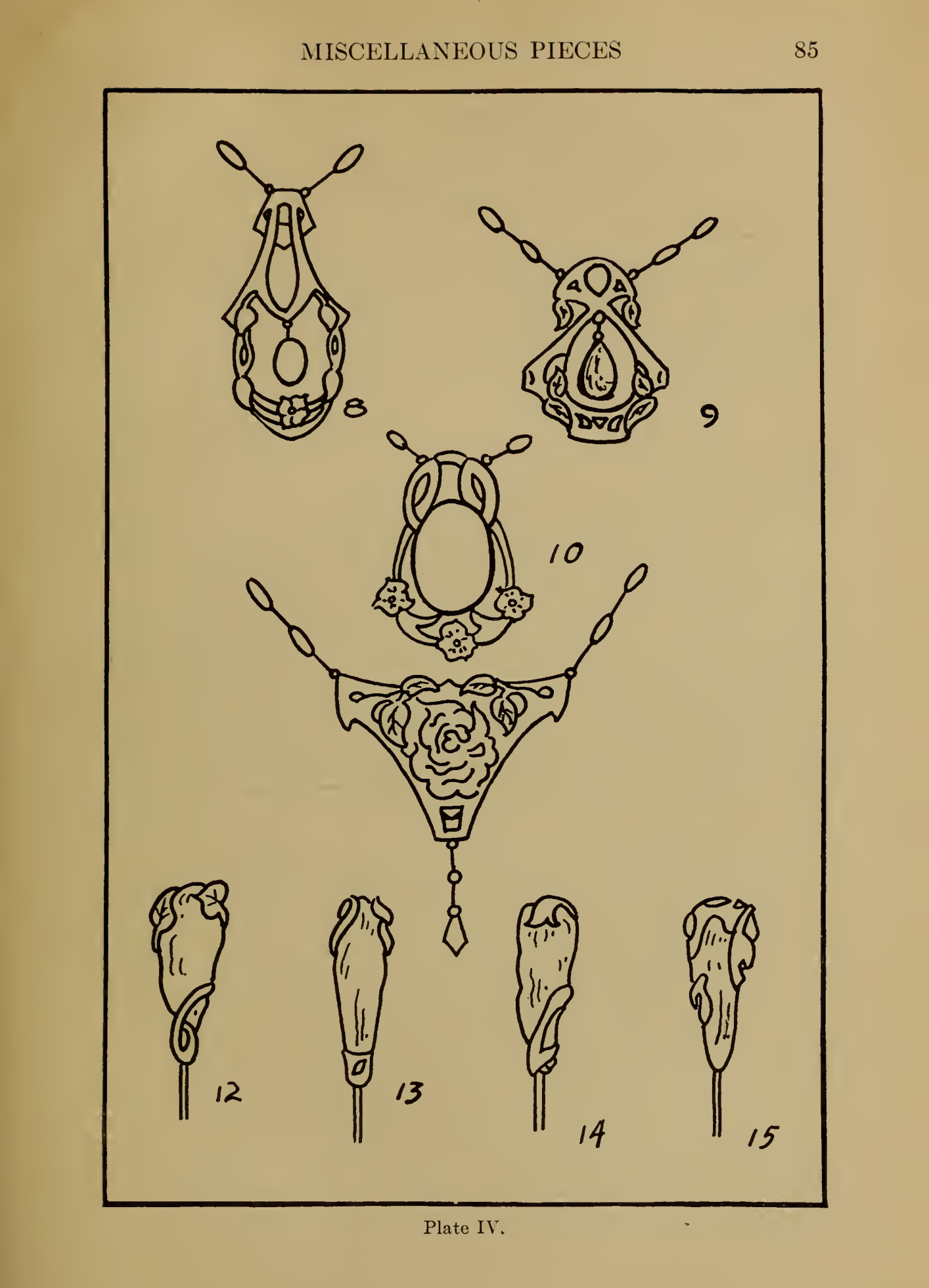


Fig. 10. This pendant is also made with the open work effect, there being no back between the border and the bezel. The flowers are made separately and soldered on. The interlaced effect is gained by carving.

Fig. 11. A coral rose is set in this pendant. The leaves were so arranged as to go half way up the side of the rose, thus breaking what would otherwise be too great a height. 


\section{CHAPTER XI.}

\section{Mounting Baroque Pearls.}

THE sets which, to us, are the most interesting to 1 mount are the baroque pearls or pearl slugs. The reason for this interest lies in the fact that each and every pearl must be mounted differently from every other one. It is very unusual to find two pearl slugs having exactly the same form, and therein lies the difference necessarily found in each mounting.

Pearl slugs vary greatly as to both shape and color, and these two facts must be taken into consideration when designing and setting. If one is fortunate enough to obtain the slugs directly from the pearl fishers, very fine specimens may be obtained for very reasonable prices. Many beautiful slugs, smooth and of good color and shape, are found in the Fox and Rock Rivers in Illinois.

Sometimes a pearl, tho otherwise good, has a bad spot, possibly a little discoloration, which must be covered with a leaf or flower when mounted. One should always keep in mind, however, that as little as possible of the good parts of the pearl should be covered.

Fig. 1 on page 88 shows a long, irregular pearl mounted in a scarfpin. We often see a pearl of this style mounted with just a pin in the back of it, and no ornamentation whatever. This could not, of course, be considered expert jewelry work as it shows no artistic ideas. It does not do the pearl justice, either, for, to 


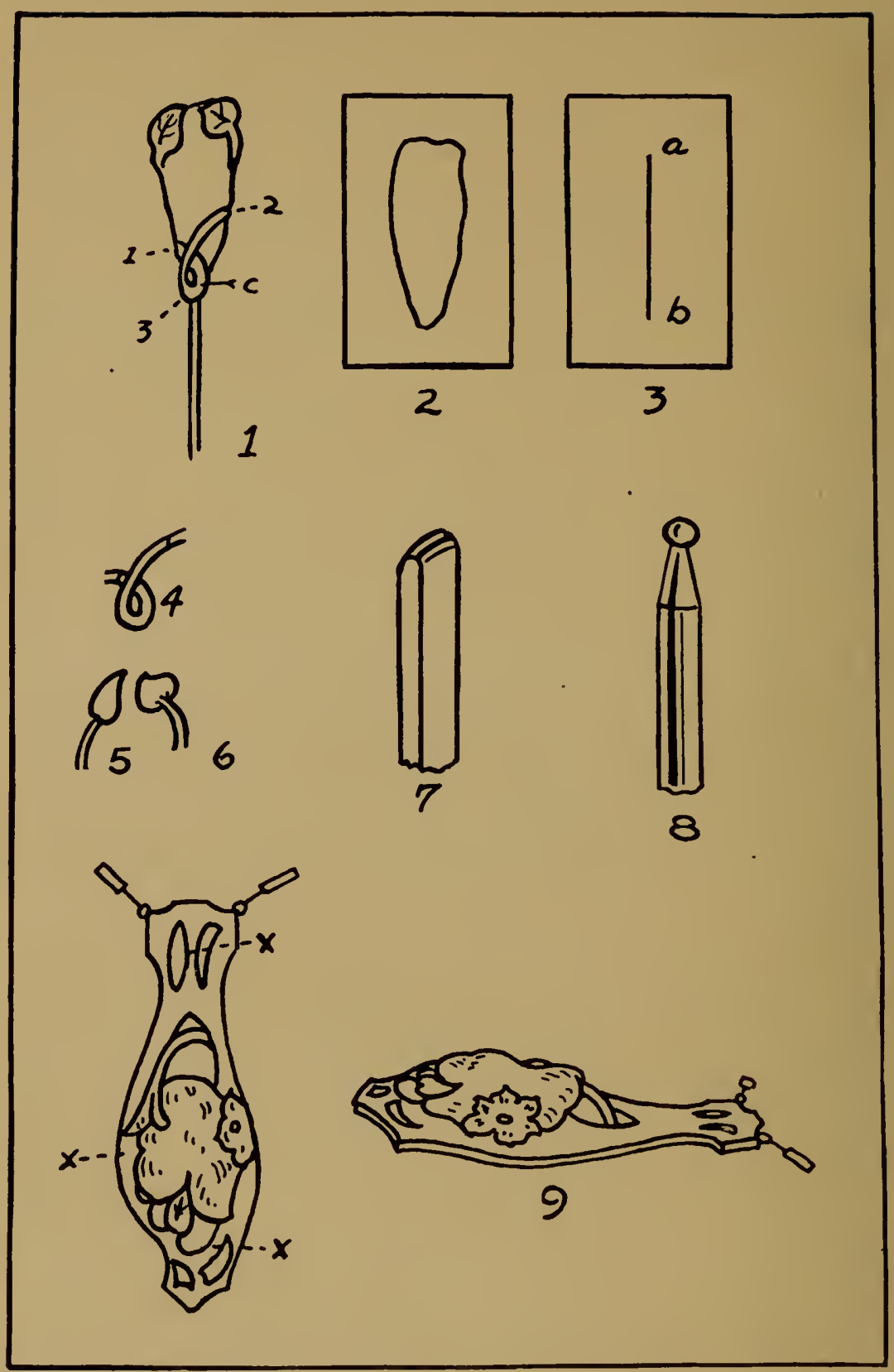


most people, the slug without any handiwork showing looks stiff and hard.

Neither should a mounting be symmetrical, as that sort of a design does not harmonize with the irregularities of the pearl.

The scarfpins referred to have a piece of silver on the reverse side of the pearl on which are soldered the ornaments. In Fig. I, which is the same as Fig. 13 on page 85, the back of the pearl is V-shaped and necessitates a piece of silver shaped the same way. The back should be made of material not heavier than 22 gauge, and should be left in quite a large piece until the shaping of it has been accomplished.

As this pearl had a straight ridge down the center of the reverse side, the dapping of the material was done in a straight line.

With a ball punch or narrow tool (Figs. 7 and 8, page 88) depressions must be made in the piece of silver which will correspond as nearly as possible to the ridges in the back of the slug. "The silver is placed on the leadblock while dapping is being done. With the tool pressed firmly on the silver, start from point (a) Fig. 3, and dap to point (b). To do this the tool should not be raised from the silver, but should be moved slowly along the line from (a) to (b) and continually tapped with the hammer. This insures a smoother depression than when the punch is moved from place to place each time it is hammered. Continue dapping until the pearl fits in the depression. As this pearl was much thicker at the top, the depression at (a) was quite deep, becoming shallower at (b) as the pearl tapered to a thin point.

The superfluous material should next be cut away, leaving the depressed part a trifle smaller than the out- 
line of the pearl except at the lower point, onto which is soldered the portion marked (c) Fig. I. The silver back, being merely for strengthening purposes and not for ornamentation, should not be visible from the front.

After the back piece has been cut out, the sides may have to be forced to the sides of the pearl, by the use of small pliers.

When the plate has been fitted as closely to the back of the pearl as possible, the edges of it are filed to a knife-like edge, thus being made to appear as much as possible a part of the pearl.

Before the leaves and design parts are made, the finished product should be pictured mentally. The side as well as the top view must be considered. The top view cannot show the entire leaf or stem. Therefore, when the leaves are transferred to the silver (gauge 22), they must be traced a little larger than the design and the stems left considerably longer, so that they will allow for the depth of the stone and overlap the back piece at least one-eighth of an inch. This overlapping is done so that the soldered place may be strong enough not to break when the pearl is set.

In Fig. 1, the designed portion, marked (c), appeared as Fig. 4 immediately after cutting out. It will be noticed that allowance for the bending over on the back has been made. When fitting the piece over the pearl, the pearl is placed in the back piece and the design part placed on top of it. Be it understood that points 1, 2 and 3, Fig. 1, are to be soldered to the back piece.

It will be necessary to shape the piece by dapping on the reverse side and bending with the pliers. When 
the piece is shaped to fit, the pearl should be removed before any soldering is done.

If one finds it difficult to make all three points touch the back piece at one time, one point may be soldered first and then the other two fitted and soldered later. If trouble arises in making the design part stay in place while being soldered, binding wire may be rolled up into a ball or form as nearly like the pearl as possible, and placed so that the piece to be soldered rests on it as it would rest on the slug.

The leaves should be sawed out, allowance being made, as was previously mentioned (Figs. 5 and 6) and then shaped to fit the pearl. They may be held in place by the use of a roll of binding wire as was explained before, while they are being soldered.

It is always a problem how to solder the leaves so that the pearl may afterwards be inserted without too great difficulty. The leaf on the right-hand side may be soldered almost exactly in the position it will have after the pearl is set. The other leaf, however, must be soldered so that the pearl may be placed in position. After the pearl is in its place this leaf is forced over the stone, thus holding the pearl securely.

At the places where the stems are soldered to the back piece, they should be filed down so that they appear to be a part of the back instead of something soldered on.

The pin is soldered to the back and the finishing done as has been explained in previous chapters.

One other problem will be explained briefly, that of a pendant shown in Fig. 9, page 88 .

This pearl is quite unusual, being very thick thru the center. The portion of it which is visible is of a 
very good white, whereas the part that the flower covers is a yellow color and necessarily was covered. The flower, of course, is also for the purpose of holding the pearl.

The pendant part is made of one piece excepting the conventional leaf, the flower and the ordinary leaf.

In this piece of work the silver back of the pearl is removed to permit the pearl to project thru the silver, thereby reducing the height of the pearl.

The pendant part is dapped so as to render the stems more graceful. The dapping was done on the reverse side of the silver at points indicated by $\mathrm{X}$.

The object in giving two views of the pendant is to show clearly the difference in a top view and that of the side. Take the flower for example, the top view shows it to be narrow; the side view gives the exact size.

This explanation is made to emphasize the fact that all designs must be pictured mentally from all angles before making. By doing this all allowances can be considered and no mistakes made.

After understanding these two problems one should be able to work out for himself designs appropriate for almost any pearl slugs. 


\section{CHAPTER XII.}

\section{Precious Stones.}

W

HEN we buy gems nowadays, we buy luxuries; and when we buy luxuries we most plainly reveal our tastes. The slogan of the art students in the Latin Quarter, that "We can do without the necessities but we must have the luxuries," seems to have an element of truth.

The love for precious stones seems to be as old as the race. The beauty, characteristics, and reputed mystic power of gems have been woven into the history, legend and story of every people of the earth.

Thruout the ancient and mediaeval times, marvelous stories of the curative powers of stones were accepted with implicit faith. Happy the sufferer from liver complaint, if he could only get possession of a ruby. Unfortunate, indeed, was Job that he could not have a sapphire, for sapphires cure boils. The Apostle Paul need never have been shipwrecked-in fact could never have been-if he had only carried in his pocket a piece of coral, for among other properties, the precious coral has the power of preventing shipwrecks. The wise Aristotle himself advised the wearing about the neck certain stones to prevent the attack of certain dread diseases. Practically every stone came to be regarded as a specific for disease, business, or matrimony, so numerous were the superstitions, some of which persist even to this day. 
Some very interesting legends and customs have arisen out of these beliefs. Perhaps the most interesting is the assignment of a particular stone with its special significance to the month of one's birth. A list of the birthstones and their sentiments follows, not as a matter of information, but as a matter of interest in this connection.

\begin{tabular}{|c|c|c|}
\hline $\begin{array}{l}\text { Month } \\
\text { January }\end{array}$ & $\begin{array}{l}\text { Stone } \\
\text { Garnet }\end{array}$ & $\begin{array}{c}\text { Denotes } \\
\text { Constancy }\end{array}$ \\
\hline February & Amethyst & Temperance \\
\hline March & $\begin{array}{l}\text { Bloodstone } \\
\text { Hyacinth }\end{array}$ & $\begin{array}{l}\text { Wisdom } \\
\text { Courage }\end{array}$ \\
\hline April & Sapphire & Repentance \\
\hline $\begin{array}{l}\text { May } \\
\text { June } \\
\text { July }\end{array}$ & $\begin{array}{l}\text { Emerald } \\
\text { Agate } \\
\text { Ruby }\end{array}$ & $\begin{array}{l}\text { Fidelity in Love } \\
\text { Health, Peace } \\
\text { Vitality }\end{array}$ \\
\hline August & $\left(\begin{array}{l}\text { Moonstone } \\
\text { Sardonyx }\end{array}\right.$ & $\begin{array}{l}\text { Felicity } \\
\text { Fidelity }\end{array}$ \\
\hline September & Chrysolite & $\begin{array}{l}\text { Joyousness } \\
\text { Purth Truth }\end{array}$ \\
\hline $\begin{array}{l}\text { October } \\
\text { November }\end{array}$ & Opal & $\begin{array}{l}\text { Hope, Keen Sight and Faith } \\
\text { Friendship }\end{array}$ \\
\hline December & Turquoise & Prosperity, Love \\
\hline
\end{tabular}

Gems of the highest rank excel in four distinct qualities or properties, namely, hardness, color, transparency, and luster. The diamond, ruby and sapphire possess all four of these properties to a marked degree, while among the commoner stones, the garnet, amethyst, and topaz possess all four properties in a lesser degree.

Generally speaking, for a mineral to rank as a gem, it must excel in three of the four properties. However, some very popular and beautiful stones have only two of these properties. The turquoise is both soft and opaque, but it has clistinctions of color and luster which give it a rare beauty.

The wearing quality and hence the permanency of a gem's beauty depend very largely upon its hardness. 
Therefore the quality of resistance to scratching is an important one. The hardness of gems has been expressed by the Mohs Scale, which takes ten common minerals from the softest to the hardest, ranking in hardness from one to ten. The following is the scale:

1. Talc

2. Gypsum

3. Calcite

4. Fluorite

5. Apatite

6. Feldspar
7. Quartz

8. Topaz

9. Corundum Ruby Sapphire

10. Diamond

The common method of identifying gems by their colors is entirely unreliable. We have become accustomed to associating certain colors with certain stones. Some people class all red stones as rubies or garnets, unmindful of the fact that garnets are also green, rose, black, brown, and yellow; that the ruby is the same mineral as the sapphire, and that diamonds, opals, carnelians, tourmalines, and others are often red.

It is a great help to one to be able to make certain group distinctions. The largest group of gems is the Quartz group. Many persons speak of quartz as if it were a single distinct stone with unvarying characteristics. Yet, among the great varieties of gems which properly belong to the quartz group but have distinct names by virtue of certain peculiarities of color, luster, and texture, may be mentioned the following popular gems:

Rock crystal, amethyst, rose quartz, cat's-eye, chalcedony, carnelian, bloodstone, agate, and onyx.

Rock crystal, or "frozen ice," as the Greeks called it and thought it to be, is the uncolored and highly crystalized form of quartz. Amethyst, rose quartz, and cat's-eye possess the characteristics of color indicated 


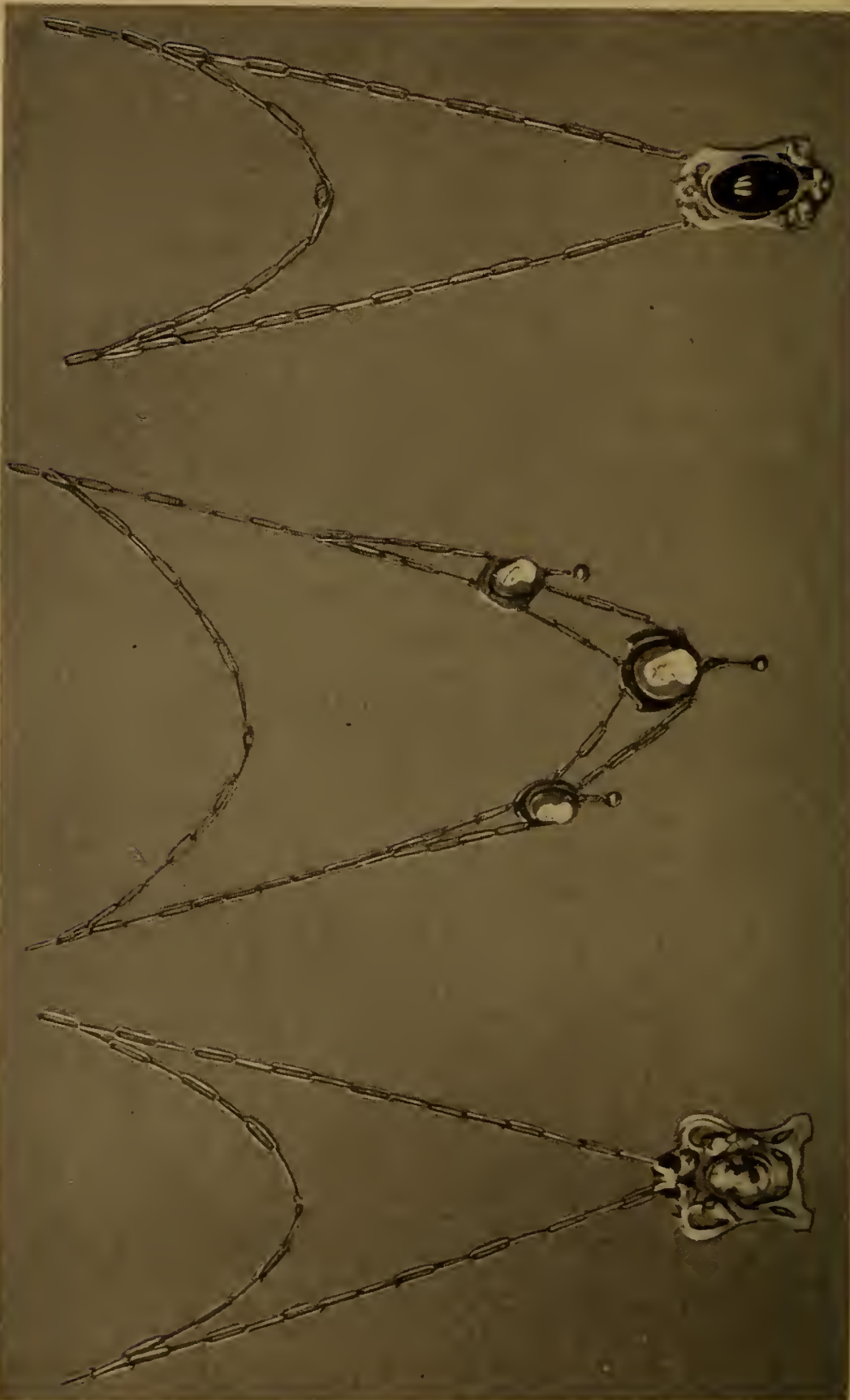

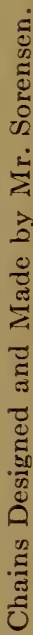


by the names. Carnelian is a red variety of chalcedony, and the bloodstone is a green variety containing specks of red jasper.

When quartz shows a distinct banded or clouded structure of various colors, it is called agate. When the bands are straight, regular, and uniform in thickness, it is called onyx. When some of the layers of the onyx are brown, it is called sardonyx, because the brown is the variety of chalcedony known as sard. The onyx is extensively used in making cameos, the figure being cut in a layer of one color, resting on a base of another color.

A great many of the varieties of agate in present day use are artificially colored, the porous structure of the stone easily absorbing fluids.

There is probably no more beautiful and popular stone than the opal. The beauty and value of the noble, or precious opal depend almost wholly upon the brilliancy and variety of its ever-changing colors. Altho beautiful and popular, the opal is easily scratched and broken, being only about $5^{\frac{1}{2}}$ in the scale of hardness.

There still lingers a peculiar superstition that opal is an "unlucky" stone. Suspicion may have arisen from the fact that the opal often loses entirely its iridescence, or "fire," and sometimes as mysteriously recovers its lost brilliancy. However, from ancient times, the opal has been the symbol of hope-not of bad luck, and it is almost the only stone that has not been successfully imitated.

Some of the most attractive settings are made of the matrix of opal, which is the dissemination of the opal thru the rock in which it is found.

The familiar turquoise is another soft but extensively used stone. It ranges in color thru blue, green, 
and gray, altho sky blue is the standard Persian stone. In time, practically all turquoises will turn green under constant exposure to strong light, heat, or acid fumes. Like the opal, the turquoise appears in a beautiful matrix, but unlike the opal, it is very easy of imitation.

The moonstone makes a beautiful setting, especially in silver. The quality of a moonstone depends upon the bluish opalescence reflected from the polished stone. A great many milky stones pass as moonstones under the name of "California Moonstone." These are transluscent chalcedony pebbles which are picked up from one of the beaches of California, and of course are not moonstones at all.

The Labradorite is closely related to the moonstone, both belonging to the feldspar family. The Labradorite has the characteristic cleavage of feldspar and shows a beautiful play of green and blue when held at certain angles to the light.

Jade, a highly prized gem of about the hardness of quartz, occurs in various shades of green. The Chinese.jade is a very light green clouded with white. The New Zealand variety is a dark green and is only about one-half as expensive as the Chinese jade. Either variety makes a very attractive setting in both gold and silver.

Besides the stones already mentioned, the following stones are both popular and satisfactory for jewelry work, altho quite soft: Malachite, hardness 3.5 ; lapis lazuli, 5.5; azurite, 4; coral, 4; Amazonite, 6.

The cutting of stone is an important consideration. Altho few stones would make pleasing settings without the aid of the lapidist, yet cutting and polishing alone cannot bring a dead, lusterless, opaque stone out of its 

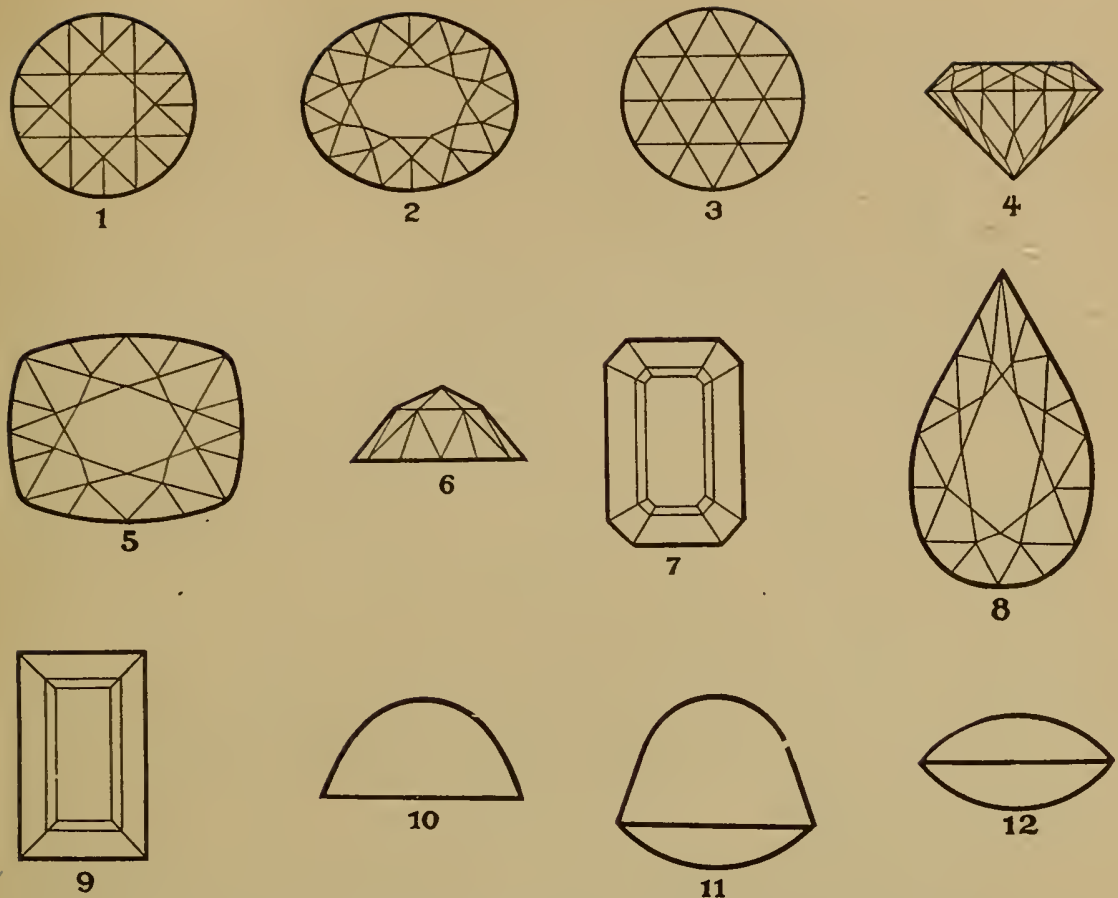

Typical Cuttings of Gem Stones. Courtesy EspositerVarni Co., Lapidists.

ugliness. The aim of the stone cutter is to take advantage of the characteristics of the particular stone and to treat it in such a way as to emphasize its natural beauty. There are two main classes of cutting. 1. Curved. 2. Faceted.

The following are the typical cuttings:

1. Round Brilliant (top)

2. Oval Brilliant

3. Rose Cut (top)

4. Round Brilliant (side)

5. Cushion Brilliant

6. Rose Cut (side)

7. Step Cut (octagon) 

8. Pear Brilliant
9. Step Cut (rectangular)
10. Cabochon (low)
11. Cabochon (high)
12. Lentil (side)

The accompanying illustrations are used thru the courtesy and with the permission of Espositer, Varni Co., the reliable and well known New York Lapidists.

A short time ago, an intelligent lady was inspecting a large selection of such gems as mentioned above and asking the prices of the various stones. On being told that the prices ranged from $50 \mathrm{c}$ to $\$ 5.00$ each, she remarked, "Of course, they're not genuine." She was greatly surprised when she was assured that the genuineness of every stone was absolutely guaranteed by a reliable lapidary.

This estimable lady, like a good many others, had been deliberately buying imitation amethysts, topazes, agates, turquoises, etc., on the ground of economy, when it turned out that she could have bought a fair grade of genuine stones for what she had paid for the imitations.

An announcement from a prominent and enterprising firm advertises for sale "Genuine Enamel Stones!" which, being interpreted, means "Genuine Fakes." There are firms in every large city which make glass imitations by the bushel, and what is more disconcerting still, they find a ready market for their trash. Thousands and thousands of dollars' worth of these imitations are sold to dealers in Mexico who promptly sell them to tourists who go home proudly carrying some "real Mexican gems direct from the mines," and leaving a hundred times their value in real American money. 
Glass can be colored, cut and polished in exact imitation of most stones. The very simplest sort of tests would detect a great many of these forgeries. For instance, stones of the quartz group rank about 7 in the scale of hardness, while glass falls below 6 . Hence, the amethyst, the rose quartz, the bloodstone, the agate, etc., will easily scratch glass. If in testing any one of the above stones, it scratches glass, it is moderately certain that the gem itself is not glass. If one of the above group fails to scratch glass, it is an imitation. Of course in the test, an edge or a corner of the stone must come in contact with the glass.

A file will easily cut glass, whereas it will scarcely make any impression at all on quartz, and stones harder than 7 , such as topaz and emerald, are not affected at all by a file. An alumium pencil will not mark the hard stones but will leave a distinct mark on glass. On the softer stones, it makes correspondingly larger and more distinct marks. Thus the test of hardness, by either of these methods, will disclose whether or not glass is masquerading under the names of amethyst, topaz, garnet, agate, jade, moonstone, or any of the stones ranking 6 or above. If such a specimen is not glass, the strong presumption is that it is genuine.

However, there are other deceptions besides making glass imitations of gems. One genuine stone of a certain color may be represented to be an entirely different and more expensive stone of the same color. Thus the garnet has been frequently substituted for the ruby, the finest grade of which is the most valuable gem known. White topaz has been sold as diamond.

Reconstructed gems are now in abundance on the market. In the cutting of such stones as rubies, sap- 
phires, emeralds, etc., an accumulation of dust and chips results. These are heated until they fuse into a solid mass. This mass is cut into gems and called "reconstructed stones," at a much smaller price than the original natural stone. This is not a vicious practice, unless the purchaser is made to believe that he is buying a genuine gem very cheaply, which he is often made to believe.

The doublet is another product where the most has been made of the small pieces of the genuine stone. In this, a very thin piece of gem is pasted on the top of a piece of glass, enamel, or other substance colored to match the genuine part. Ruby, emerald, and sapphire doublets are being sold in great quantities. Usually the line where the genuine and the false parts come together may be seen on close examination.

Opal doublets may be bought which have a very thin layer of high grade opal on a composition base of an entirely different color. In this, an effort is made to use a thin piece of fine opal to the best advantage frankly, without pretense or deception.

It is well to become familiar with the various standard stones, their properties and their tests. But after all, much of the matter concerning gems will be left to the jeweler or the lapidary, and it is very important to deal with one or the other upon whom entire reliance can be placed. 





SMITHSONIAN INSTITUTION LIBRARIES 